Portland State University

PDXScholar

4-20-2021

\title{
Climatic Controls on the Kinematics of the Hooskanaden Landslide, Curry County, Oregon
}

\author{
Kara Kingen \\ Portland State University
}

Follow this and additional works at: https://pdxscholar.library.pdx.edu/open_access_etds

Part of the Geomorphology Commons, and the Remote Sensing Commons Let us know how access to this document benefits you.

\section{Recommended Citation}

Kingen, Kara, "Climatic Controls on the Kinematics of the Hooskanaden Landslide, Curry County, Oregon" (2021). Dissertations and Theses. Paper 5678.

https://doi.org/10.15760/etd.7550

This Thesis is brought to you for free and open access. It has been accepted for inclusion in Dissertations and Theses by an authorized administrator of PDXScholar. Please contact us if we can make this document more accessible: pdxscholar@pdx.edu. 
Climatic Controls on the Kinematics of the Hooskanaden Landslide, Curry County,

\title{
Oregon
}

by

\section{Kara Kingen}

A thesis submitted in partial fulfillment of the requirements for the degree of

\author{
Master of Science \\ in \\ Geology
}

\author{
Thesis Committee: \\ Adam Booth \\ Ashley Streig \\ Curt Peterson \\ Ben Leshchinsky
}

\section{Portland State University} 2021 


\begin{abstract}
Slow-moving earthflows represent major sources of sediment transport and erosion and are problematic for the management of critical infrastructure. The Hooskanaden Landslide - a slow-moving earthflow on the southwest coast of Oregon crosses US Highway 101 and has been a site of continued interest to the Oregon Department of Transportation (ODOT) due to the weak lithology, erosive environment, and recurrent surge behavior (every $\sim 15$ years). Past surges, including the most recent (2019), have occurred during the winter, suggesting that velocity changes are predominantly controlled by climatic inputs. To examine the response of the Hooskanaden Landslide to seasonal and other periodic climate cycles (El Niño-Southern Oscillation, and Pacific Decadal Oscillation), manual feature tracking on orthorectified aerial photographs and satellite images from PlanetLabs was used to create a surface velocity time series from 1980 to late 2019 . In comparing our velocity time series to local precipitation records over the same period, it is clear that periods of seasonal acceleration correspond with above average precipitation. However, periods of surging did not correspond to years with the highest seasonal precipitation, although they do appear to correlate with transitions between warm and cold phase climate cycles. Additionally, extensive surface mapping and carbon dating were performed to understand the morphology and origins of this landslide. Logs exposed by erosion at the toe of the landslide were sampled and used for radiocarbon dating and ${ }^{14} \mathrm{C}$ wiggle matching. Sample calendar age ranges were constrained using stratigraphic and varve models within OxCal Bayesian statistical modeling software. Based on agreement between
\end{abstract}


multiple age models from two sets of samples, we estimate that this slide has been active since $\sim 1770$ AD - several decades after the last Cascadia Subduction Zone earthquake. While this suggests that the initial failure was not coseismic, it is possible that seismic stresses may have weakened the basal plane to allow for future failure. Mitigating landslide hazards requires knowledge of landslide kinematics and behavior over decadal to century timescales. The findings of this study can be used to better predict and plan for future surge events - which will likely continue to occur. 


\section{Table of Contents}

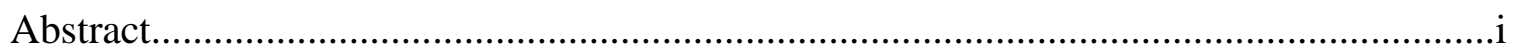

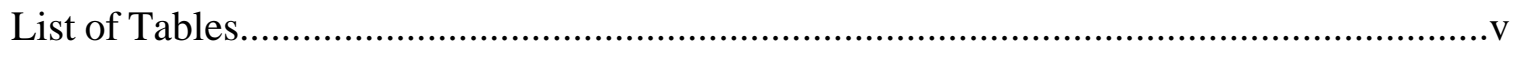

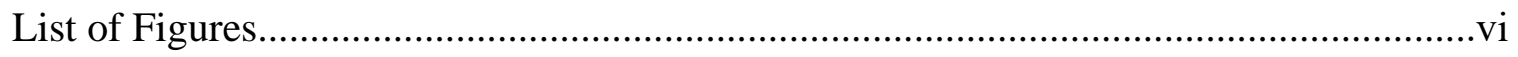

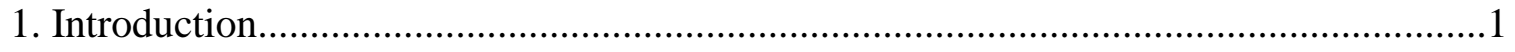

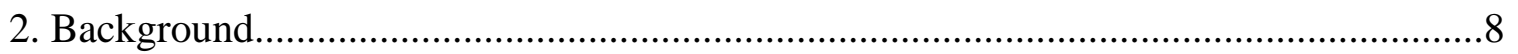

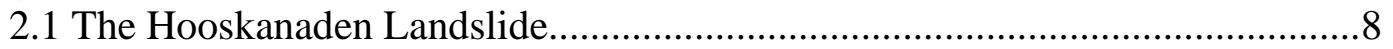

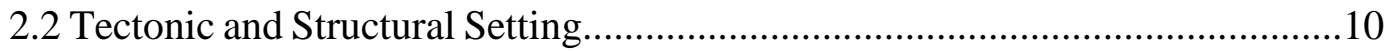

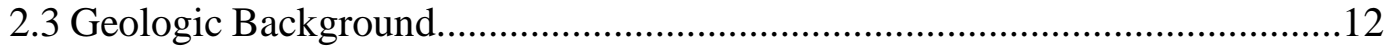

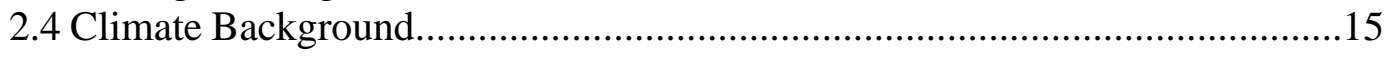

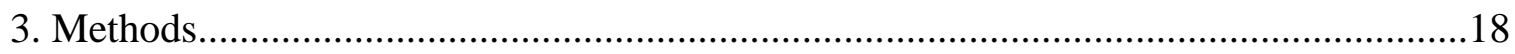

3.1 Borehole Data and Surface Mapping...................................................... 18

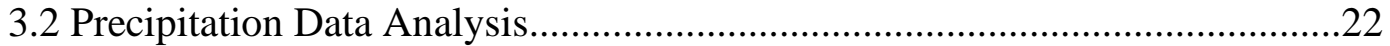

3.3 Surface Velocities at Seasonal to Annual Timescales......................................24

3.4 Surface Velocities at Decadal Timescales.....................................................28

3.5 Motion at Century Timescales...............................................................29

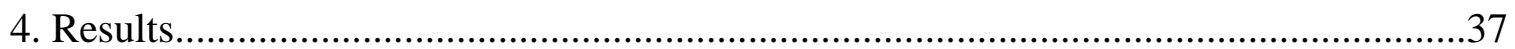

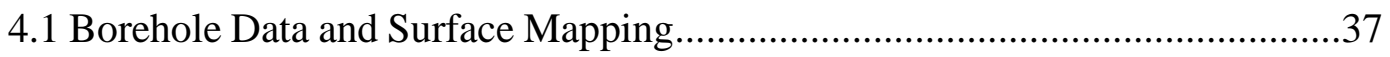

4.2 Landslide Kinematics at Seasonal to Annual Timescales...............................43

4.2.1 Satellite photo-based displacements.........................................43

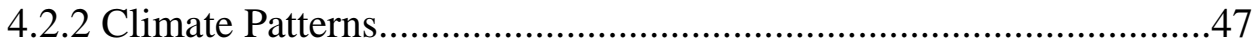

4.2.3 Terrestrial Lidar-Derived Displacements...................................49

4.3 Decadal Kinematics..............................................................................54

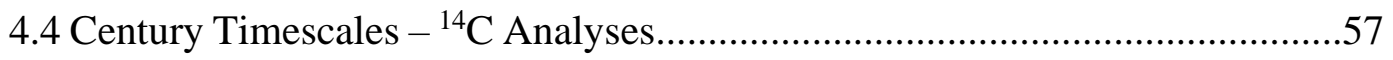

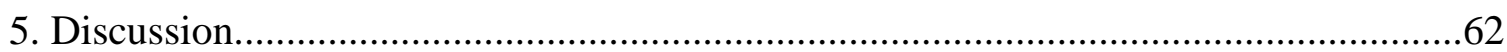

5.1 Surficial Expressions of Kinematic Behavior...........................................6. 62

5.2 Kinematic Behavior and Seasonal to Annual Climate Cycles.........................65

5.3 Kinematic Behavior and Decadal Climate Cycles.......................................68

5.4 Age Interpretation of the Hooskanaden Landslide..........................................71

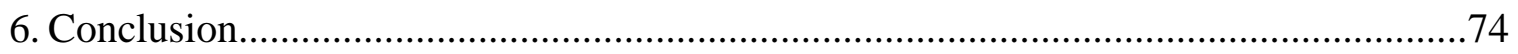

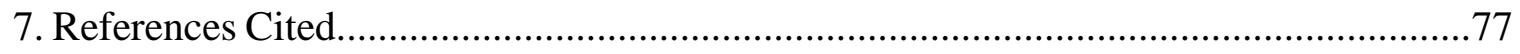

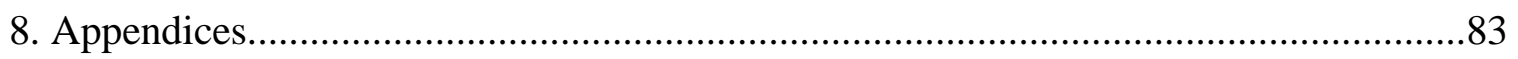

8.1 Appendix A - List of Supplemental Files............................................. 83 


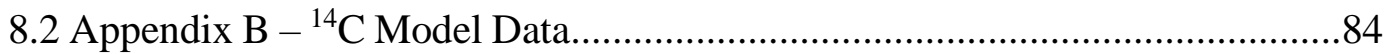




\section{List of Tables}

1. The root-mean-square error reported in CloudCompare resulting from alignment of stable-ground portions of terrestrial laser scans..........................................49

2. Results of radiocarbon analysis as provided by DirectAMS and NOSAMS

3. Statistical analyses of relationship between average velocity and precipitation

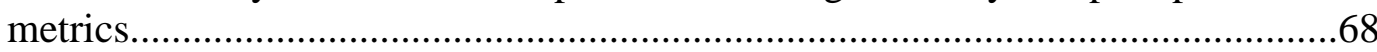

4. Average surface velocities from Xu et al. (2020) compared to those determined within this study. 


\section{List of Figures}

1. Location of the Hooskanaden Landslide (black polygon). Inset map shows lidar of the study area with hillshade and slope derivatives

2. ODOT Drone images taken of the Hooskanaden Landslide following a recent surge in February of 2019.

3. Tectonostratigraphic terranes of the southernmost Oregon coast, with the mapped extent of the Whaleshead fault zone.................................................................11

4. Plots showing the geographic distribution El Niño (left) vs. La Niña (right) effects

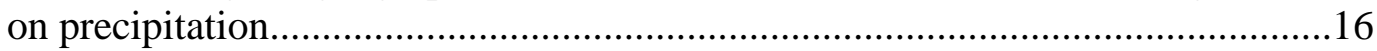

5. Locations field-developed cross-section, and TLS data collection locations........20

6. Locations of weather stations used to create precipitation time series, color coded by distance from the Hooskanaden Landslide.................................................23

7. Feature tracking example, showing tracked features in satellite images of the Hooskanaden Landslide, taken on 02/21/2019, and 03/11/2019.

8. Locations of all carbon samples collected from the toe of the Hooskanaden Landslide.

9. Tree round HEF-0609-6, from which samples were collected for ${ }^{14} \mathrm{C}$ dating and tree ring analysis

10. Stratigraphic column compiled using mud rotary drill logs from ODOT research group......

11. Mapped features observed on the surface of the Hooskanaden Landslide, overlying satellite image from Planet Labs taken September $21^{\text {st }}, 2019$

12. Photograph showing evidence of ground deformation on the surface of the Hooskanaden Landslide. Boundary between disturbed and undisturbed ground is shown

13. Image showing continuous drainage from a culvert beneath the newly reconstructed section of US Highway 101, taken in the late summer of 2019

14. Profile of the Hooskanaden Landslide generated using SLIDE. The yellow area represents the slide material above the failure plane, the brown area represents the 
bedrock below the failure plane. The geometry of groundwater surface (GWS) is indicated by the blue line.

15. Displacement, velocity, and precipitation time series for the seasonal to annual timescale (2009-2019).

16. Averaged displacement vector directions for each time interval from 2009-2019. Average vectors are shown in azimuth, which has been divided into $20^{\circ}$ sections. Sections are color coded to show the relative proportions of average vectors within each section.

17. The highest $2 \%$ of relative precipitation values on the seasonal to annual timescale with respect to time, and the number of days of highest precipitation that occurred each water year.

18. Correlation between landslide surface velocity, and Pacific Decadal Oscillation (PDO) and El Niño-Southern Oscillation (ENSO) periods

19. Distances between point clouds computed in CloudCompare. Showing results for 06.08_1 to 08.17_1 (21a), and 06.08_3 to 08.17_3 (21b). Results of manual feature tracking are also shown for 06/07/2019 to 08/17/2019 (21c)

20. Distances between point clouds computed in CloudCompare. Showing results for 08.17_1 to 09.21_1 (22a), and 08.17_3 to 09.21_3 (22b). Results of manual feature tracking are also shown for $08 / 17 / 2019$ to $09 / 21 / 2019$ (22c)...................52

21. Distances between point clouds computed in CloudCompare. Showing results for 06.08_1 to 09.21_1 (23a), and 06.08_3 to 09.21_3 (23b). Results of manual feature tracking are also shown for 06/07/2019 to 09/21/2019 (23c).

22. Point displacement and point velocity values plotted for each time interval within the decadal timescale (1980-2009). Daily and relative precipitation values are plotted for the same period. .55

23. Correlations between point displacement and point velocity, and Pacific Decadal Oscillation (PDO) and El Niño-Southern Oscillation (ENSO) periods....

24 . The highest $2 \%$ of relative precipitation values within the decadal timescale (1980-2009), as well as the number of days with the highest $2 \%$ of precipitation within each year.

25. Probability density functions of radiocarbon ages, calibrated and modeled using OxCal (version 4.3) and the IntCal 13 atmospheric curve (Reimer et al., 2013; Bronk Ramsey, 2017). 
26. Mapped surface features (Figure 11) compared to 1939 aerial imagery of the Hooskanaden Landslide.

27. Graphs of average displacement vs. precipitation statistics for each day with highest $2 \%$ of precipitation, including daily precipitation, relative precipitation, a two-week sum of daily precipitation, and a two-week sum of relative precipitation 


\section{Introduction}

Slow-moving earthflows are glacier-like masses of rock and soil characterized by average velocities of 0.1 to $5 \mathrm{~m} / \mathrm{yr}$, which may experience periods of dormancy and reactivation (Bovis and Jones, 1992; Mackey et al., 2009). Although commonly referred to as "earthflows," a more accurate name is "composite earth slide-flow" (Cruden and Varnes, 1996), given that they exhibit both basal sliding and internal deformation at different locations within the slide mass. Their morphology is tongue or teardrop shaped with bulging toes, and they are generally longer than they are wide (Keefer and Johnson, 1983; Highland and Bobrowsky, 2008). Usually, these types of flows occur as complexes, rather than a single episode (Keefer and Johnson, 1983). This means that slow-moving earthflows can have a significant impact on the overall geomorphology of a region by reducing relief and slope, and depositing larger volumes of sediment in streams than could be achieved by a single event alone.

Highways along the west coast of the United States are frequently impacted by slow-moving earthflows, often forcing roads to close or undergo costly repairs. Portions of US Highway 101 (US101) in Oregon (Figure 1) have been made inaccessible multiple times over the past few decades due to slow-moving landslides (Schultz et al., 2012). This is economically detrimental for small coastal communities, which are almost entirely dependent on tourism and are largely inaccessible other than by US101. More importantly, US101 represents a vital evacuation and emergency response route for many surrounding communities, which could have devastating consequences if blocked during an emergency or natural disaster. 
Due to their low average velocity, earthflows are rarely fatal. They can however be problematic for land management and represent major sources of sediment transport and erosion (Mackey et al., 2009). Active earthflows have the potential to deflate their source basins several orders of magnitude faster than regional erosion rates (Kelsey, 1978). This means that in any given landscape where earthflows occur, the earthflows alone can make up a relatively small amount of the overall surface area, but still represent a disproportionately large amount of overall regional sediment loss. The displaced sediment is transported downslope, occasionally supplying large sediment loads to channels, as well as damaging or obstructing roads and major highways.

Slow-moving earthflows can also be dangerous, as they do occasionally experience sudden acceleration, which can result in unpredictable loss of life (Petley et al., 2002; Reid et al., 2003). This is referred to as surge behavior, where the earthflow rapidly increases velocity for a period of time (Keefer and Johnson, 1983) or fails catastrophically. A recent example of this is the Mud Creek Landslide in California, which after years of slow, stable sliding, surged in the spring of 2017 , following an extreme shift from drought conditions to heavy rainfall (Handwerger et al., 2019). The surge event buried a quarter mile of State Highway 1 in California with slide debris more than 20 m deep (Ritchie, 2018).

Controls on the initiation of surge behavior are still poorly constrained, as are the relationships between interacting mechanisms controlling motion. Despite having been studied all over the world for several decades, the spatial distribution of slow-moving landslides is also still poorly understood (Scheingross et al., 2013). This lack of 
understanding and the long-term evolution of earthflows over decades and centuries makes their potential economic impact difficult to estimate (Strozzi et al., 2010). Because of this, accurate predictions cannot always be made as to when or where earthflows may occur or what their damage potential may be.

Like other types of landslides, slow-moving earthflows can have many triggering mechanisms, the most common of which include increased pore pressure due to prolonged or intense rainfall or snowmelt, erosion at the toe, anthropogenic modifications, and earthquakes (Keefer and Johnson, 1983; Highland and Bobrowsky, 2008). However, the mechanism most commonly attributed with controlling motion is increased pore pressure due to fluxes in precipitation or groundwater flow (e.g., Iverson and Major, 1987; Bovis and Jones, 1992; Bontemps et al., 2018). This is supported by what is generally observed in most regions where landsliding is prevalent; mass wasting tends to occur more frequently following heavy rain events. For slow-moving earthflows, higher velocities (including surging) are typically observed during the wet season, while relatively little to no movement is seen in the dry season.

While it is commonly understood that precipitation (and therefore, pore pressure at the earthflow's failure plane) changes seasonally, less is known about the potential influences of longer-term climate cycles on landslide motion due to challenges in quantifying earthflow behavior prior to the observational record. Although previous studies point to generations of dormant slope failures as possible evidence that longer term climatic forcing may have an effect on earthflow activity (Bovis and Jones, 1992; Mackey et al., 2009), periodic changes in hillslope morphology following extreme 


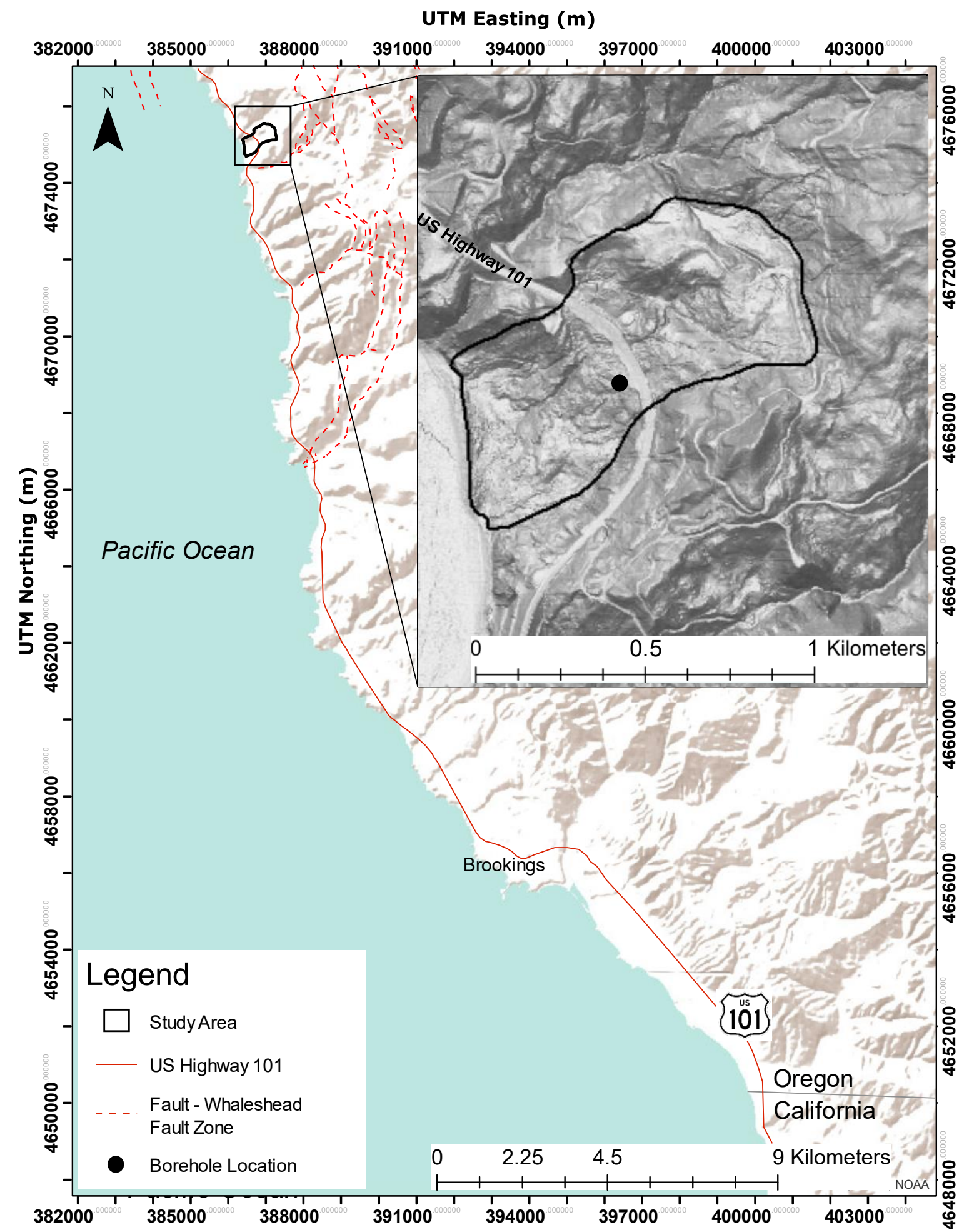

Figure 1: Location of the Hooskanaden Landslide (black polygon). Inset map shows a composite hillshade and slope map derived from 2015 lidar (available through the Oregon Lidar Consortium) of the Hooskanaden Landslide. The black dot within the inset map (area also shown in Figure 5) represents the location of a borehole drilled in Winter of 2017-2018. 
climatic events make the more subtle influences of long-term climate cycles harder to recognize (Bovis and Jones, 1992). In this study, we addressed this gap in timescales by examining both short-term (years) and long-term (decades) climatic effects on the Hooskanaden Landslide in southwestern Oregon (Figure 1). To do this, both remote and field techniques were employed to reconstruct a history of activity on the Hooskanaden Landslide over multiple timescales. This site is ideal for this study due to its proximity to US101, its weak underlying lithology, and its ongoing erosive environment, given constant wave action at the sea cliff (landslide toe).

Attempts to further our current understanding of earthflows come at a crucial time. Increased precipitation is a primary driver in the initiation and acceleration of many earthflows. Based on the most recent projections from the U.S. Global Change Research Program (2018), total precipitation in the western U.S. is projected to increase up to $20 \%$ during winter and spring between the years 2070-2099 (relative to the period of 1986-2015).

Heavy precipitation has already been observed as becoming more intense and more frequent across most of the United States during the last century, and the frequency of the heaviest $1 \%$ of precipitation events is expected to increase by $10-40 \%$ on the southern Oregon Coast by the end of the $21^{\text {st }}$ century (U.S. Global Change Research Program, 2018). All of this could mean a significant increase in earthflow activity in the Pacific Northwest region of the United States before the end of the $21^{\text {st }}$ century (e.g., Malet et al., 2005; Bennett et al., 2016b). 
To properly understand the long-term behavior of these types of landslides, it is important to understand two things: the conditions that lead to changes in flow behavior, and the conditions which lead to their initiation. Changes in earthflow deformation rates, as reported for lithologic and climatic environments in the Pacific Northwest region are primarily driven by changes in precipitation. If the Hooskanaden Landslide has behaved like these other earthflows, then its deformation cycles could correlate to seasonal and/or decadal climate cycles (or multi-annual climate cycles). To investigate this possibility, the changes in the displacement and velocity of points along the landslide's surface were compared to daily precipitation records from 1980 through 2019. If increased velocity and surge behavior are in fact controlled by increases in pore pressure, there should be a clear positive correlation between precipitation and surface velocity at seasonal to decadal time scales.

For failure to occur in a landmass, the effective stress (and consequently the frictional strength, defined as the stresses which hold the landmass together, resisting movement) must be decreased enough to initiate mass wasting. The two most likely causes of decreased effective stress are coseismic ground shaking and increased pore pressure - particularly in loose granular material (such as unconsolidated sand with some mud content), where shaking induces contraction, causing pore pressures to spike and residual strengths to plummet (Seed and Idriss, 1982). One such example is the Turnagain Heights Landslide in Anchorage, Alaska, which occurred during the earthquake of March $27^{\text {th }}, 1964$, causing the ground surface to drop an average of over $10 \mathrm{~m}$, lateral displacements of several hundred meters, and the destruction of several 
houses (Seed and Wilson, 1967). Though this landslide was of different composition than the Hooskanaden Landslide (marine clay vs. mélange), it is still a prime example of how catastrophic the combination of high pore pressure and ground shaking can be. Major landslides like Turnagain Heights have been responsible for much of the damage and loss of life that occurs during earthquakes (Seed and Idriss, 1982). Along the Oregon Coast, several large earthflows have been linked, although not directly dated, to the last great Cascadia Subduction Zone earthquake of 1700 AD (Schultz et al., 2012). Coseismic landslides are a well-documented hazard in other subduction zone regions with more recent earthquakes. For example, over 3,000 coseismic landslides occurred following the 2011 Tohoku Earthquake, 80\% of which occurred in Quaternary soils and Neogene rocks (Wartman et al., 2013). Based on the location of the active Hooskanaden Landslide near the Cascadia Subduction Zone, it seems reasonable to speculate that its activity could have been triggered by the 1700 AD Cascadia earthquake. To determine a minimum age for the landslide, ${ }^{14} \mathrm{C}$ samples were collected for dating from multiple stratigraphic units (interpreted as distinct landslide deposits overlying older failure planes) found at the wave-cut toe of the landslide. The oldest sample was selected for further ${ }^{14} \mathrm{C}$ dating using dendrochronology and wiggle matching to better constrain this minimum age. A modeled radiocarbon age prior to $1700 \mathrm{AD}$, would mean that the age of the landslide predates the most recent Cascadia earthquake. 


\section{Background}

\subsection{The Hooskanaden Landslide}

The Hooskanaden Landslide is a slow-moving earthflow located on the coast of Curry County, the southwesternmost county in Oregon. Previous work done on this landslide includes a recent study released in September of 2020, which used pixel offset tracking of satellite images, lidar, and Interferometric Synthetic Aperture Radar (InSAR) to recreate a 12-year surface displacement history for the Hooskanaden (Xu et al., 2020). Via comparison between displacement history and precipitation records, that study revealed that the displacements were predominantly controlled by intensity and temporal pattern of precipitation. In order to fit precipitation trends to displacement behavior, $\mathrm{Xu}$ et al. (2020) used a "threefold rainfall threshold," which included daily precipitation, as well as precipitation over the previous 3-day period and over the previous water-year.

This earthflow has been under observation by the Oregon Department of Transportation (ODOT) for several decades due to its proximity to US101 (Figure 1). Aerial imagery obtained from the United States Army Corp of Engineers (USACE) indicates that this slide has been active since at least 1939 (imagery available by request through the USACE Arial Photos Library via https://www.nwp.usace.army.mil/Library/ Aerial-photos/). Large surge events which close the highway have periodically isolated entire cities (including Port Orford, Gold Beach and Brookings) from the rest of the county, due to a lack of detour options. According to a recent internal 2019 update from ODOT, typical annual movement for the slide is about a meter per year, which does not impair the roadway, but does require around $\$ 75,000$ in annual maintenance cost. Small failures where the road surface drops 2-3 m occur every 10 years (2006 and 2016) and 


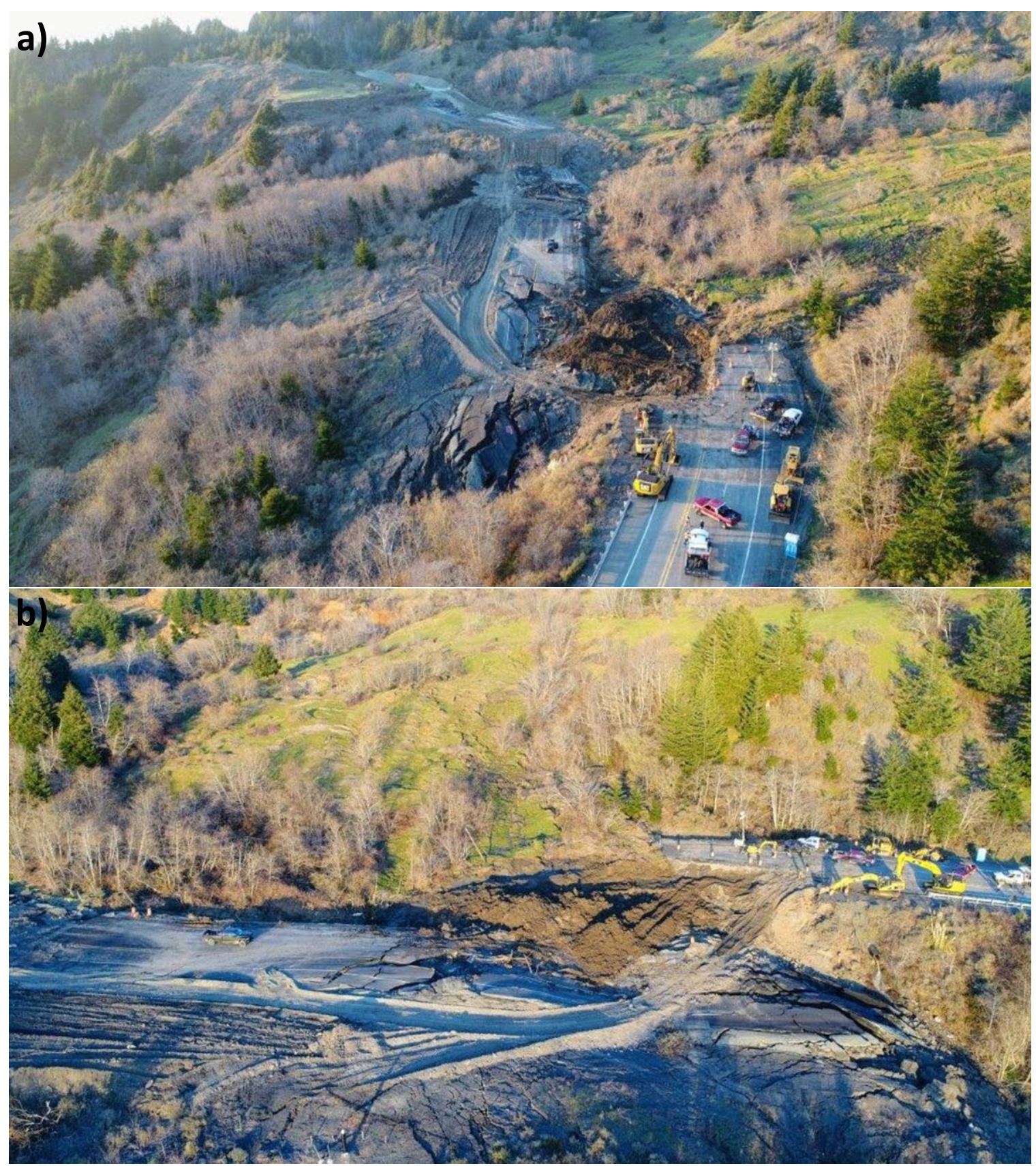

Figure 2: Drone images taken of the Hooskanaden Landslide following a recent surge in February of 2019. (a) is looking to the north, and (b) is looking to the east. Images provided by the Oregon Department of Transportation.

cost \$1.26 million per event in repairs. Larger failures, which typically involve 30-40 m

horizontal and $10 \mathrm{~m}$ vertical displacement, occur every 20 years (1977, 1995, and

2019) and cost \$5-7 million to repair. The most recent of these failures occurred in late 
February of 2019, which caused about $500 \mathrm{~m}$ of US101 to drop roughly $20 \mathrm{~m}$ in elevation, and slide $\sim 30 \mathrm{~m}$ downslope to the west (Figure 2; Alberti et al., 2020). After nearly two weeks of complete closure, US101 reopened as a single lane of travel on March $9^{\text {th }}, 2019$. Two paved lanes of travel with a reduced speed limit were not opened until May $6^{\text {th }}, 2019$.

\subsection{Tectonic and Structural Setting}

Curry County lies within the Klamath Mountains geologic province, which extends from $\sim 100-150 \mathrm{~km}$ north to $\sim 120-150 \mathrm{~km}$ south of the Oregon-California border. In the northern part of this province, a north-northwest striking series of high- angle faults known as the Whaleshead fault zone is mapped in the Mesozoic bedrock. Figure 3 shows the full extent of the Whaleshead fault zone, while Figure 1 shows individual faults in relation to the Hooskanaden Landslide. The southern Whaleshead fault zone deforms marine terraces aged $80 \mathrm{ka}$ and older, and thus was active within the late Quaternary. Average late Quaternary vertical slip rates of $0.5 \mathrm{~mm} / \mathrm{yr}$ and post-200-ka left-lateral slip rates of $2.5 \mathrm{~mm} / \mathrm{yr}$ indicate high rates of activity on at least one strand of the Whaleshead fault zone (Personius et al., 2003). Tectonic uplift over time has also created a series of additional terraces, or former wave-cut platforms, which now reside above sea level and run roughly parallel to the shore beyond the study area. 


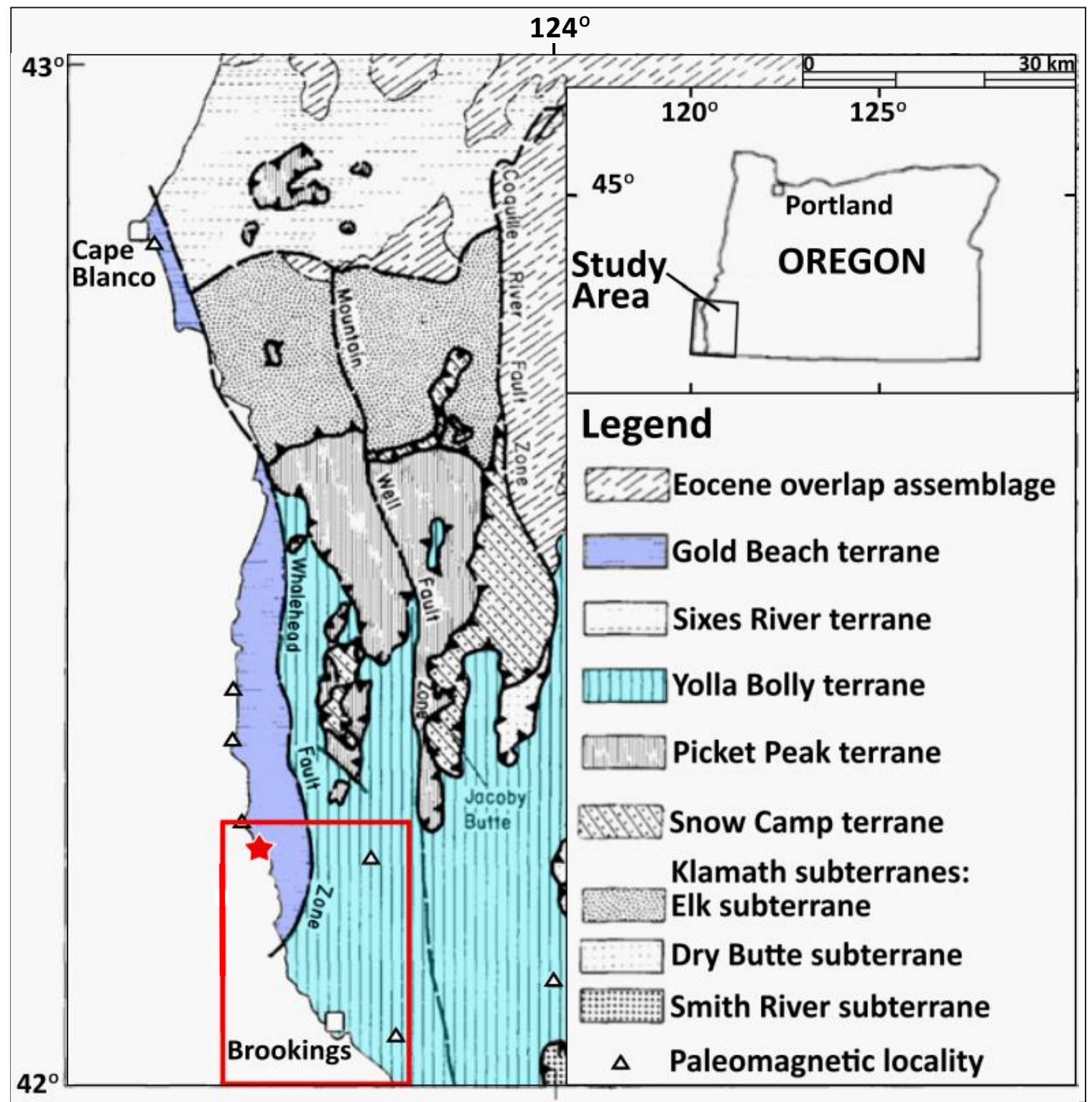

Figure 3: Tectonostratigraphic terranes of the southernmost Oregon coast, as well as the extent of the Whaleshead (here as "Whalehead") fault zone (modified from Blake et al., 1985). Location of the Hooskanaden Landslide is shown by the red star. Red lines indicate boundaries of Figure 1.

The Cascadia subduction zone extends along the west coast of Oregon from northern California to Vancouver Island, and accommodates convergence of the Juan de Fuca Plate with the North American plate (Nelson et al., 1995). Convergence causes interseismic uplift along the coast, and shapes the geomorphic setting of the coastline - 
for example, areas that have experienced rapid or long-term uplift are often characterized by prominent headlands and small pocket beaches, whereas coastal areas that have experienced subsidence often have embayments or marshes (Muhs et al., 1992). Although uplift rates vary greatly along the western United States coastline, the Oregon coast is estimated to be uplifting during the historic interseismic period between 0.07 and $0.10 \mathrm{~mm}$ per year (Burgette et al., 2009; Peterson and Cruikshank, 2014). This shoreparallel variation in tectonic uplift and associated variation in coastal erosion is attributed to the role that local structures play in differential uplift along the coast. The highest estimated uplift rate on the southern Oregon Coast $(0.8 \mathrm{~mm} / \mathrm{yr})$ is attributed to the Whaleshead fault zone, which encompasses the Hooskanaden Landslide (Kelsey and Bockheim, 1994). Given that erosion rates tend to track uplift rates over geologic time scales (Balco et al., 2013), the Hooskanaden Landslide region may also have a higher erosion rate than the surrounding areas, which could further exacerbate the long-term stability of this slide.

\subsection{Geologic Background}

The Klamath Mountains province consists of westward-younging bands of metamorphic and igneous marine rocks, which were likely deposited horizontally, then deformed into their current arcuate pattern following their accretion during the Nevadan Orogeny (Dott Jr., 1971; Blake et al., 1985). The coastal region has a complex geologic history, with Mesozoic sedimentary bedrock overlain by a series of tectonostratigraphic terranes, which are juxtaposed against one another by the Whaleshead fault zone (Dott Jr., 1971; Kelsey, 1978). This includes the Gold Beach, the Yolla Bolly, Sixes River, 
Pickett Peak, Snow Camp, and Western Klamath terranes (Figure 3). This summary will focus on the Gold Beach and Yolla Bolly terranes due to their proximity to the Hooskanaden Landslide. Specifically, geologic mapping (Dott Jr, 1971) suggests that the Hooskanaden Landslide is predominately within the Hunter Cove Formation, and to a lesser extent, the Otter Point Formation of the Gold Beach terrane. The slide material itself is characterized by individual blocks of more resistant lithology which are surrounded by a much weaker matrix, also called block-in-matrix (BIM) topography (Mohney et al., 2019).

The Gold Beach terrane occurs to the west of the Whaleshead fault zone (Figure 3) and consists of the Upper Jurassic Otter Point Formation, unconformably overlain by the Upper Cretaceous Houstenaden (alternate name for Hooskanaden) Creek unit, Cape Sebastian Sandstone, and Hunters Cove Formation (Blake et al., 1985). Otter Point ranges from a relatively undeformed sedimentary rock, to a highly sheared mélange of interbedded volcanic sandstones and mudstones, radiolarian cherts, and many graded beds of andesitic conglomerate and breccia, likely deep marine in deposition (Koch, 1966; Blake et al., 1985). The overlying Cretaceous units grade from deep- to shallowmarine deposition moving up section (Dott Jr., 1971). The Houstenaden Creek unit is a coarsening-upward section at least $500 \mathrm{~m}$ thick, which consists of poorly exposed mudstone with calcareous concretions and thin siltstone and fine-grained sandstone beds, overlain by alternating beds of sandstone and mudstone (Bourgeois and Dott Jr., 1985). Cape Sebastian Sandstone is largely a massive, fine- to medium-grained sandstone unit approximately $250 \mathrm{~m}$ thick, although the lower third does contain abundant coarse- 
grained sandstone beds and conglomerate lenses (Dott Jr., 1971). Finally, the Hunters Cove Formation is the youngest unit in the Gold Beach terrane, and is characterized by thin, alternating turbidites, sandstone, and mudstone beds which can be rippled or finely laminated, as well as interspersed coarse-grained channels, slumps, and burrows (Dott Jr., 1971; Bourgeois and Dott Jr., 1985). Directly east of the Whaleshead fault zone is the significantly more expansive Yolla Bolly terrane (Figure 3), which consists of sedimentary and igneous rocks of the Upper Jurassic and Lower Cretaceous Dothan Formation (Blake et al., 1985). This formation is comprised of a fractured to highly sheared sequence of graywacke and mudstone with chert, breccia, pillow basalt, minor conglomerate, and occasional limestone lenses in the graywacke-mudstone sequence (Ramp et al., 1977).

The Yolla Bolly, along with the Otter Point formation of the Gold Beach terrane, is considered comparable with the coastal Franciscan Formation of northern California (Koch, 1966), and some authors consider the Dothan Formation and the Franciscan Formation to be the same unit (e.g., Dott Jr., 1971; Ramp et al., 1977), despite differences in quartz grain concentrations (Bounds, 1982). While few studies have been published on earthflows in the Gold Beach or Yolla Bolly terranes (Alberti et al., 2020), earthflows in the Franciscan mélange are well documented (e.g., Kelsey, 1978; Mackey et al., 2009; Mackey and Roering, 2011; Bennett et al., 2016b). For that reason, this study will assume that the flow behavior of the Hooskanaden mélange is not significantly different from that of the Franciscan Complex. 


\subsection{Climate Background}

El Niño-Southern Oscillation (ENSO) is a periodic variation in winds and sea surface temperatures over the eastern Pacific Ocean. These cycles occur irregularly every few years, with effects that last several months. In the Pacific Northwest, ENSO forcing events that occur during the late summer through fall strongly impact winter weather and precipitation patterns, which can have other detrimental effects on coastlines. Short-term ENSO-related beach sand displacements in 1978, 1982-83, 1997-98, 2015-16 have been related to beach erosion and sandy sea cliff failures (e.g. Peterson et al., 1985; Sallenger et al., 2002). ENSO-induced beach erosion, in addition to precipitation, could lead to increased downslope movement in the Hooskanaden Landslide by debuttressing its toe via wave action.

In the Pacific Northwest, ENSO periods of above-average sea surface temperatures (El Niño years) are correlated with dry winters, while periods of below-average sea surface temperatures (La Niña years) are associated with wet winters (Ropelewski and Halpert, 1986). However, throughout California, El Niño events are associated with anomalously high rainfall, while La Niña events tend to coincide with low rainfall (Fierro, 2014). Figure 4 nicely demonstrates this apparent climate boundary at the Oregon-California border, by showing how precipitation differs from the long-term average in each US Climate Division during the winter months (December through March) following El Niño (left) and La Niña (right) events. This distinction is important, given that the Hooskanaden Landslide lies just to the north of the Oregon-California border. However, given that precipitation anomalies are reported along the Oregon Coast 
as a single US Climate Division (see Oregon Coast in Figure 4), and that the climate surrounding the Hooskanaden Landslide more resembles that of northern California than the mid or northern Oregon Coast, precipitation patterns at the Hooskanaden Landslide are anticipated to more closely represent those seen in California, with higher precipitation correlating with El Niño events.

\section{NOAA/NCEI Climate Division Composite Precipitation Anomalies (cm) Versus 1951-2010 Longterm Average}

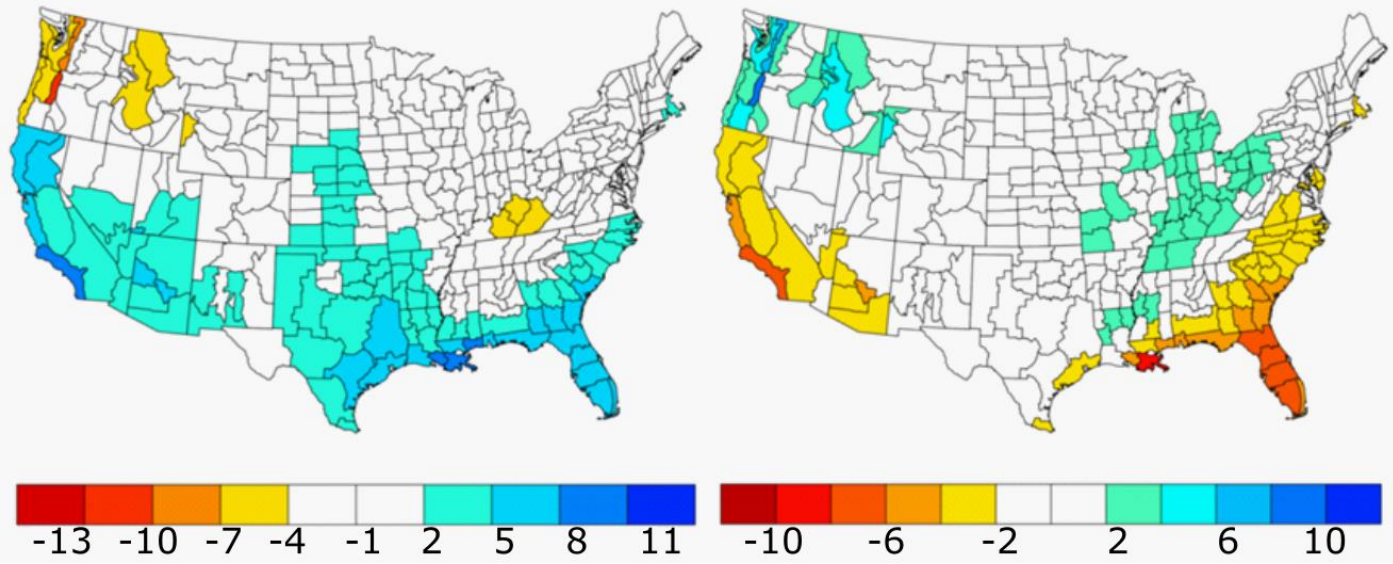

Figure 4: Maps showing the geographic distribution of precipitation effects in the winter months (December through March) following El Niño (left) and La Niña (right) events from occurring in the late summer to fall, from 1956 to 2018 (NOAA, 2020).

In addition to ENSO, the Pacific Decadal Oscillation (PDO) also reflects Pacific Northwest weather trends. PDO fluctuations are similar to ENSO, but occur on pendecadal ( 50yrs) and interdecadal ( 20yrs) timescales, with dominant cold phases from 1890 to 1924 and 1947 to 1976 , and dominant warm phases from 1925 to 1946 and 1977 through at least the late 1990s. Most above-average winter precipitation occurs on the Oregon Coast when the PDO and ENSO are in synch during cold ENSO/cold PDO and neutral ENSO/cold PDO phases (Goodrich, 2007). Given the previously discussed difference in the effect of ENSO on Oregon vs. California precipitation, it is reasonable 
to suspect that more precipitation will occur at the Hooskanaden Landslide correlating to warm phase PDO. Therefore, greater Hooskanaden Landslide activity will likely occur where warm ENSO and warm PDO phases coincide. This would mean decreasing velocities in the late 1990 's, possibly increasing again in the 2000 s. 


\section{Methods}

A variety of remote sensing and field-based methods were utilized to investigate the evolution of the Hooskanaden Landslide over its minimum lifetime, and to examine how this earthflow is affected by climatic cycles over multiple timescales: seasonal to annual, decadal, and century (prehistoric). A detailed reconstruction of surface velocities over these timescales was required to observe changes in velocity behavior, but a thorough understanding of the complex slide morphology (surface and subsurface) was equally necessary to accurately interpret surface velocity patterns.

\subsection{Borehole Data and Surface Mapping}

Drill logs and inclinometer data provided by collaborators at OSU were used to construct a stratigraphic column, based on the depths and descriptions of collected samples, as well as blow counts, to infer lithologic boundaries. This information was compiled into a scaled model, which shows the thickness and composition of all lithologic units encountered during drilling, as well as the depth of the failure plane.

Between June and September of 2019, I compiled a detailed map of the earthflow's surface features using remote sensing data - including aerial imagery and 2015 lidar (available through the Oregon Lidar Consortium) - and field observations. First, possible features of interest (scarps, lateral margins, gullies, and thrust features) were identified in the remote sensing data, then those features were further inspected in the field. In addition to the previously identified features of interest, I also mapped other surface features (tension cracks, shear margins, standing water, and hummocky topography) encountered while traversing the landslide. Map data was collected both on paper (drawn 
onto a physical map), as well as GPS points in Avenza (including field observations, measurements, and images). I then used point data from Avenza in ArcGIS (Esri, version 10.7.1), along with all other data, to precisely map all identified features using lines and polygons.

During mapping efforts, I also constructed three field-developed cross-sections (locations are shown in Figure 5). The cross-section locations were selected based on accessibility and significant features identified in the field. These were made using a measuring tape and an OMNISLOPE (Brunton) inclinometer, following the procedure outlined in Williamson et al. (1991). Starting upslope of a feature of interest, typical sections were identified between each significant slope break, moving in a straight line downslope. The length and slope angle of each typical section were recorded, along with any other significant observations (e.g. standing water). Typical sections were then tied together in Microsoft Excel, using the length and slope angle of each typical section to trigonometrically calculate the distance (horizontal) and elevation (vertical) change expressed on the slide surface within each section, ultimately producing a relative elevation profile. These were then tied to the map in ArcGIS using GIS points collected at the beginning and end of each cross-section.

Borehole data, mapped features and cross-sections were then used to determine the most-likely failure plane geometry along a detailed profile of the Hooskanaden Landslide. This was done in SLIDE (Rocscience) by combining the field developed cross-sections with an elevation profile taken down the center of the lidar DEM, parallel 


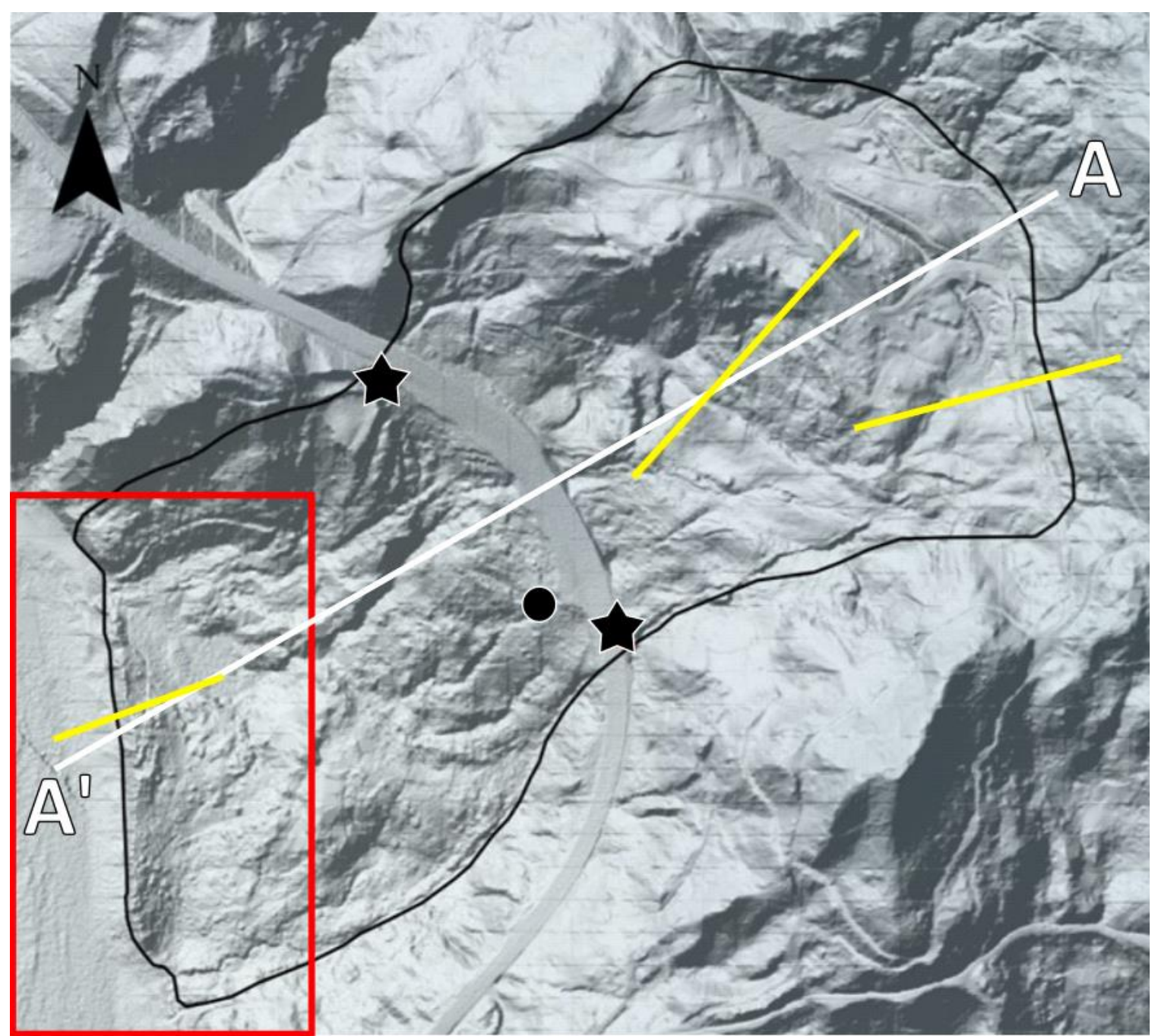

Figure 5: Locations of field-developed cross-sections (yellow lines), and TLS data collection (black stars), overlying 2015 lidar hillshade derivative. Line A to A' shows the location of the lidar profile used to anchor cross-sectional profile data. Extent of this figure also shown in Figure 1 inset. Borehole location shown by black dot. The red rectangle represents the approximate extent of Figure 8.

to the general downslope direction (Figure 5). The failure plane morphology was then approximated using the slope at the headscarp (based on field-developed cross-sections), the depth to failure (from the boring $\log$ ), and the location of the failure plane observed at the toe. Values of cohesion, friction angle, and unit weight values for the sandstone and siltstone of the Franciscan Mélange were assigned below the assumed failure plane (48 $\mathrm{kPa}, 30^{\circ}$, and $21 \mathrm{kN} / \mathrm{m}^{3}$ ) and values for colluvium were assigned above the failure plane 
(0 kPa, 25 , and $\left.19.7 \mathrm{kN} / \mathrm{m}^{3}\right)$, as defined by Stark et al. (2011). Locations and elevations where standing water was found at the surface were used to approximate the geometry of the groundwater surface (GWS).

Failure plane morphology (angle and depth at unknown points) was then manually adjusted via back analysis until a Factor of Safety (FOS) as close as possible to (but greater than) 1 was achieved. For an infinite slope with uniform GWS and hydrostatic pore water pressure, FOS is a ratio between the driving and resisting forces in a given slope,

$$
F O S=\frac{R}{D}=\frac{\mathrm{C}+\left(\gamma_{\mathrm{s}} H-\gamma_{w} h\right) \cos ^{2} \theta \tan \phi}{\gamma_{s} H \sin \theta \cos \theta}
$$

where $R$ and $D$ are the resisting and driving stresses, respectively, $C$ is cohesion, $\gamma_{\mathrm{s}}$ is the unit weight of landslide material, $H$ is the landslide depth, $\gamma_{w}$ is the unit weight of water, $h$ is the height of the GWS above the failure plane, $\theta$ is the slope angle, and $\phi$ is the material's internal friction angle. When the available resisting force exceeds the driving force (FOS > 1), the slope is stable and not moving. When the driving force exceeds the resisting force $(\mathrm{FOS}<1)$, the slope is actively failing or surging. The Hooskanaden Landslide is stable in that acceleration is small, suggesting that driving and resisting stresses are approximately balanced. Due to this balance, the model was back calibrated to achieve a safety factor as close to FOS $=1$ as possible. For this analysis, I used the Janbu method of slices within SLIDE to calculate FOS for a series of idealized "slices" throughout the slide mass, because it uses a correction factor to account for the effect of the interslice shear forces, which is based on cohesion, internal friction angle, and the 
shape of the failure surface (Fredlund and Krahn, 1977). Since cohesion and internal friction angle were assumed constant (as discussed above), this method allowed back calibration of the model by optimizing for the shape of the failure surface.

\subsection{Precipitation Data Analysis}

In order to examine whether changes in landslide surface motion correspond to climatic changes, a precipitation time series needed to be created. This was done using weather station data available through the National Oceanic and Atmospheric Association (NOAA). Weather station locations relative to the Hooskanaden Landslide are shown in Figure 6. The closest of these stations (US1ORCY0012) is about $11 \mathrm{~km}$ southeast of the Hooskanaden Landslide, but only has data from November of 2012 to February of 2016 with $74 \%$ coverage. There are seven more stations within $\sim 25 \mathrm{~km}$ southeast of the field site, all covering different time periods with different coverage densities. Since these stations are located relatively close to each other and to the study site, I assumed these stations would best approximate actual precipitation at the landslide. Daily precipitation data from these eight stations were therefore used to produce a precipitation time series for our period of interest (March of 1980 to October of 2019) with $44 \%$ coverage. Remaining data gaps were then filled in using data from the other weather stations shown in Figure 6, the furthest of which was $\sim 132 \mathrm{~km}$ from the slide. Since those stations are much farther from the landslide, they are likely affected by different local weather patterns that may not reflect conditions at the landslide. To correct for this, once the precipitation time series was completed, I calculated the average precipitation for each calendar day at each different weather 


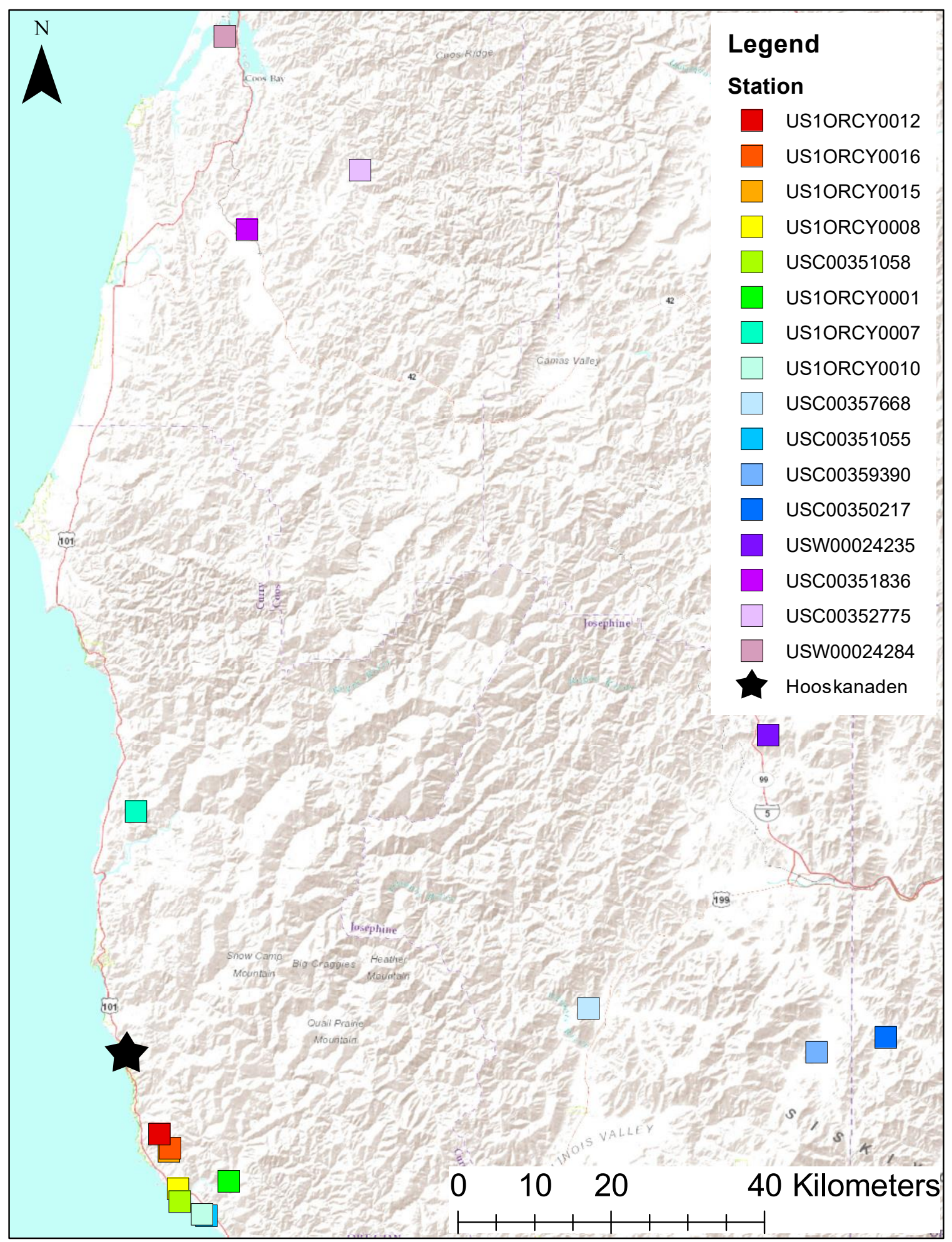

Figure 6: Weather stations used to create precipitation time series; color coded by distance (warmer colors are closer) from the Hooskanaden Landslide (black star). 
station and normalized daily precipitation measurements by those average values. This was done to account for variations in precipitation resulting from the different weather station locations and elevations. Daily, average, and relative precipitation values for each day in the timeseries, as well as the associated weather station, are included as Supplemental Files (further described in Appendix A). Landslide displacement and velocity data were then compared to the relative precipitation recorded for that day, reflecting whether that amount was unseasonably high or low for the given area.

\subsection{Surface Velocities at Seasonal to Annual Timescales}

Using modern satellite images from Planet Labs, I've performed manual feature tracking in ArcGIS to observe the movement rate of features (predominately bushes, large boulders, and trees) on the surface of the landslide. Planet Labs provides images that are publicly available, orthorectified, and georeferenced, and are available as far back as 2009 for the Hooskanaden Landslide study area. More recent imagery (2016 to modern) is collected daily at a $3 \mathrm{~m}$ spatial resolution. Imagery prior to 2016 was collected weekly to monthly at a $5 \mathrm{~m}$ resolution. Images were selected in approximately 30-day intervals, including only images that had $100 \%$ coverage of the study area with minimal to no cloud coverage. This allowed for surface velocities to be estimated with monthly temporal resolution from 64 lower resolution (5 m) images from 2009-2016 and 36 higher resolution images ( $3 \mathrm{~m}$ ) from 2016-2019.

By measuring the distance these features move from image to image (displacement), and the time interval between images, I was able to estimate a surface velocity for each feature. An example of this is shown in Figure 7. Distances were 

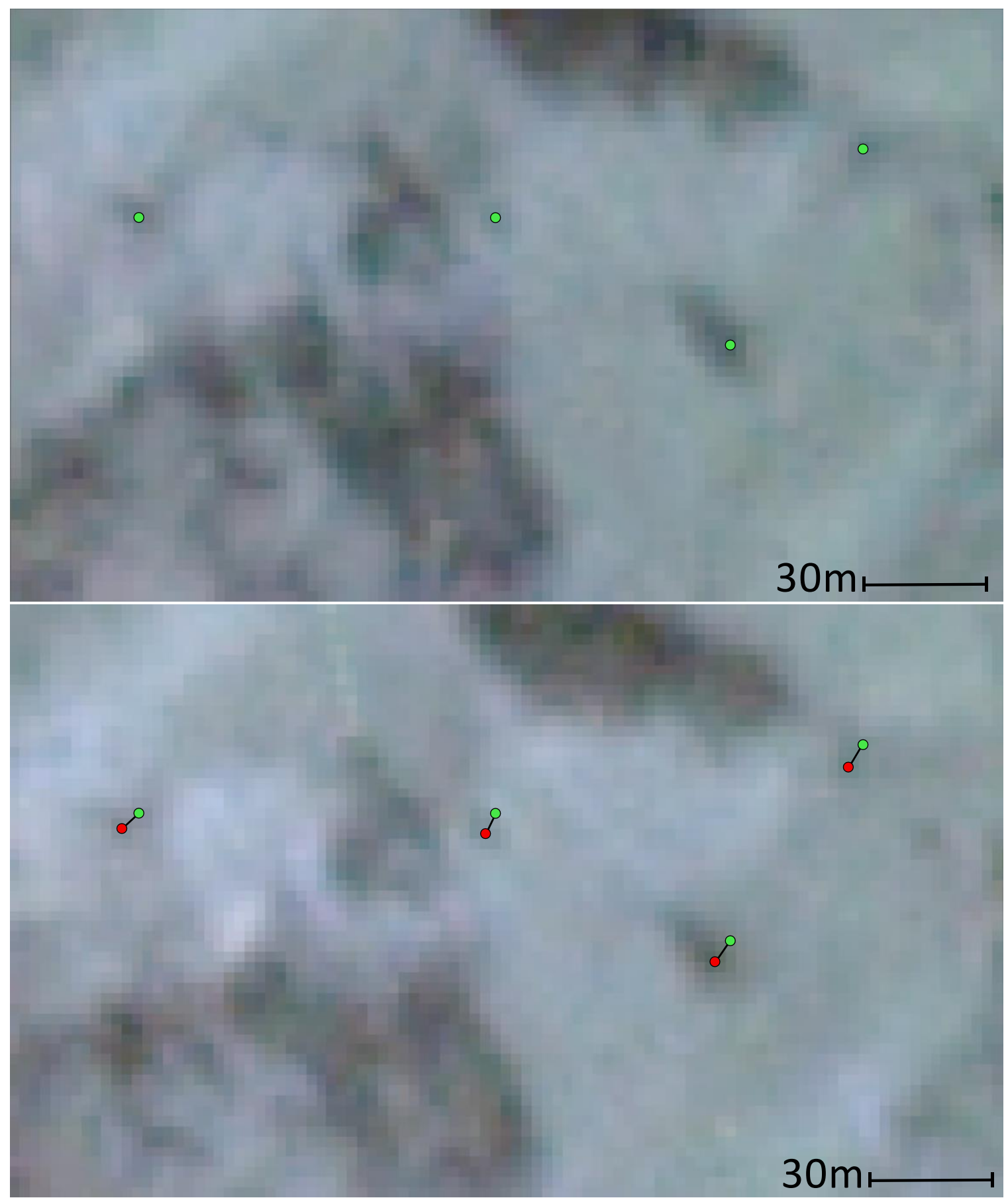

Figure 7: Satellite images showing a portion of the surface of the Hooskanaden Landslide, taken on 02/21/2019 (top), and 03/11/2019 (bottom), which spans the most recent surge. The green points show the locations of tracked features on $2 / 21 / 2019$. The red points show the new locations of those same features on $3 / 11 / 2019$. The black line connecting each point pair represents the displacement vector for the given feature. 
calculated using the change in a given feature's UTM easting and northing coordinates ( $\mathrm{x}$ and $\mathrm{y}$ directional components) over time, and solving for the map-view distance using the distance formula:

$$
d=\sqrt{\left(x_{1}-x_{0}\right)^{2}+\left(y_{1}-y_{0}\right)^{2}}
$$

where $x_{0}$ and $y_{0}$ are the initial UTM easting and northing coordinates, $x_{1}$ and $y_{1}$ are the final UTM easting and northing coordinates, and $d$ is magnitude of the displacement vector. Because all images did not contain elevation data, vertical displacements could not be measured. Given that not all features move along the surface at the same rate, and not all features are trackable in every image pair, I determined both the maximum and average displacement and velocity for each time interval to characterize the landslide's overall movement.

Image alignment bias was estimated using the same manual feature tracking method, but using presumed stable points (such as road intersections, houses, and volcanic outcrop features), which were persistent throughout multiple images, outside of the mapped earthflow area. By differencing the easting and northing UTM coordinates of stable features as described above, the apparent offset in the $\mathrm{x}$ and $\mathrm{y}$ direction was determined for multiple points within each set of images. This represents any alignment error between images. Averaged $\mathrm{x}$ and $\mathrm{y}$ directional error components were used to correct feature tracking results, by subtracting the average error in the $\mathrm{x}(\mathrm{y})$ direction, from the final UTM easting (northing) coordinate. After correcting for bias, the vector sum of the standard deviation from the $\mathrm{x}$ and $\mathrm{y}$ error components was used to estimate 
the remaining error. This vector sum represents the minimum detectable displacement (MDD) for each set of images.

Field-based methods were also utilized to test the accuracy of the feature tracking method, as well as to gain a more comprehensive understanding of the morphology of the earthflow. All fieldwork for this study was performed from the late spring to the late summer, 2019. During that time, high resolution topographic data was collected on three separate occasions (June $8^{\text {th }}$, August $17^{\text {th }}$, and September $21^{\text {st }}$ ), using a FARO terrestrial laser scanner (TLS). This TLS unit has an accuracy of $\pm 2 \mathrm{~mm}$ at a distance of $10 \mathrm{~m}$ from the scanner, which increases marginally with increasing distance from the scanner, according to the manufacturer, which reflects ideal conditions such as measuring the distance to a flat, reflective surface. Each collection of TLS data consisted of two scans, one from near the northern shear margin just west of the highway, and one from near the southern shear margin to the east of the highway (Figure 5). These locations were chosen based on their vantage, proximity to the highway, and visibility of the more mobile section on the earthflow. Point clouds were aligned (using CloudCompare) by selecting and aligning only the stable areas in common between the two clouds. This was done by first manually selecting pairs of similar points between clouds and minimizing the root mean square error (RMSE) of the distances between each point pair. The alignment was then optimized using all points on stable ground via an Iterative Closest Point (ICP) algorithm, which also minimized the RMSE between points within the selected area of both clouds (Besl and McKay, 1992). Once the stable sections were aligned, the same rigid body transformation (referred to as the rototranslation matrix, which quantifies the 
translation on and the rotations around the $\mathrm{x}, \mathrm{y}$, and $\mathrm{z}$ axes) was applied to the remaining portion of the cloud, so that all points were shifted in the same fashion. A change analysis was then performed by manually selecting similar points between the two clouds within the unstable landmass area. Given that the satellite image-based manual feature tracking results represent two-dimensional displacements (as they do not account for elevation), only the $\mathrm{x}$ and $\mathrm{y}$ components of each point coordinate in the lidar point clouds were used to calculate the two-dimensional displacement. This was done as described above using the distance formula (Equation 2). The resulting displacements were then compared to the displacements yielded by the satellite image-based manual feature tracking method.

\subsection{Surface Velocities at Decadal Timescales}

To extend the record of landslide movement to before 2009 (the oldest satellite images available via Planet Labs), I also analyzed historic aerial images using the same manual feature tracking method. The UTM coordinates of a given feature were utilized to calculate displacements following the methodology explained above. Single frame aerial images used in this analysis were obtained from the USGS EROS Archive, and are available via USGS Earth Explorer (https://earthexplorer.usgs.gov/). For this analysis, photographs from 1980, 1985, 1992, 1997, and 2002 have been downloaded at a 1:12,000 scale, with a resolution of 1,000 dpi, along with each image's corresponding camera calibration report. Each image was orthorectified and georeferenced using COSICORR software (ENVI 5.4), as detailed in Bontemps et al. (2018) and Leprince et al. (2007). This was done by tying each of the images to the $1 \mathrm{~m}$ resolution airborne lidarderived digital elevation model by manually selecting common points between the two 
images. Approximately 20 points were selected per image, and spaced out evenly across the 3 X $3 \mathrm{~km}$ DEM. Points selected were largely anthropogenic features (road intersections, houses, and other buildings). Once tie points were selected, the orthorectification was calibrated using information provided by the camera calibration report (see Ayoub et al., 2017 for further explanation). The resulting images were 3 X 3 $\mathrm{km}$, at $1 \mathrm{~m}$ resolution. Uncertainty and the MDD were estimated by measuring displacements of persistent features outside the boundary of the slide, as described above.

As with the satellite images described above, calculated rates of motion were compared to the precipitation time series. By extending the record of motion over several decades, I was able to examine the possible impact of longer climate cycles such as ENSO and PDO on earthflow movement.

\subsection{Motion at Century Timescales}

In order to constrain the minimum age of the Hooskanaden Landslide, several samples from trees contained within the landslide deposits were collected for radiocarbon $\left({ }^{14} \mathrm{C}\right)$ dating. This relies on the inference that trees grew on stable blocks during periods of relative stability, and were uprooted and killed by a surge and incorporated in the slide deposits during mass wasting events. Age dating samples were taken from logs found preserved within the stratigraphy of the eroding toe, along the beach just below the earthflow (to the west). The locations of these are shown in Figure 8, where the black line represents the toe of the landslide as mapped by the Oregon Department of Geology and Mineral Industries (DOGAMI). Note that some sample collection locations fall outside of 


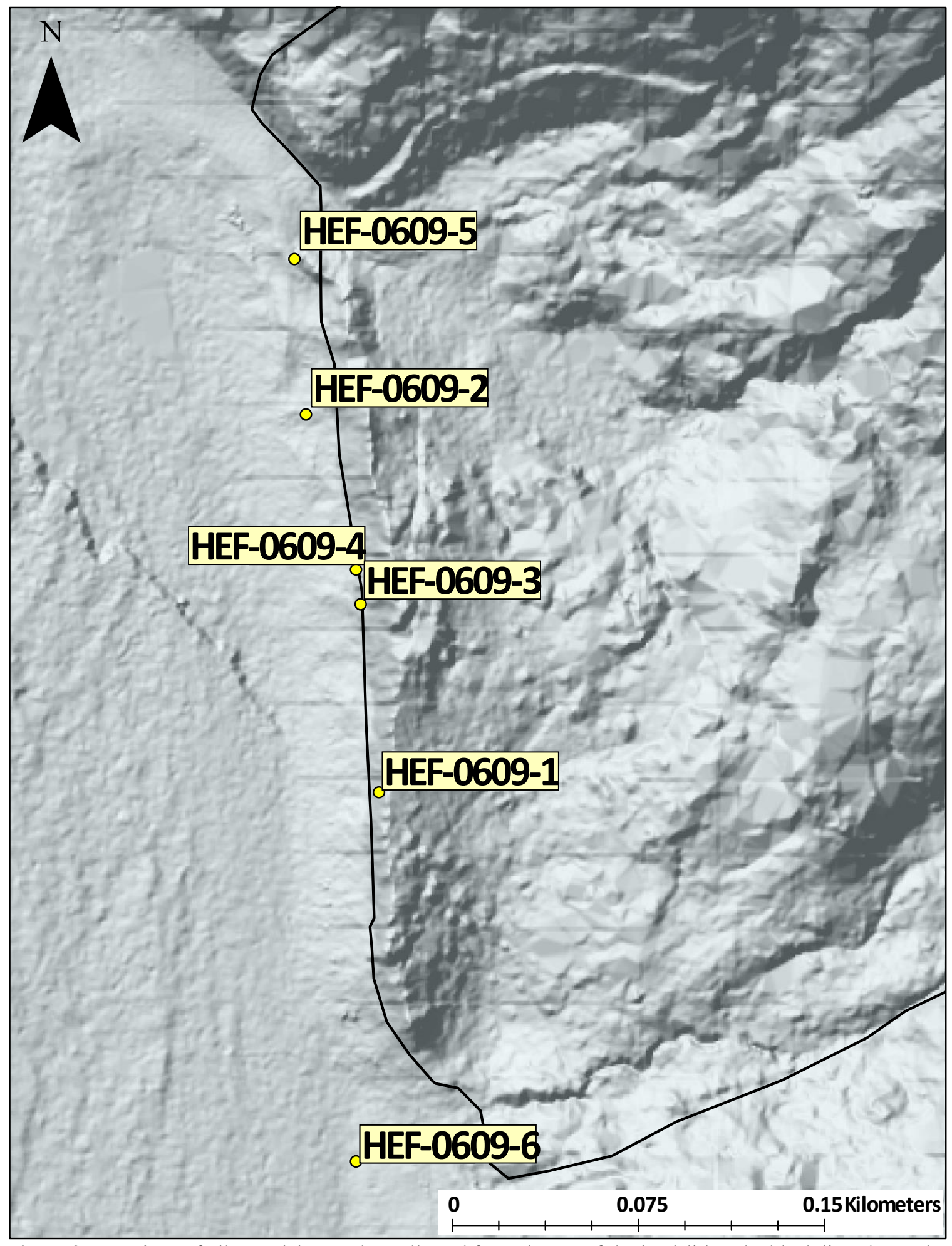

Figure 8: Locations of all tree slab samples collected from the toe of the landslide. The black line shows the approximate mapped boundary (DOGAMI) of the modern landslide deposit. Figure extent shown in Figure 5 . 
the previously mapped toe boundary - mapping efforts described in section 3.1 were used to update the modern extent of this formation. Using a chainsaw, rounds were cut from these logs, perpendicular to growth, in order to preserve the growth rings. From six total tree slab samples, three were selected for preliminary age dating: HEF-0609-3, HEF0609-5, and HEF-0609-6 (Figure 8). Slab HEF-0609-6 was obtained from the lowest visible landslide deposit (modern beach level), and was thus interpreted as our oldest representative sample (assuming that lower stratigraphic units are older than those above them). HEF-0609-5 was obtained from a stratigraphically higher deposit within the upthrust toe of the slide. Tree slabs HEF-0609-3 and HEF-0609-4 were collected from the same stratigraphic layer, so only one of the two was selected for analysis. Slabs HEF0609-1 and HEF-0609-2 were excluded from analysis, as these were quite small with few growth rings, which would have made them difficult to use for dendrochronology ${ }^{14} \mathrm{C}$ wiggle matching purposes. Material from the outermost growth ring, beneath the bark, was submitted for each of the three selected samples to DirectAMS for accelerator mass spectrometry (AMS) ${ }^{14} \mathrm{C}$ dating, in order to obtain the age closest to the time of tree death (Panek, 2015). All ${ }^{14} \mathrm{C}$ determinations provided by the lab were converted to calendar ages using OxCal version 4.4 software (Bronk Ramsey, 2009). This conversion is necessary because carbon concentrations have fluctuated in the atmosphere through time. Measured concentrations of ${ }^{14} \mathrm{C}$ do not represent the true age of the sample.

Measured ${ }^{14} \mathrm{C}$ ages for samples were calibrated and modeled using OxCal version 4.3 (Bronk Ramsey, 2009) and the IntCal 13 atmospheric curve (Reimer et al., 2013), to convert lab measured radiocarbon ages to calendar ages for each of the samples. Ages 
for calibrated samples were trimmed using stratigraphic ordering information in which older samples are stratigraphically lower than younger samples in OxCal.

Based on the results of the stratigraphic age model for the section exposed at the toe of the slide, one of the initial three tree rounds (HEF-0609-6) was selected for additional ${ }^{14} \mathrm{C}$ analysis, and samples were collected from multiple growth rings. This tree slab sample is interpreted to be the oldest, as it was found in the lowest visible stratigraphic level. By submitting samples from multiple growth rings within the same tree slab, with each sample separated by a known number of years (or rings), the sample age gap can be used to match the ${ }^{14} \mathrm{C}$ ages of the samples with the wiggles in the ${ }^{14} \mathrm{C}$ calibration curve (Bronk Ramsey, 2001; Reimer et al., 2013). This allows the researcher to constrain which part of the carbon calibration curve samples plot within, thereby eliminating some of the possible ages obtained during calibration and improving precision.

The HEF-0609-6 tree slab sample was highly weathered, and heavily eroded on the exposed side, making it difficult to determine the number of growth rings preserved. However, the unexposed side appeared to be relatively intact. To prepare the sample, after sanding one side smooth, growth rings along two transects were counted from the center of growth to the outermost edge (Speer, 2012). The locations of these transects were chosen to avoid fungal growth (and possible contamination), and to include the highest possible number of growth rings (furthest distance from the center of growth). Then each growth ring was counted and marked along the full length of each transect 
(Figure 9). Transect A had a total of 59 growth rings, while transect B had a total of 81 growth rings.

Prior to collecting any further sample material, I had sample HEF-0609-6 examined by a biologist (Dr. Daniel Ballhorn, of the Ballhorn Chemical Ecology Lab at Portland State University) to determine more about the particular tree species. Dr. Ballhorn was able to identify this as a species of poplar (more specifically, Populus trichocarpa). This species has radially symmetrical growth rings under normal growth conditions, and can live up to around 200 years (DeBell, 1990). Additionally, Dr. Ballhorn identified some black fungal growth, growing perpendicular to the growth rings (indicated by the black arrow in Figure 9). This type of fungal growth is common in poplars, and typically persists only within the woody portion of the tree - not extending into the bark. Because this fungal growth, where present, extends all the way to the outer edge of the sample, it is unlikely that this sample has any bark left on it (and what was initially interpreted as bark is likely just highly desiccated wood). Therefore, we cannot be certain that the outermost growth ring on this sample is the original outermost growth ring that was present at the time of tree death. Because this tree species can live up to 200 years, and there were 81 growth rings counted along transect B, it is possible that the outermost growth ring of the sample has an older radiocarbon age than that of the original outermost growth ring of the tree at time of tree death. Therefore, the date of the outermost growth ring submitted from the sample will be assumed to represent the approximate date of tree death, within 119 years. 


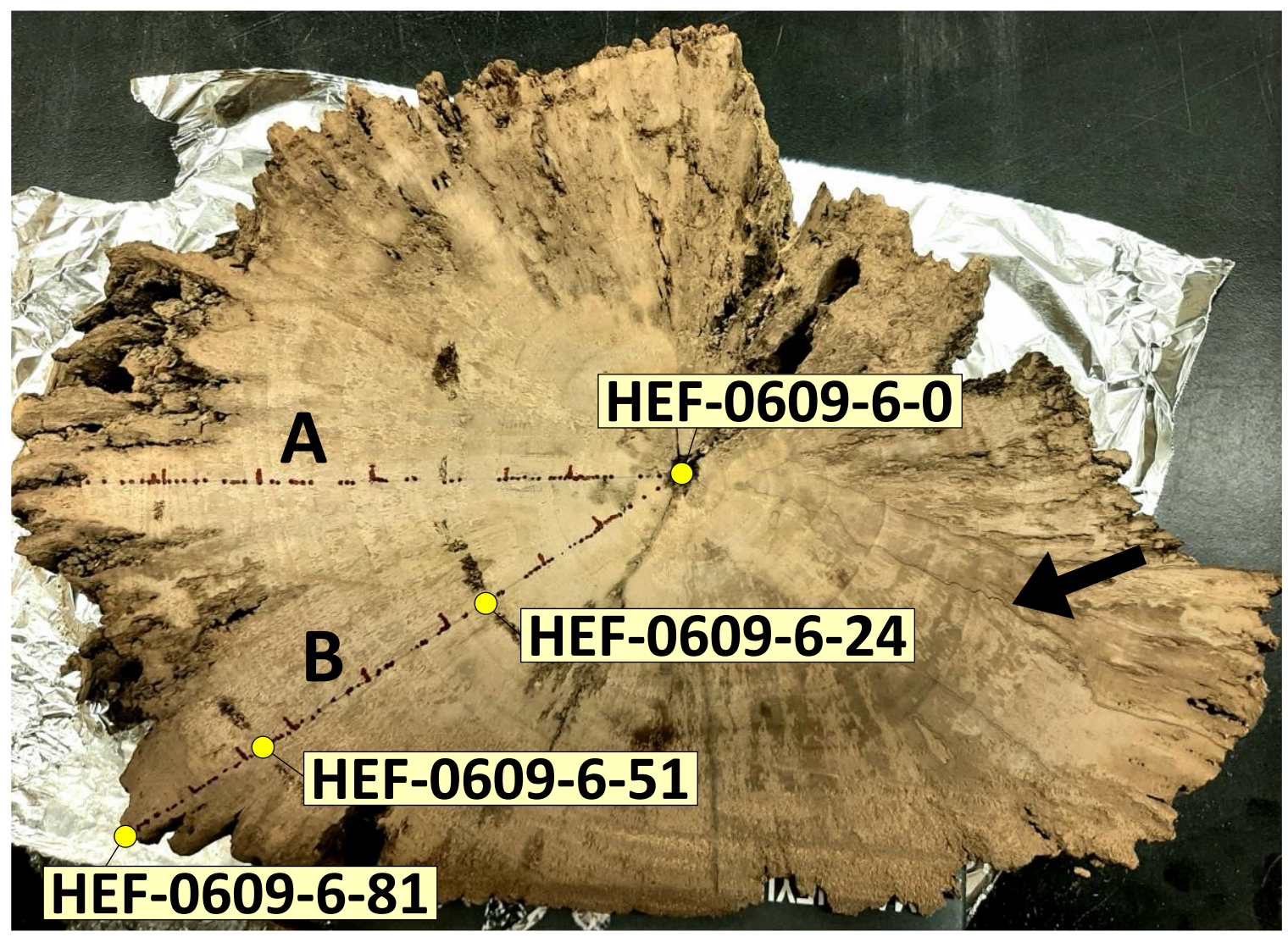

Figure 9: Tree round HEF-0609-6. Transects A and B are labeled, and growth rings counted along transects are marked with dots, with dashes denoting every 10 rings. The black arrow shows the location of a black fungal growth, which extends from the center of tree growth radially outward. Rings from which additional sample material was collected are labelled (HEF-0609-6-0, HEF-0609-6-24, HEF-0609-6-51, and HEF0609-6-81).

For analysis, material was collected from the outermost growth ring (HEF-06096-81), innermost growth ring (HEF-0609-6-0), and two additional intermediate growth rings (HEF-0609-6-24, and HEF-0609-6-51 respectively; Figure 9). The locations of the additional two samples were selected based on their assumed location on a steep portion of the carbon calibration curve (to reduce the number of intercepts of the ${ }^{14} \mathrm{C}$ age with the calibration curve, hopefully yielding a narrower calibrated age range) and growth ring thickness (thicker growth rings reduce the possibility of contaminating the sample by accidentally including material from adjacent growth rings). Material was collected from multiple points along each of the specified growth rings, while carefully tracing the 
ring to ensure all material collected for each sample was within the correct growth ring. These four samples were then submitted to the National Ocean Sciences Accelerator Mass Spectrometry (NOSAMS) lab at the Woods Hole Oceanographic Institution. This lab was selected to process our second set of samples, because they allow for processing with ${ }^{13} \mathrm{C}$ splits, which yields the percent modern ${ }^{14} \mathrm{C}$ with reduced analytical uncertainty. Measured ${ }^{14} \mathrm{C}$ ages provided by NOSAMS were then calibrated and used in statistical age models using both a dendrochronological model (D_Seq) and a varve model (V_Seq) within OxCal (Bronk Ramsey, 2001) to estimate the time of tree death. Both models allow samples to be input in chronological order with the known number of years (tree rings) between each sample. The D_Seq model, like the stratigraphic model, uses the order of the samples, but also includes the number of years (or rings) between samples. Similarly, the V_Seq model uses the order of the samples and the known number of years between samples and allows error in the number of years between samples to be specified. Sources of such error could include miscounted rings, skipped rings in which the tree did not produce growth rings or cross-contamination from neighboring rings during sample collection or sanding (Speer, 2012).

It should be noted that there is some uncertainty regarding the meaning of ${ }^{14} \mathrm{C}$ ages relative to the age of an earthflow. When dating landslides in general, the age of the outermost growth ring of an entrained wood sample is commonly accepted to be a close maximum age for landslide initiation (Panek, 2015). However, we are attempting to date a feature that has been consistently active (rather than a single instantaneous failure) since at least the 1930s, which adds more uncertainty. Assuming that these samples were 
entrained upon initiation, and that they were still living immediately prior to being entrained, then their age represents the true age of the earthflow. However, if they were entrained during a subsequent period of movement sometime after initiation, they will still provide us with a minimum age. In contrast, if samples were collected from trees which were already dead upon initiation and entrainment, they will give a biased old estimated age for Hooskanaden Landslide initiation. All of these possibilities will be considered when analyzing the calibrated and modeled ages. 


\section{Results}

\subsection{Borehole Data and Surface Mapping}

Due to broad interests in this earthflow, several datasets were made available to this author through collaborators at Oregon State University (OSU) and ODOT. Those baseline datasets provided the foundation of this study. Specifically, these data include inclinometer and piezometer data, and drill logs with subsurface data from a single borehole drilled into the earthflow (location shown in Figure 1). Inclinometer results clearly show the failure plane at $\sim 30 \mathrm{~m}$ depth. Initial inclinometer data, along with the time and distance over which instrumentation sheared, allowed the researchers to estimate an average velocity of 1-5 m/yr at the failure plane between December 2017 and January 2018. Figure 10 shows the stratigraphic column through the Hooskanaden Landslide, as compiled from ODOT drill logs. The subsurface lithology here is predominately sandstone, mudstone, and siltstone, with highly sheared sections and slickenslide surfaces beginning around $20 \mathrm{~m}$ depth - about $10 \mathrm{~m}$ above the modern failure plane. Much of the section is weathered or decomposed, as well as sheared.

Surface mapping efforts were completed in late September of 2019, seven months following the most recent surge. Evidence of recent ground disturbance was observed across much of the slide surface, with large, fractured, brittlely-deformed blocks, as well as deposits that suggested a softer composition with more internal deformation (mapped in Figure 11 as hummocky topography). Within the upper half of the slide (upslope from US101), the ground was still highly deformed and fractured in many sections, while 


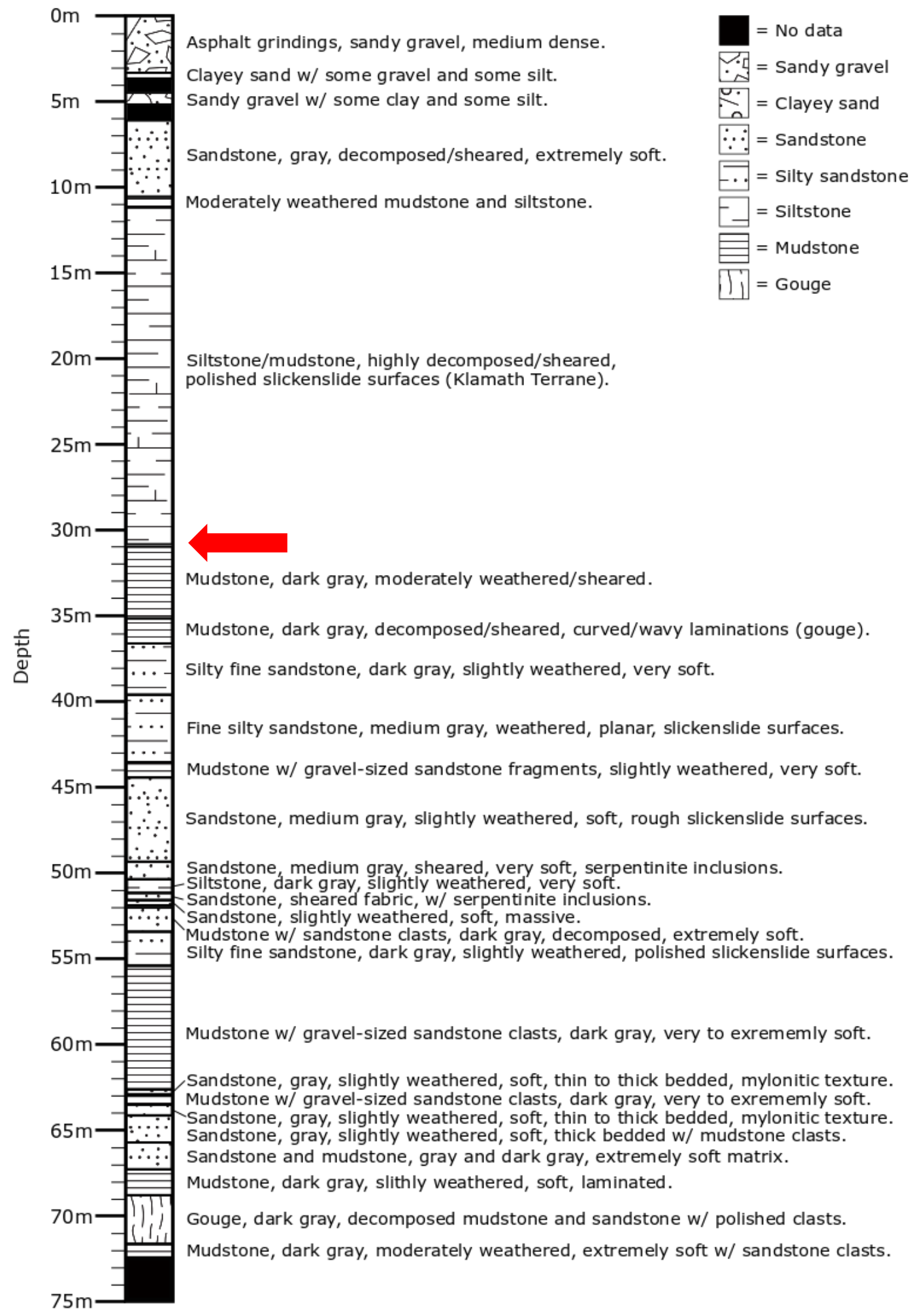

Figure 10: Stratigraphic column based on mud rotary drill logs from ODOT research group. The red arrow at $\sim 30 \mathrm{~m}$ depth indicates the location of the failure plane, as indicated by inclinometer data. 


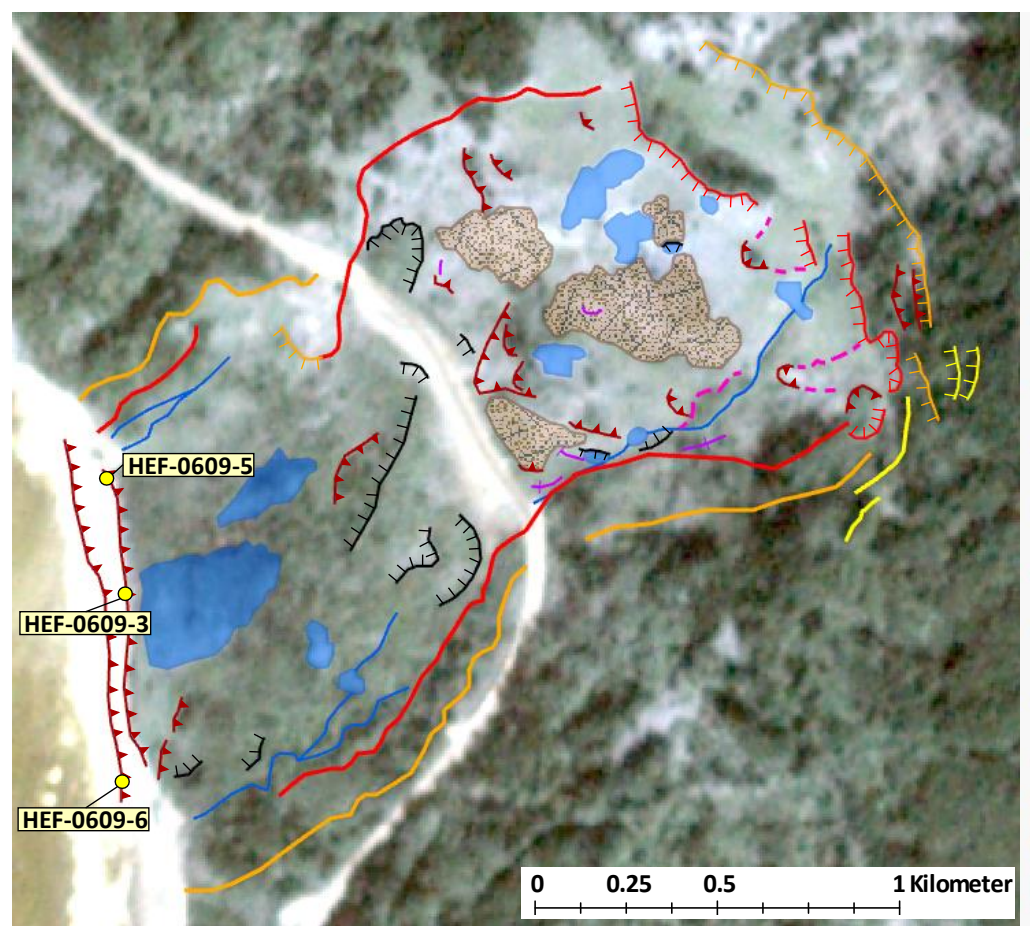

\section{Legend}

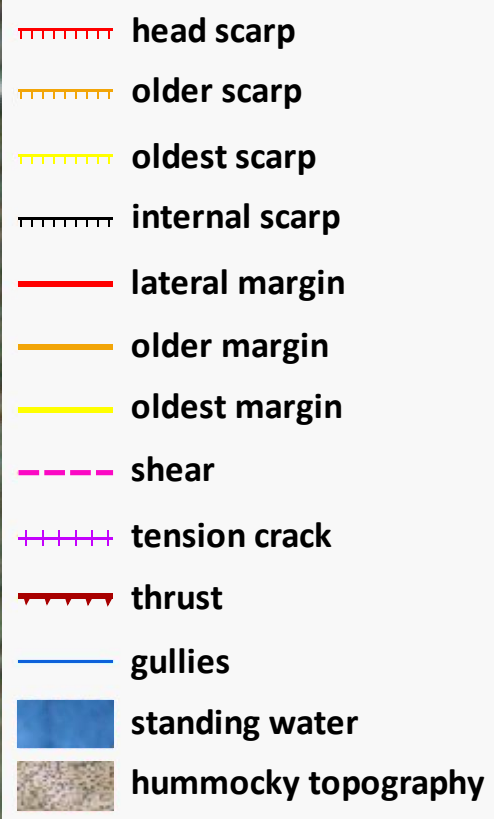

Figure 11: Map of surface features derived from field observations, overlying satellite image from Planet Labs taken September $21^{\text {st }}$, 2019. Extent and orientation match that of Figure 1 inset. Locations of carbon samples submitted for analysis are shown by yellow dots.

others were still vegetated and showed little sign of ground disturbance. Figure 12 shows a good example of undisturbed vs. disturbed ground within the slide mass, which I interpret to be a boundary between a rigid block (undisturbed), and the weaker surrounding matrix (disturbed). Hiking this section revealed several discontinuous headscarps likely related to the most recent surge event, as well as much more subdued scarp-like features further upslope (Figure 11). Tension cracks were observed in the upper slide section along the southeast margin. Highly pronounced, angular shear margins were observed along the NW and SE flanks of the slide deposit, with more diffuse shear margins further out. Several internal scarps were also observed, bounding both brittle and soft-sedimentary failures, and predominately striking NNE in the lower half of the slide. Thrust features were found throughout the surface of the slide mass, 


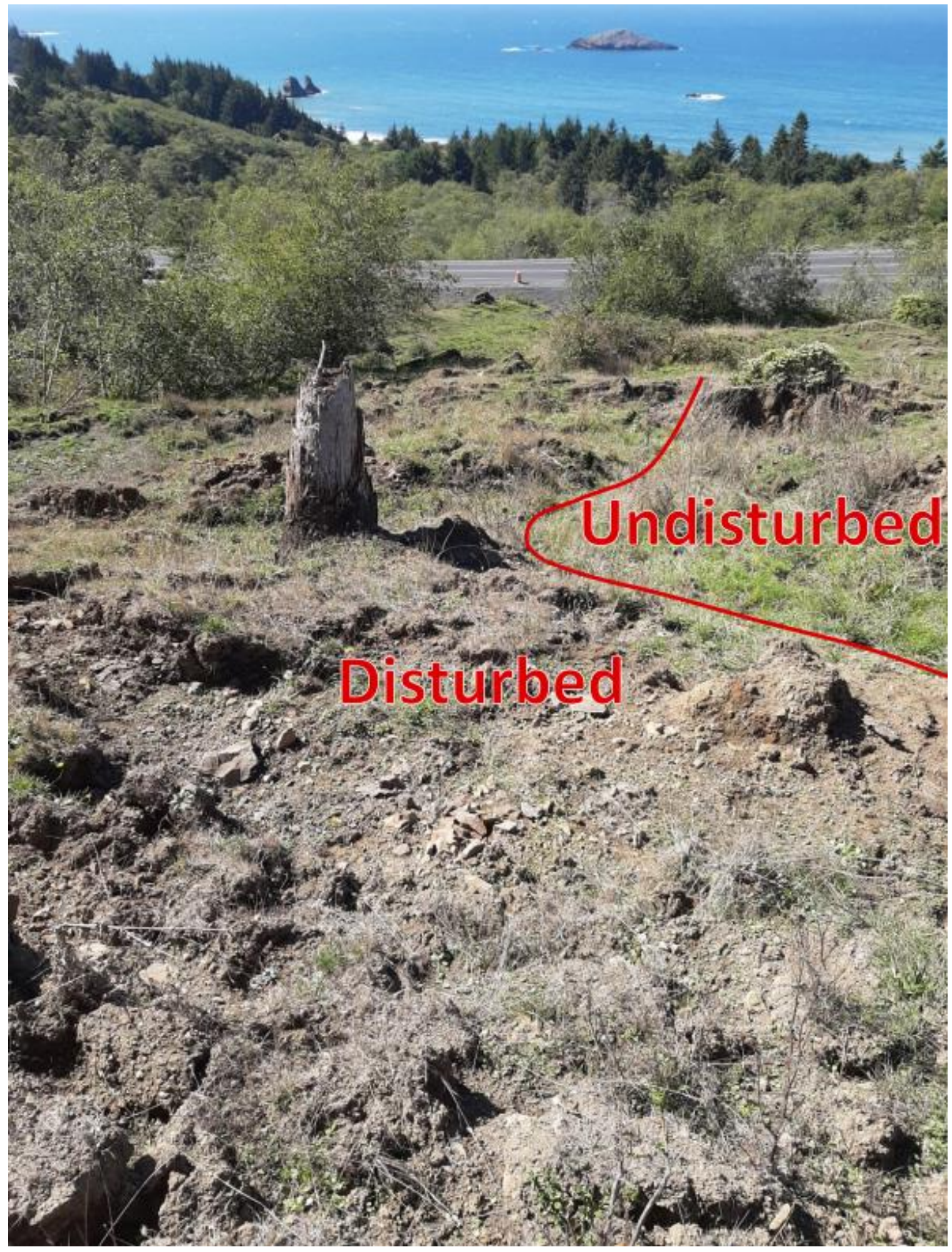

Figure 12: Photograph showing preserved evidence of ground deformation along the surface of the Hooskanaden Landslide (looking in downslope direction) in the late summer of 2019. Boundary between disturbed and undisturbed ground represented by the red line. 


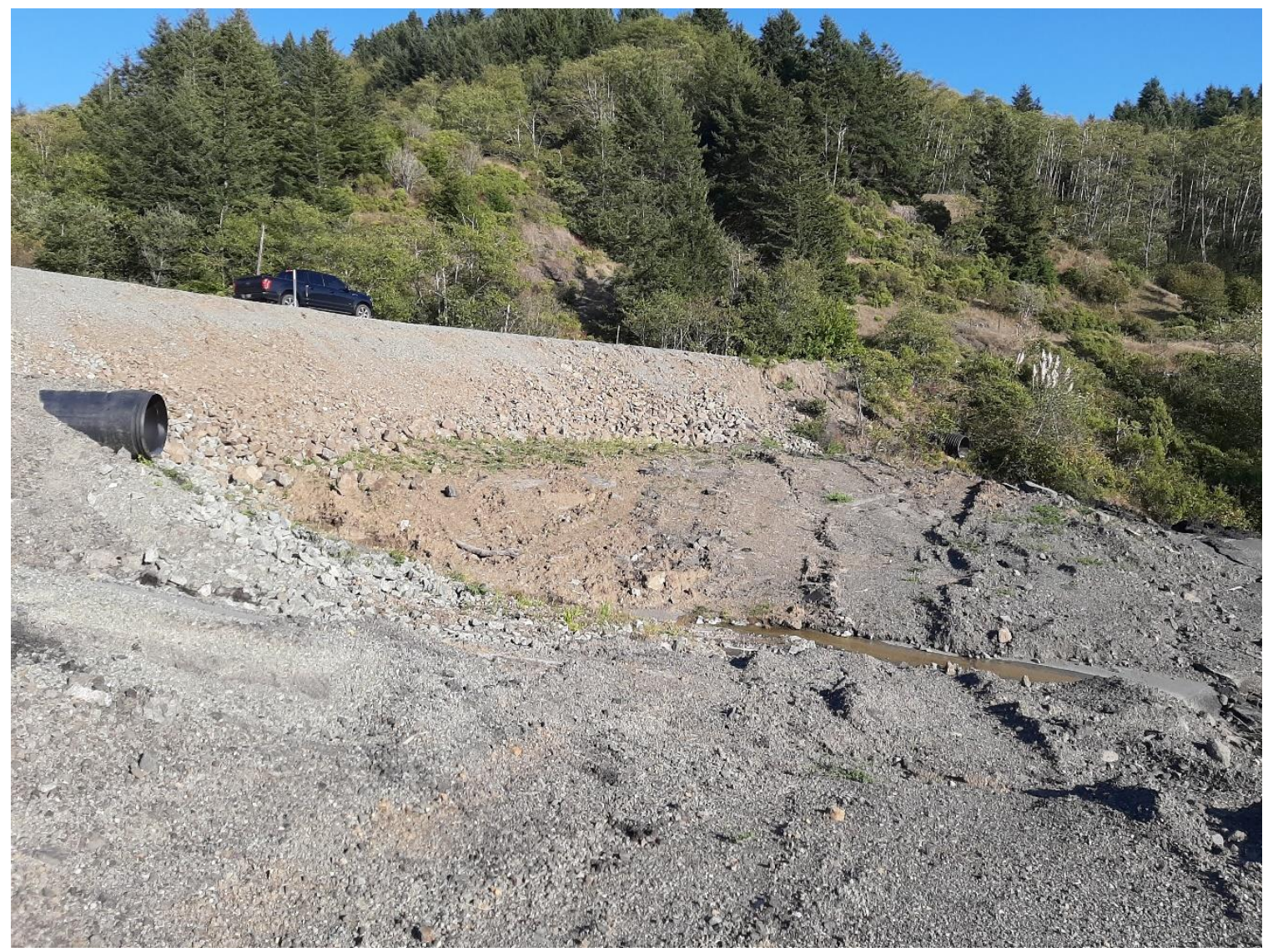

Figure 13: Photograph showing continuous drainage from a culvert installed beneath the newly reconstructed section of US Highway 101, taken in the late summer of 2019.

most of which strike $\sim \mathrm{NW}$. The largest of these was observed at the toe of the landslide, which appeared to uplift and override a portion of the pre-existing beach on the wave-cut platform.

Additionally, there was a great deal of standing water found on the surface of the slide, despite being mapped at the end of the dry season. Figure 13 shows water continuously draining from a culvert that was installed beneath US101 when it was rebuilt following the last surge. While the presence of standing water was prevalent in both the upper and lower sections of the slide deposit, a particularly large sag pond ( 100 by $\sim 160 \mathrm{~m}$ ) was observed just upslope of the uplifted slide toe (Figure 11). There is 
evidence of gullying along both lateral margins, although this was much more prevalent along the southeastern margin.

Field-developed cross-sections, elevation data obtained from lidar, borehole data, mapped features, and locations where standing water was found were combined to generate a slope stability model using SLIDE (Figure 14). This model was calibrated to achieve a FOS as close as possible to $1(\mathrm{FOS}=1.006)$. Where standing water was found on the landslide's surface, the GWS was assumed to be very close to the surface at that point. Because so much of the surface was saturated, the GWS elevation was modeled as very close to the surface of the slide mass. However, there is a fair amount of uncertainty related to the friction angle used, given that a previously documented value was used (Stark et al., 2011) rather than an experimentally derived one for this specific location.

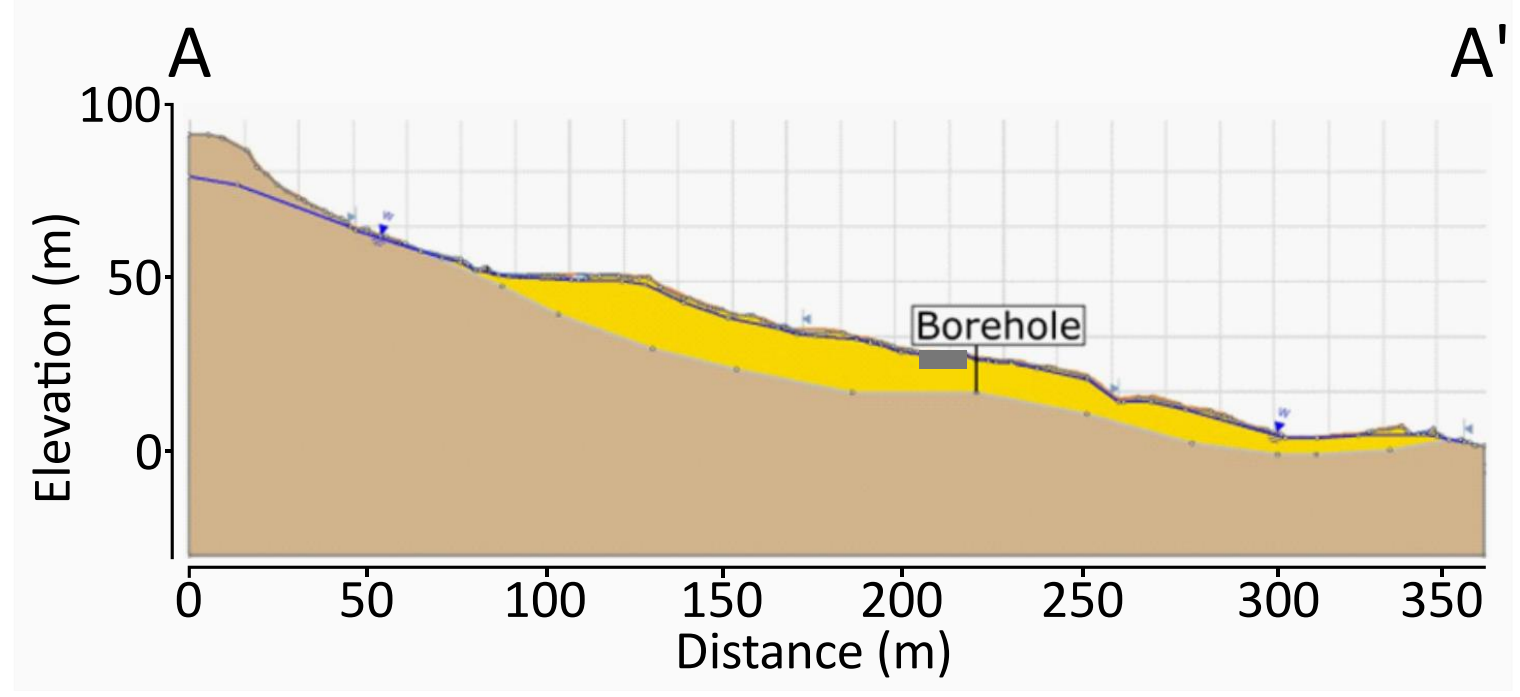

Figure 14: Profile of the Hooskanaden Landslide generated using SLIDE. The yellow area represents the slide material (colluvium) above the inferred failure plane. The brown area represents the bedrock (assumed friction angle and cohesion of Franciscan Mélange) below the failure plane. The geometry of the GWS is indicated by the blue line. The gray rectangle upslope from the borehole represents the location of US101. 
Decreasing the friction angle could result in a lower GWS, but for the purposes of this model, the position of the GWS was assumed to be fixed, and the model was calibrated only by manually changing the geometry of the failure surface.

The basal morphology of the slide mass (yellow) was estimated using the location and slope of the headscarp, the location of the failure surface observed at the toe, and the location of the borehole and depth to the failure surface. The estimated depth to the failure plane is greatest in the upper section and decreases in the mid-section (just above the highway), then it increases again before reaching the toe. This mid-slope decrease is constrained by the depth to the failure plane observed in the borehole data (Figure 10). While the solution shown in Figure 14 is not absolute (other possible solutions do exist), I found no possible solutions that achieved an approximately stable FOS without increasing the depth to failure both upslope of the highway, and near the toe.

\subsection{Landslide Kinematics at Seasonal to Annual Timescales}

\subsubsection{Satellite photo-based displacements}

Feature tracking results are displayed as both a displacement time series, and a velocity time series to demonstrate the effects of normalizing displacements by the time between images (Figure 15). There is an apparent baseline of $\sim 0.03 \mathrm{~m} /$ day within the average velocity data, though in many cases the MDD was higher than this (average of $0.096 \mathrm{~m} /$ day, with a standard deviation of $0.063 \mathrm{~m} /$ day). Average velocity represents the average of all point displacement values. While some point velocity values were treated as negative (points which appear to "move" upslope), all average velocities were greater 


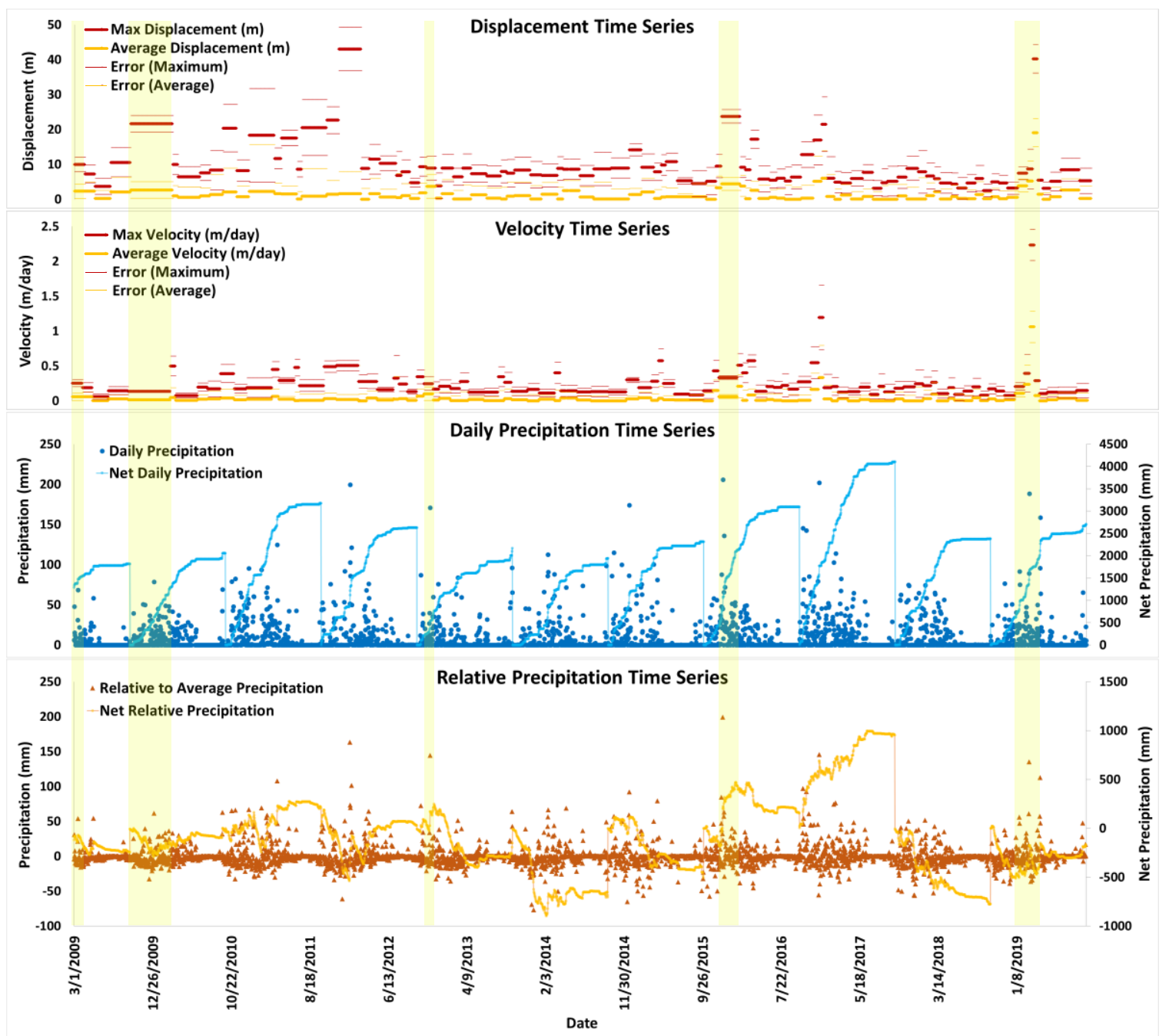

Figure 15: From top to bottom, displacement, velocity, daily precipitation, and relative precipitation time series. Highlighted sections show periods where the average velocity exceeded the MDD (March - April 2009, October 2009 - March 2010, October - November 2012, November 2015 - February 2016, and December 2018 - March 2019).

than zero. Where the average velocity falls below the MDD, the overall surface of the landslide was not detectably active. During periods where the average velocity exceeds the MDD (highlighted in Figure 15), the overall surface of the landslide is measurably moving. Displacements, velocities, and MDD values for the full time series (1980-2019) are included in Supplemental Files (further described in Appendix A). 
The overall direction of the velocity vectors varies within $\sim 180^{\circ}$ throughout the time series. This can be seen in Figure 16, which shows the direction of the averaged vector components for each time interval. Averaging those vectors across the modern time series (2009-2019) yields an average displacement direction of $214.8^{\circ}$ (approximately to the $\mathrm{SW}$ ), with an overall average velocity of $4.5 \mathrm{~cm} / \mathrm{day}$, which is less than the average MDD. The average direction of displacement roughly coincides with the mean dip of the rock bedding units, which is estimated as $\sim 250^{\circ}$ (Parker, 1979).

Within the maximum velocity data, the baseline is $\sim 0.13 \mathrm{~m} /$ day, which exceeds the average MDD. This means that, while the overall landslide surface may not be detectibly moving over all time intervals, there is at least one point on the landslide surface which is detectibly moving over all time intervals. Initially, I suspected to find that this was because of a specific section that was regularly more active, but this was not the case. Rather, maximum displacement vectors are dispersed across the slide surface throughout the time series, without any apparent sequence or order.

The displacement data shows that there is a mean maximum displacement of 10.4 $\mathrm{m}$ (standard deviation of $7.6 \mathrm{~m}$ ), and mean average displacement of $1.3 \mathrm{~m}$ (standard deviation of $1.7 \mathrm{~m}$ ). The largest displacements (defined here as values exceeding the mean plus the standard deviation) occur from October of 2009 through March of 2010 (over 160 days), September through November of 2010 (52 days), January through April of 2011 (96 days), July through October of 2011 (94 days), October through December of 2011 (46 days), January to March of 2012 (85 days), November to December of 2012 (35 


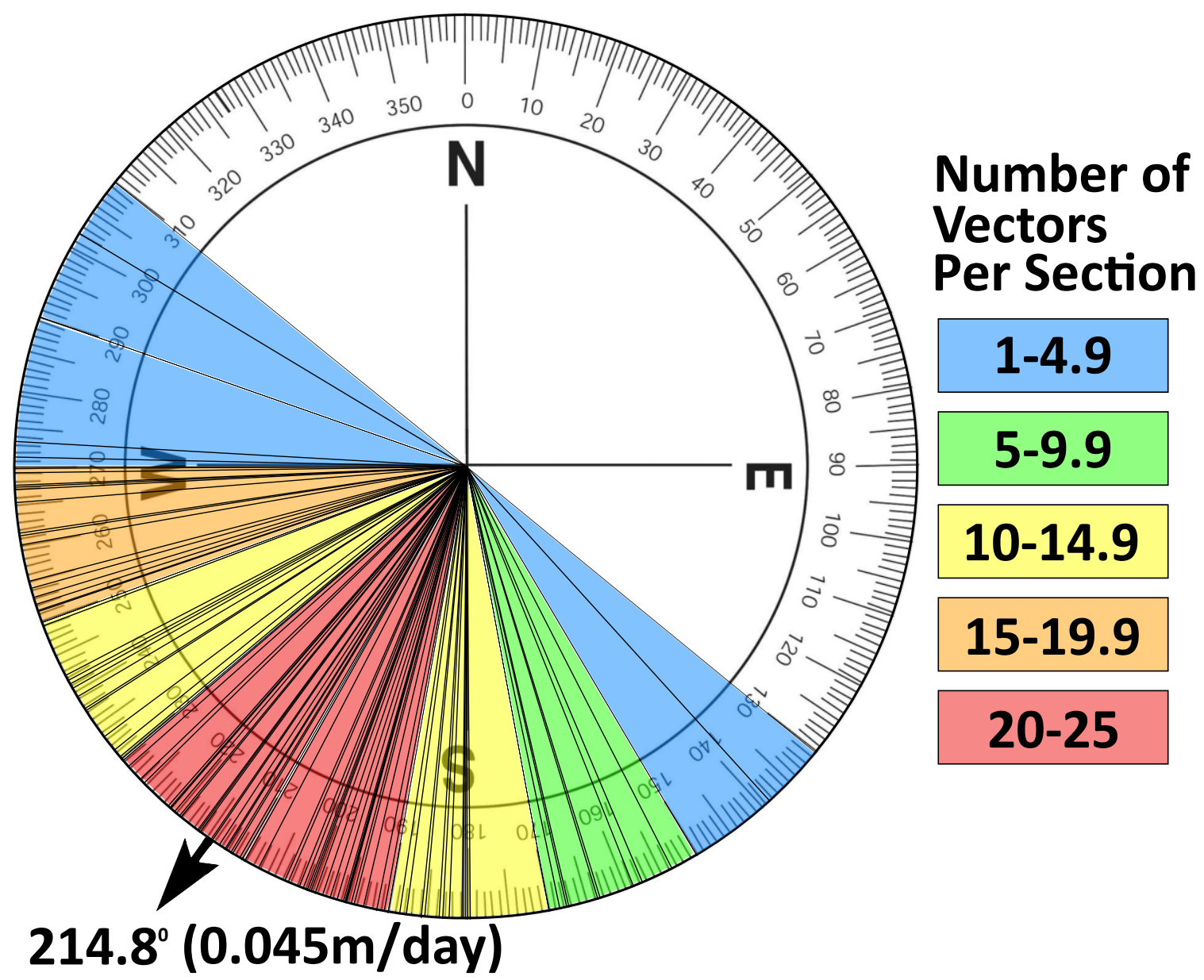

Figure 16: Averaged displacement vector directions for each time interval from 2009-2019. Each average vector (black lines) represents one time interval. Average vectors are shown in azimuth, which has been divided into $20^{\circ}$ sections. These sections are color coded to show the relative proportions of average vectors within each section, with the largest numbers occurring between $190^{\circ}$ and $230^{\circ}$. The black arrow shows the overall average direction of landslide surface movement $\left(214.8^{\circ}\right)$, as well as the overall average velocity (0.045 m/day).

days), November of 2015 (22 days), November of 2015 to February of 2016 (71 days),

February to March of 2016 (21 days), November to December of 2016 (31 days),

December of 2016 (18 days), December of 2018 to January of 2019 (35 days), January to

February of 2019 (21 days), and February to March of 2019 (18 days).

The highest maximum and average velocities (Figure 15) occur in March to April of 2010 (over a 20-day period), April through May of 2011 (26 days), July of 2011 (18 
days), October to December of 2011 (46 days), December of 2011 to March of 2012 (85 days), April to May of 2015 (17 days), November of 2015 (22 days), February of 2016 (18 days), March to April of 2016 (30 days), November to December of 2016 (31 days), December of 2016 (18 days), January to February of 2019 (21 days), and February to March of 2019 (18 days). This includes both the known 2016 and 2019 surge events.

\subsubsection{Climate Patterns}

Daily precipitation values range from 0 to $205.7 \mathrm{~mm}$, with an average of $5.9 \mathrm{~mm}$ and a standard deviation of $13.8 \mathrm{~mm}$. Relative precipitation (daily precipitation - average precipitation) ranges between and -76.5 and $199.3 \mathrm{~mm}$, with an average of $-0.02 \mathrm{~mm}$ and a standard deviation of $12.39 \mathrm{~mm}$. In order to look at the effects of extreme precipitation events outside of typical seasonal fluctuations, I've isolated the dates with the highest $2 \%$ of Relative Precipitation values (two standard deviations above the average). Between March of 2009 and September of 2019, 176 instances occur (Figure 17): 10 in the water year occurring from 2008-2009, 15 in 2009-2010, 26 in 2010-2011, 23 in 2011-2012, 13 in 2012-2013, 12 in 2013-2014, 14 in both 2014-2015 and 2015-2016, 25 in 2016-2017, 15 in 2017-2018, and 16 in 2018-2019.

To look at the impact of longer scale climate cycles on velocity, I've plotted the same velocity time series shown previously, along with both ENSO and PDO hot and cold phases (Figure 18). The first section of the time series from 2009 to early 2014, shows consistently low velocities, and is dominated by a PDO cold phase. ENSO switches between warm and cold, but PDO remains consistently cold throughout this 


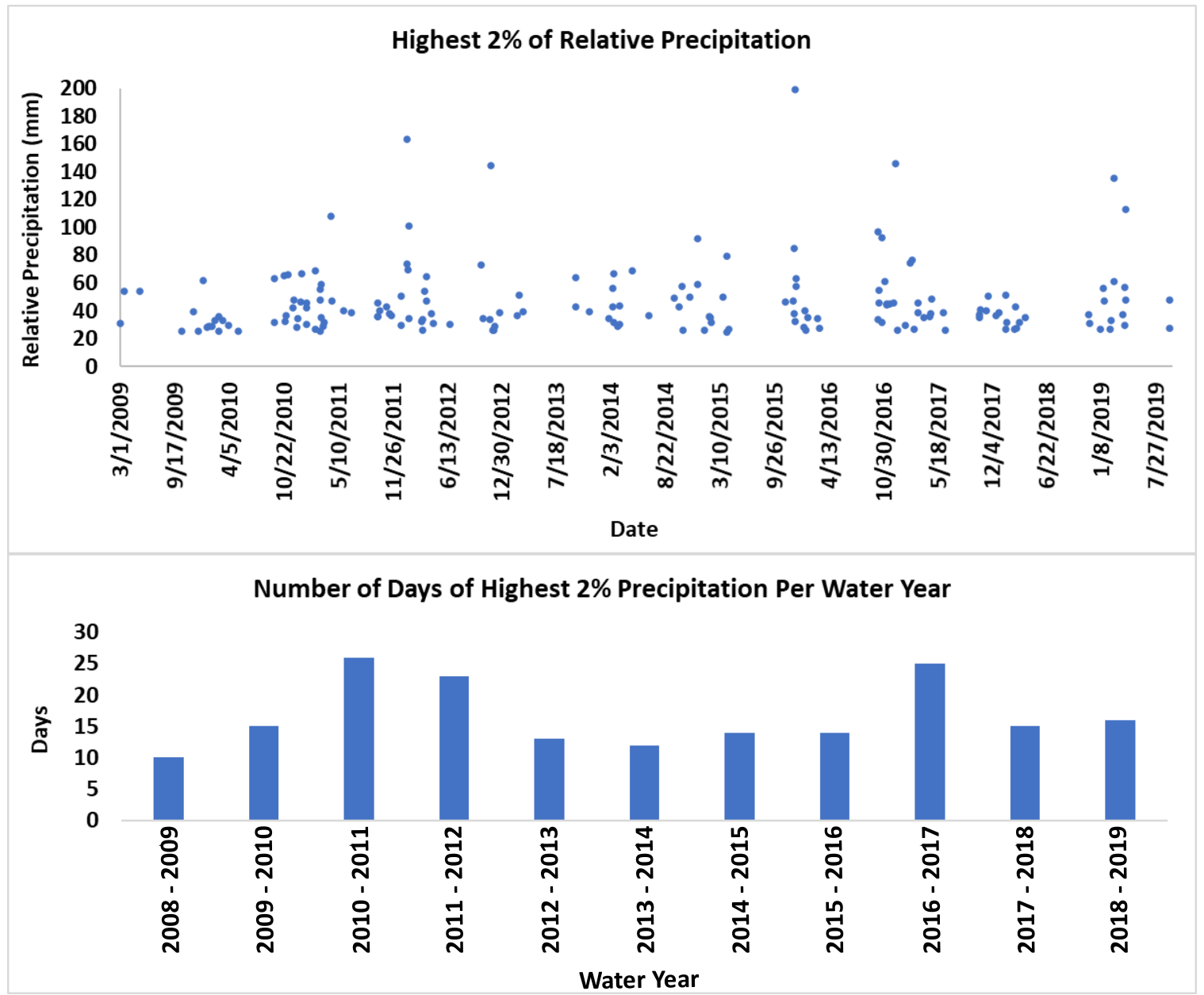

Figure 17: The highest $2 \%$ of relative precipitation values on the seasonal to annual timescale with respect to time (top), and the number of days of highest precipitation that occurred each water year within the same timeframe (bottom).

period. From 2014 to 2017, we see our first dramatic spike in velocities, as well as generally higher average velocities. The first half of this segment shows both PDO and

ENSO in a warm phase. In the latter half, ENSO switches to cold and then dissipates.

PDO briefly switches to cold and back to warm, right before the visible spike in velocity in 2016. The final section, from 2018 through 2019, begins again in a PDO cold phase with generally low maximum and average velocities. We can also see an ENSO warm phase beginning in late 2018. In early 2019, the PDO cold phase dissipates, returning to 
average sea surface temperatures. This dissipation appears to correlate with another visible spike in velocity in early 2019.

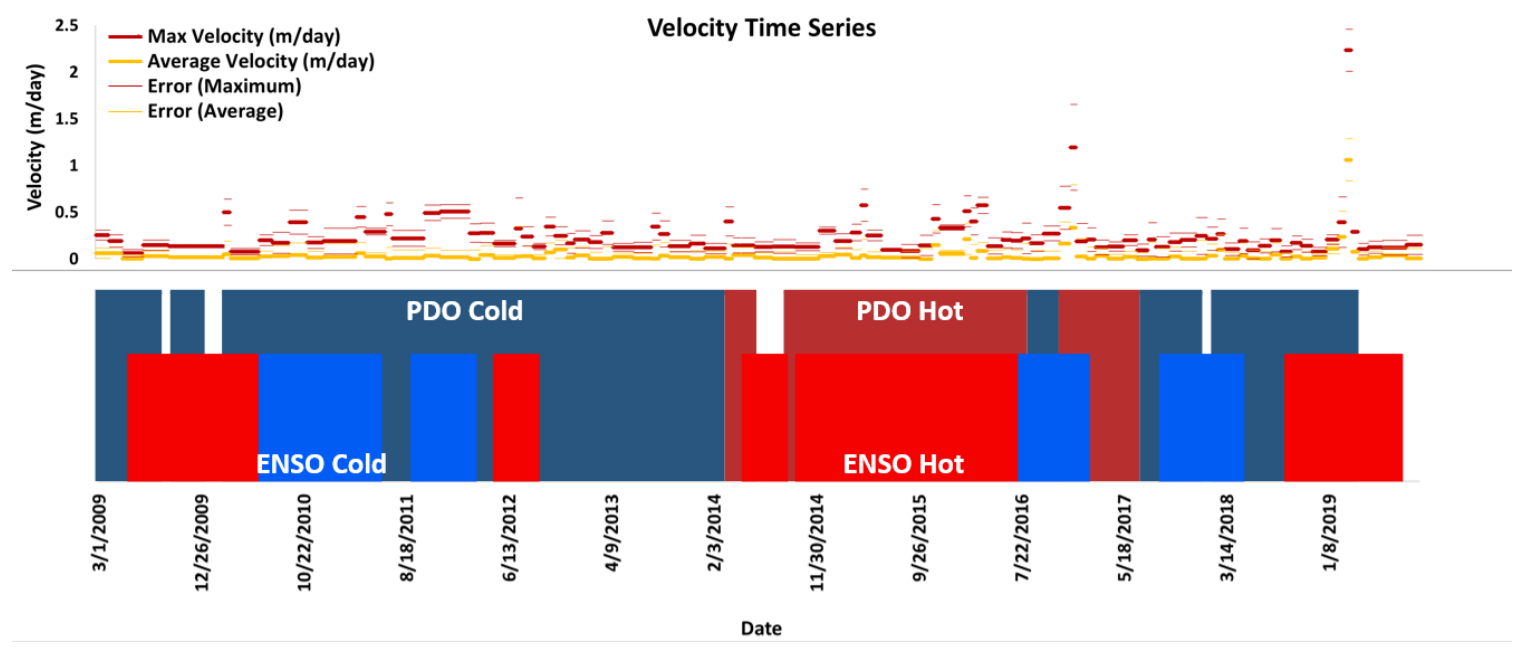

Figure 18: Correlation between velocity (top), and PDO and ENSO phases (bottom). Hot phases are shown by the red blocks, cold phases in blue. PDO periods are shown by the taller, darker blocks, with ENSO periods represented by shorter, brighter blocks.

\subsubsection{Terrestrial Lidar-Derived Displacements}

Relative accuracy of the TLS point clouds ranged from $\sim 2$ to $7 \mathrm{~cm}$ (Table 1). The average $\operatorname{MDD}\left(M D D=\sqrt{2 *\left(R M S E^{2}\right)}\right)$ for this data is $0.05 \mathrm{~m}$ with a standard deviation of $0.025 \mathrm{~m}$, meaning distances greater than $5 \pm 2.5 \mathrm{~cm}$ are statistically observable.

\begin{tabular}{|r|r|r|r|r|r|r|} 
& 06.08_1 & \multicolumn{1}{c|}{$06.08 \_2$} & $08.17 \_1$ & $08.17 \_2$ & $09.21 \_1$ & $09.21 \_2$ \\
\hline $06.08 \_1$ & & & 0.020 & & 0.042 & \\
\hline $06.08 \_2$ & & & & 0.065 & & 0.021 \\
\hline $08.17 \_1$ & 0.020 & & & & 0.016 & 0.049 \\
\hline $08.17 \_2$ & & 0.065 & & & & \\
\hline $09.21 \_1$ & 0.042 & & 0.016 & & & \\
\hline $09.21 \_2$ & & 0.021 & & 0.049 & & \\
\hline
\end{tabular}

Table 1: Root-mean-square error (RMSE, reported in $\mathrm{m}$ ) of stable-ground ICP alignment of terrestrial laser scans (TLS) in CloudCompare. Each TLS ID (Date_\#) is shown as both a row and a column, and the numbers at the intersections of each row and column show the RMSE for the alignment of those two clouds. In all cases, the precision achieved was a few $\mathrm{cm}, 6.5 \mathrm{~cm}$ at most. 
Figures 19-21 show distances between point clouds from scan locations TLS 1 and TLS 2, as well as the manual feature tracking results from each period for direct comparison. In the first time interval (June to August, 2019, Figure 19), we see an average displacement of $17 \mathrm{~cm}$ (standard deviation of $25.6 \mathrm{~cm}$ ) in the TLS data, which exceeds the MDD, but is smaller than determined from the satellite photo data (average displacement of $2.62 \mathrm{~m}$, standard deviation of $3.78 \mathrm{~m}$ ). Between 19a and 19b, the majority $(67.5 \%)$ of the points tracked in the TLS data show displacements of less than $10 \mathrm{~cm}$, which is comparable to the MDD.

From August to September 2019 (Figure 20), we begin to see some larger displacements in the TLS data (as high as $57 \mathrm{~cm}$ ), though the average is similar to the previous interval $(18 \mathrm{~cm}$, standard deviation of $13.8 \mathrm{~cm})$. In this case, the majority (47.5\%) of displacements fall between 10 and $50 \mathrm{~cm}$, closely followed (45\%) by less than $10 \mathrm{~cm}$ displacements. The average displacement for the feature tracking data in this period (20c) is $26 \mathrm{~cm}$, with a standard deviation of $2.86 \mathrm{~m}$.

Over the entire TLS monitoring period (June to September, 2019), the TLS displacements in Figure 21 ( $a$ and b) are similar that those of August to September, 2019. Once again, the majority of displacements observed (47.5\%) were between 10 and $50 \mathrm{~cm}$, shown by the density warmer color points in Figure 21, though in this case the average displacement is $29 \mathrm{~cm}$ (standard deviation of $14.1 \mathrm{~cm}$ ). This is expected, given that Figure 21 encompasses the time periods represented by Figures 19 and 20, so displacements seen here are equivalent within uncertainty to the combined displacements 


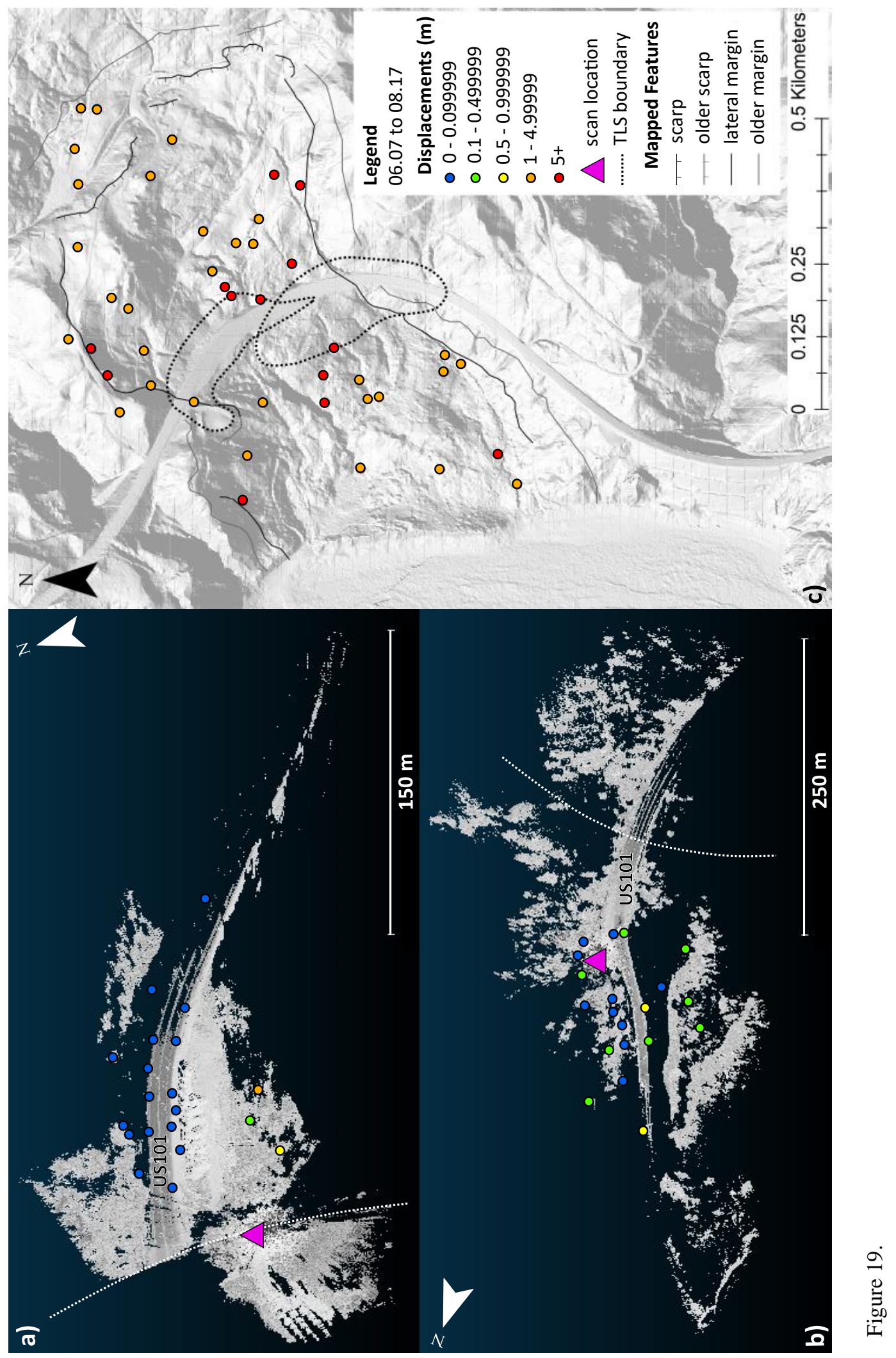




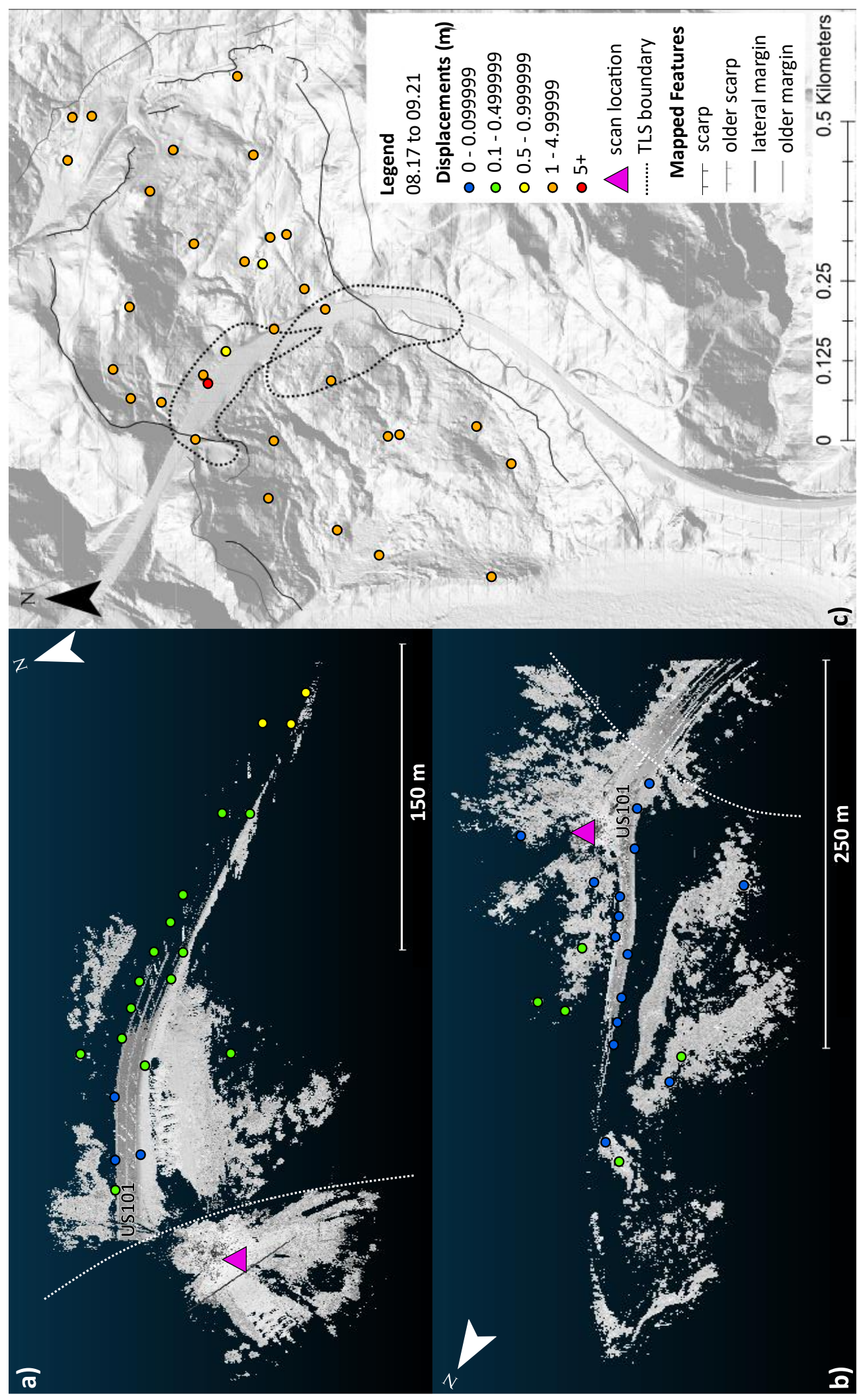

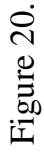







Figures 19-21: Horizontal distances between points selected using CloudCompare. Showing results for 06.08_1 to 08.17_1 (19a), 08.17_1 to 09.21_1 (20a), and 06.08_1 to 09.21_1 (21a); as well as 06.08_3 to 08.17_3 (19b), 08.17_3 to 09.21_3 (20b), and 06.08_3 to 09.21_3 (21b). The white dotted line shows the approximate location of the lateral margin of the earthflow. Results of manual feature tracking are also shown for the periods $06 / 07 / 2019$ to $08 / 17 / 2019$ (19c), 08/17/2019 to 09/21/2019 (20c), and 06/07/2019 to 09/21/2019 (21c). Displacements in meters are shown using points overlying 2015 lidar with hillshade derivative. Mapped headscarps and margins (previously shown in Figure 11) are used here to show the landslide boundary. The black, dotted lines indicate the approximate area covered by each scanning location, with TLS1 being the more northern of these two polygons, and TLS2 to the south.

of the previous two figures. In the satellite photo data (21c), the average displacement across the landslide surface is $3.42 \mathrm{~m}$, with a standard deviation of $3.06 \mathrm{~m}$.

For Figure 20, the average displacement calculated from the TLS data was within the error $(\mathrm{MDD}=0.096 \mathrm{~m})$ of the average displacement determined using the satellite photo manual feature tracking method. For Figures 19 and 21, the average displacement from satellite photo manual feature tracking was approximately $3 \mathrm{~m}(2.6$ and $3.39 \mathrm{~m}$, respectively) greater than that of the TLS data, which is the resolution of the satellite images used to produce these results.

\subsection{Decadal Kinematics}

The large gaps in time between aerial images (5-7 years) resulted in larger uncertainties in the manual feature tracking results at this timescale. Because MDD values were so large for this series (average of $17.3 \mathrm{~m}$, standard deviation of $9.3 \mathrm{~m}$ ), I chose to plot only the magnitudes of each displacement and velocity vector which exceeded each MDD (referred to as point displacement and point velocity), rather than presenting maximums and averages with large error bars for the surface of the landslide as a whole. Figure 22 shows the point displacement and point velocity values for each time interval on the decadal timescale, plotted at the end of each interval. 


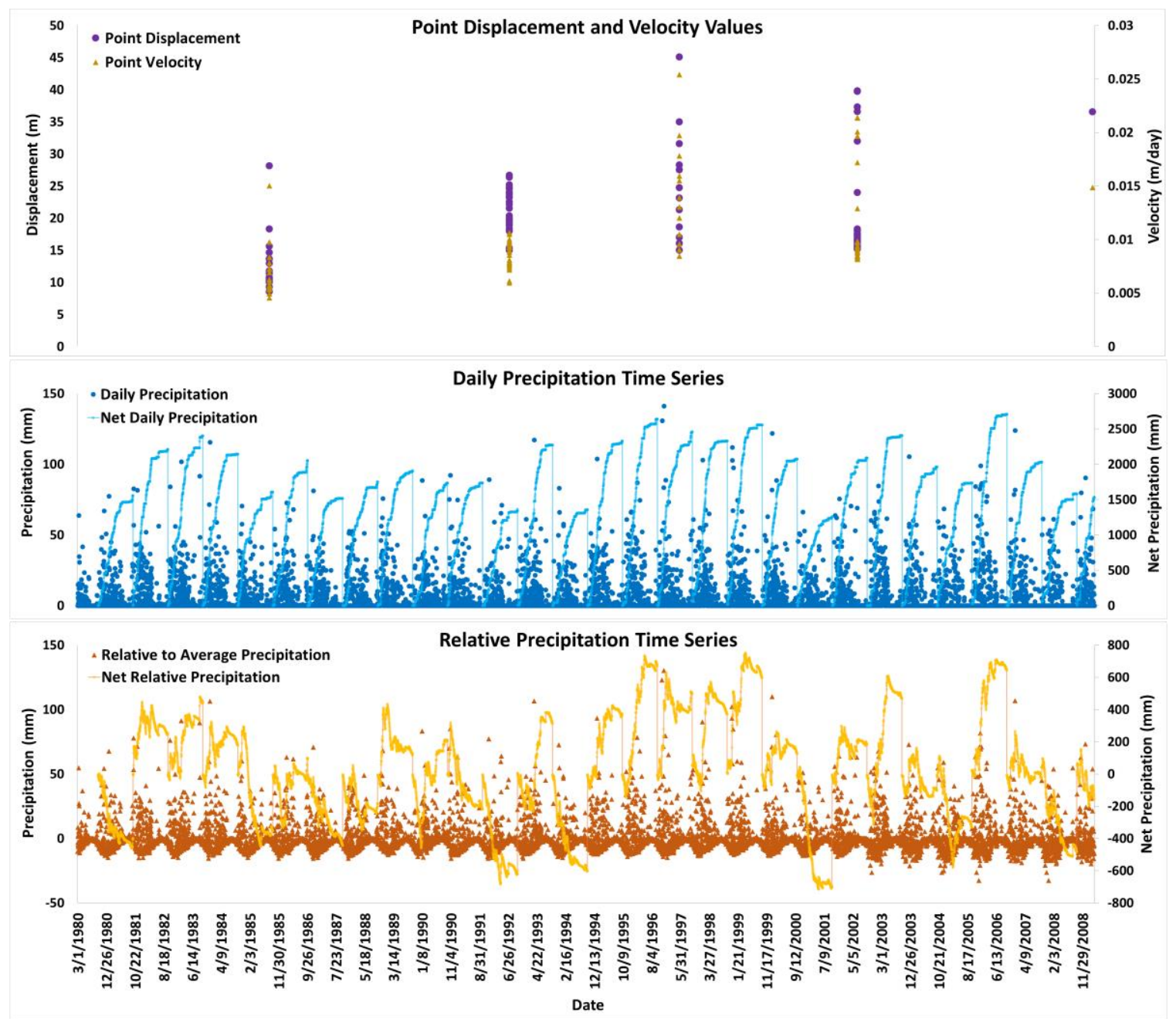

Figure 22: Point displacement and point velocity values (top) plotted for each time interval (at the end of said interval) within the decadal timescale. Daily and relative precipitation values (bottom) are plotted with respect to time.

The lowest point displacement and point velocity values are observed between 1985 and 1992. From 1985 to 1991, net relative precipitation values are consistently in the low positives, while the water year from 1991 to 1992 is consistently negative. The period from 1992 to 1997 contains the highest point displacement and velocity values, with the second highest occurring between 1997 and 2002. Over the same period, we see two shifts from negative to positive net relative precipitation (1992 and 1994), as well as a several-year period of some of the highest relative precipitation values (1994 to 2000). 
In 2001, we see another shift from negative to positive net relative precipitation. From 2002 to 2009 , only one displacement/velocity value exceeded the MDD.

To look at the relationship between displacement and velocity behavior and longterm climate cycles, I've also plotted the same point displacement/velocity time series over warm and cold ENSO and PDO phases (Figure 23). We can see both ENSO and PDO warm phases from 1985 to 1998, cold phases from 1998 to 1991, and warm phases again until 1994. While PDO briefly flips to cold and back to warm again in late 1994, ENSO remains warm (or neutral) until 1988. Cold phases dominate from 1998 to 2002, with the exception of a brief PDO warm phase switch in late 2000.

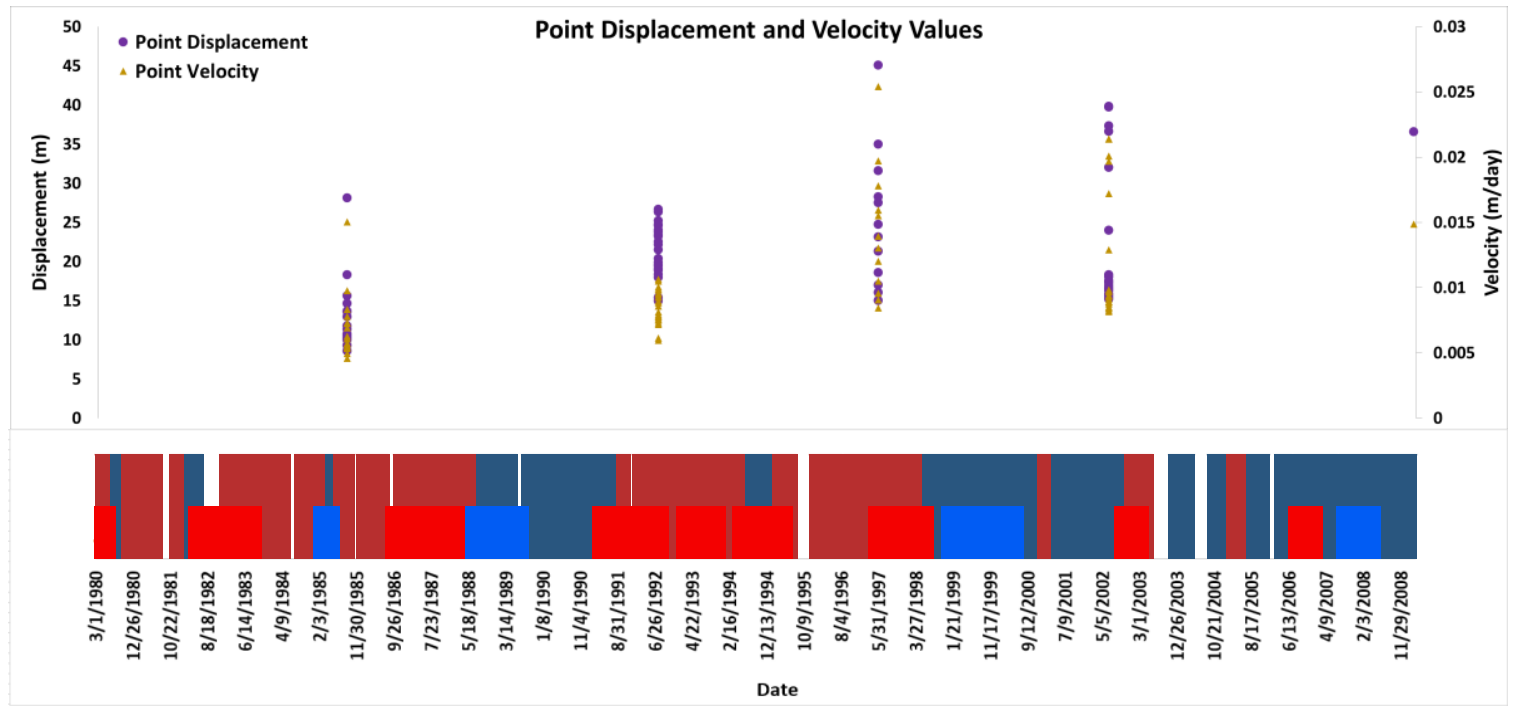

Figure 23: Point displacement and point velocity (top), and ENSO/PDO warm and cold phases (bottom).

Figure 24 shows the highest $2 \%$ of relative precipitation values, as well as the number of those values that occurred each year from 1980 through 2008 . Both the greatest relative precipitation value $(130.3 \mathrm{~mm})$, and the largest number of days with highest $2 \%$ relative precipitation values (30 days) occurred in 1996 - during the period where the highest velocities were also observed. 


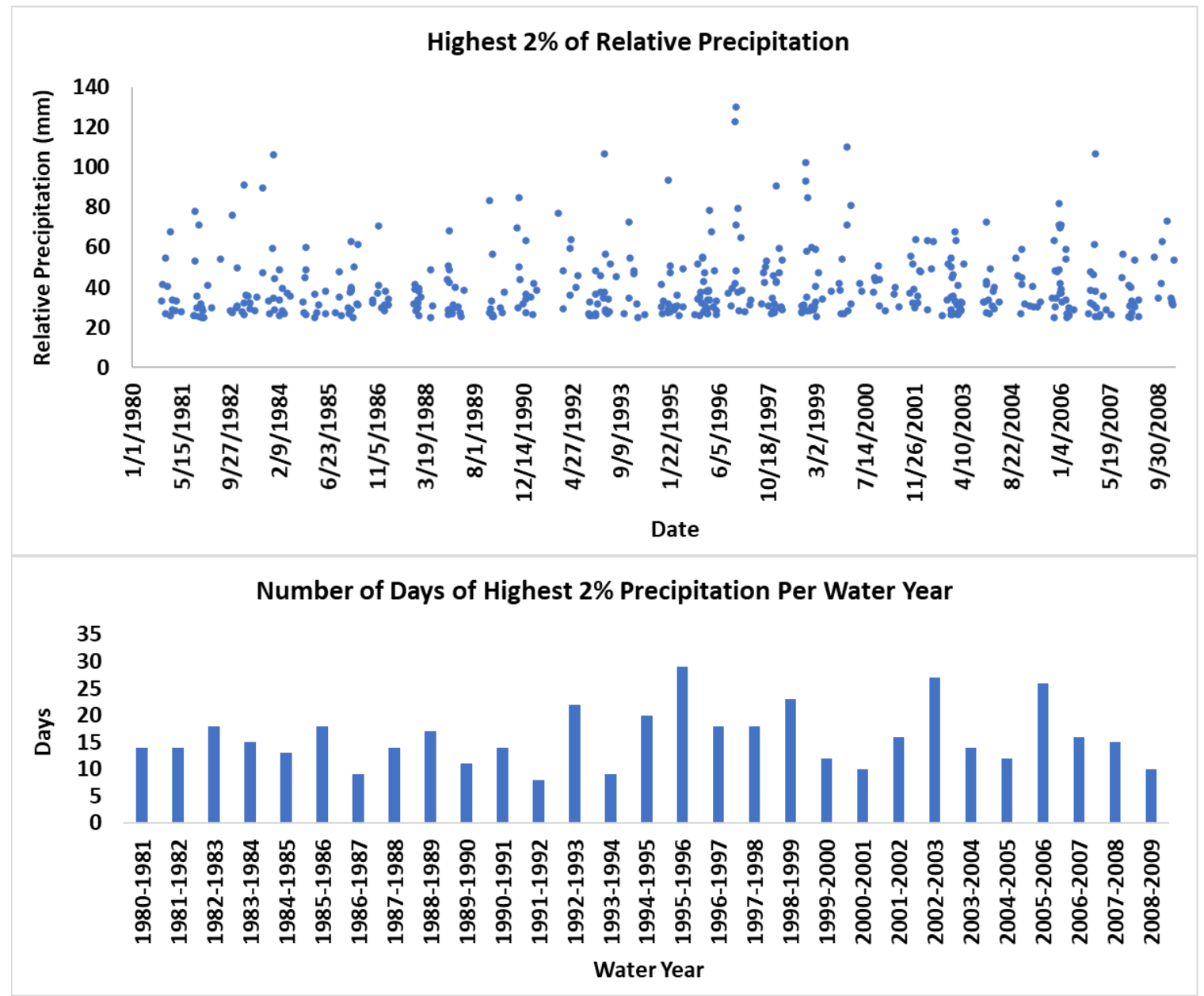

Figure 24: The highest $2 \%$ of relative precipitation values within the decadal timescale, plotted with respect to time (top), as well as the number of days with the highest $2 \%$ of precipitation within each year (bottom).

\subsection{Century Timescales $-{ }^{14}$ C Analyses}

Radiocarbon ages as reported by DirectAMS and NOSAMS are included with all lab information in Table 2

. These include the measured ${ }^{14} \mathrm{C}$ age, as well as the analytical error for each sample. Where applicable (samples HEF-0609-6-0, HEF-0609-6-24, HEF-0609-6-51, and HEF-0609-6-81), the $\delta^{13} \mathrm{C}$ is also included, although the fraction of modern carbon was reported to already reflect this correction. This dataset has been previously published 


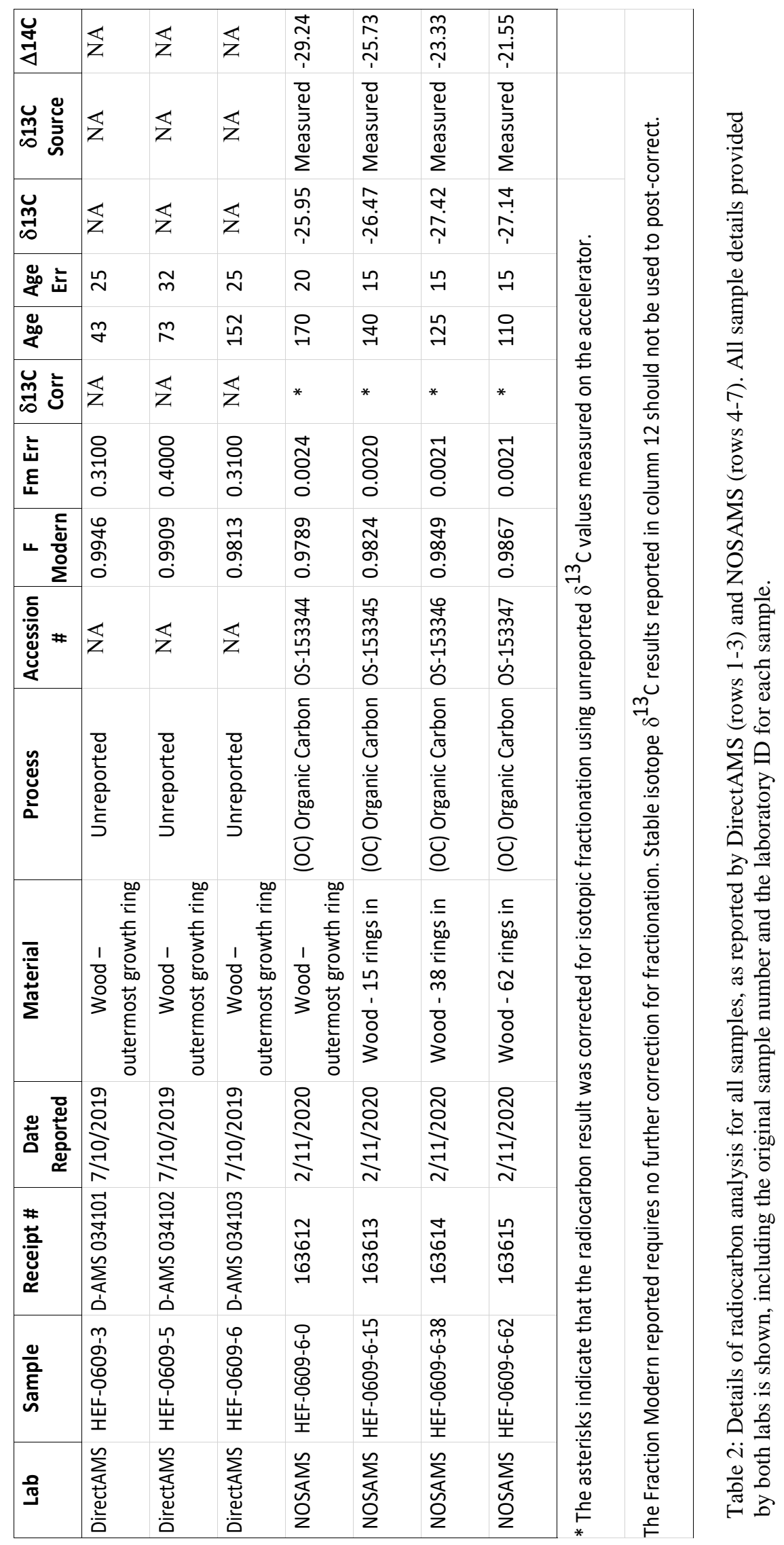


in Alberti et al. (2020), though the modeled ages have been updated within this study to reflect a more accurate ring count performed under magnification using jewelers glasses.

Probability density functions of calibrated ages and statistically modeled ages from all radiocarbon age models are shown in Figure 25. OxCal output tables for all models, including modeled and unmodeled ages with probabilities, are included in the Appendix. Samples HEF-0609-3, HEF-0609-5, and HEF-0609-6 were calibrated and modeled using a stratigraphic model (Figure 25a). The stratigraphically oldest of these (HEF-0609-6) has three possible modeled ages, with calendar dates extending from 1660 to $1843 \mathrm{AD}$, after using stratigraphic information to rule out more recent calendar ages. Based on this model, an age of $\sim 1815$ AD is the most likely (60.7\%) time of tree death for this sample (highlighted in red), with a second most likely age (34.5\%) of $1700 \mathrm{AD}$ (highlighted in yellow). The stratigraphically intermediate sample (HEF-0609-5) has a range of possible calendar dates from 1694 to 1921 AD. The final and youngest sample has possible ages ranging from 1712 to 1963 AD.

The second set of samples (HEF-0609-6-0, HEF-0609-6-24, HEF-0609-6-51, and HEF-0609-6-81), was calibrated and modeled using both the D_Seq and V_Seq models, and a boundary condition of 1939 AD (based on the date of the earliest available aerial photo of this landslide). These samples were taken from the same tree slab as HEF-06096, which was the oldest of the three tree slabs used in the stratigraphic model. In the D_Seq model, multiple issues arose due to one sample not having a possible age fitting the ridged (no error allowed) dendrochronologic constraints of the model. Without 


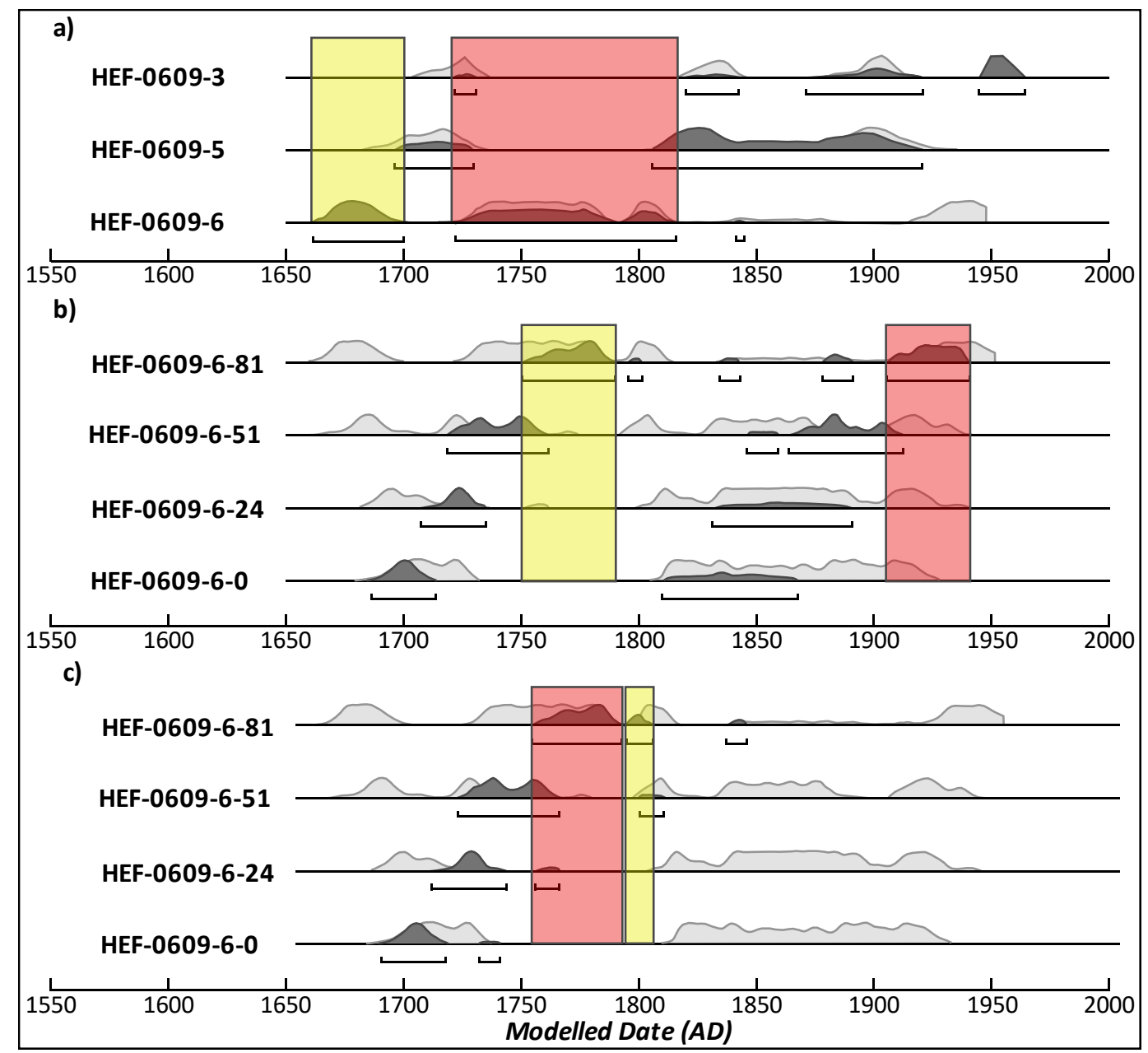

Figure 25: Probability density functions of sample calendar ages calibrated and modeled using OxCal (version 4.3) and the IntCal 13 atmospheric curve (Reimer et al., 2013; Bronk Ramsey, 2017). Light gray curves show calibrated ages, dark gray curves show trimmed, statistically modeled ages. Most probable calendar ages are highlighted in red, with second most probable ages highlighted in yellow. Ages for the outermost growth rings of samples HEF-0609-3, HEF-0609-5, and HEF-0609-6 are modeled using a stratigraphic model (a). Radiocarbon determinations for samples HEF-0609-6-0, HEF-0609-6-24 HEF0609-6-51, and HEF-0609-6-81 were calibrated and modeled using a varve model with 3, 5, and 10 years of allowed error between growth rings from inner to outermost ring, and boundary conditions of $1939 \mathrm{AD}$ (b), and $1843 \mathrm{AD}(\mathrm{c})$.

applying an upper age boundary condition, one sample (HEF-0609-6-38) fails to plot either a calibrated or modeled age. Using a boundary condition of 1939 AD, all samples fail to plot a modelled age due to "poor agreement", and the model returns only the calibrated ages without the given boundary. These problems were likely due to 
contamination by poor sample collection precision or sanding as described in the methods section, so this model was excluded from the final age analysis.

The V_Seq model, also using a boundary condition of 1939 AD (25b), predicts five possible age ranges for the outermost growth ring of tree slab HEF-0609-6. The most probable $(48.7 \%)$ of these is $\sim 1922 \mathrm{AD}$, with a second most probable $(32.4 \%)$ of $\sim 1769$ $\mathrm{AD}$ - followed by $1883 \mathrm{AD}(7.4 \%), \sim 1838 \mathrm{AD}(3.9 \%)$, and $1799 \mathrm{AD}(3.0 \%)$.

However, the youngest three of those ages are inconsistent with the stratigraphic model, which predicted that tree slab HEF-0609-6 has a date of tree death between 1660 and 1843 AD. To that end, a second V_Seq model was run using a boundary condition of $1843 \mathrm{AD}(25 \mathrm{c})$. This model returned a most probable (78.0\%) age of $\sim 1770 \mathrm{AD}$, a second most probable (13.6\%) age of $\sim 1798 \mathrm{AD}$, and a third $(3.9 \%)$ of $\sim 1838 \mathrm{AD}$. 


\section{Discussion}

\subsection{Surficial Expressions of Kinematic Behavior}

The Hooskanaden Landslide may be generally moving to the southwest, but the overall pattern of deformation appears to be much more complex. The juxtaposition of brittle and soft deformation is indicative of BIM topography - meaning that the slide does not move as a coherent mass, but rather consists of stable blocks which may persist for years, and a matrix that deforms at a much more rapid rate. Given that wide tension cracks (which I interpret to be related to the more resistant blocks, which would deform more brittlely than the less cohesive matrix) were only found in the uppermost section of the landslide (Figure 13), it is possible that the majority of these more resistant blocks reside above the highway. Tension cracks indicate primarily extension in the upper section, and thrust features indicate primarily compression in the lower section (which would be expected for this type of landslide). However, we do see additional, small, localized thrust features in both sections, as well as internal scarps in the lower section. This evidence suggests that there are localized areas of compression occurring in the upper section, possibly caused by weaker matrix material being buttressed by more resistant blocks, or superficial movements superimposed on the deeper main landslide. Additionally, internal scarps in the lower section are interpreted to indicate localized extension, which may be due to a lack of buttressing in some areas along the toe, as debris in that area is constantly eroded by wave action.

Additionally, there appear to be some structural controls that cause the overall slide mass to behave differently within different sections, although the average direction of 
sliding does roughly correspond to the dip direction of the underlying bedrock. This could be partially related to the undulate basal surface inferred within the SLIDE profile (Figure 14). NW-striking thrust features in the upper slide section indicate movement to the southwest, while NNE-striking internal scarps in the lower half of the slide indicate primarily vertical displacements on structures that dip in the northwest direction. Lateral margins may be constrained by large, resistant blocks present along the flanks of the slide mass (Castro et al., 2019). To support this idea, the surface features mapped during this study were compared to the 1939 USACE aerial imagery (Figure 26). While this image was not orthorectified, and thus cannot be used to measure change across images, it can still be used for a rough comparison of slide morphology. What appears to be the northern lateral margin of the 1939 slide deposit, indicated by a band of freshly exposed soil, roughly follows the older mapped lateral margin along that side. Similarly, the southern lateral margin of the 1939 slide appears close to but slightly north of the southern modern lateral margin. Mapped headscarps all plot upslope of the furthest upslope portion of the visible 1939 slide deposit. Unfortunately, no imagery was available from this period that contained the full extent of the mapped features. However, from what we can observe, it appears that while the headscarp may have retrogressed upslope at one point, the lateral margins of this slide have remained in roughly the same locations for nearly a century.

During the most recent surge (February of 2019), higher surface velocities were observed in the mid-section of the slide nearest the highway, but particularly along the 


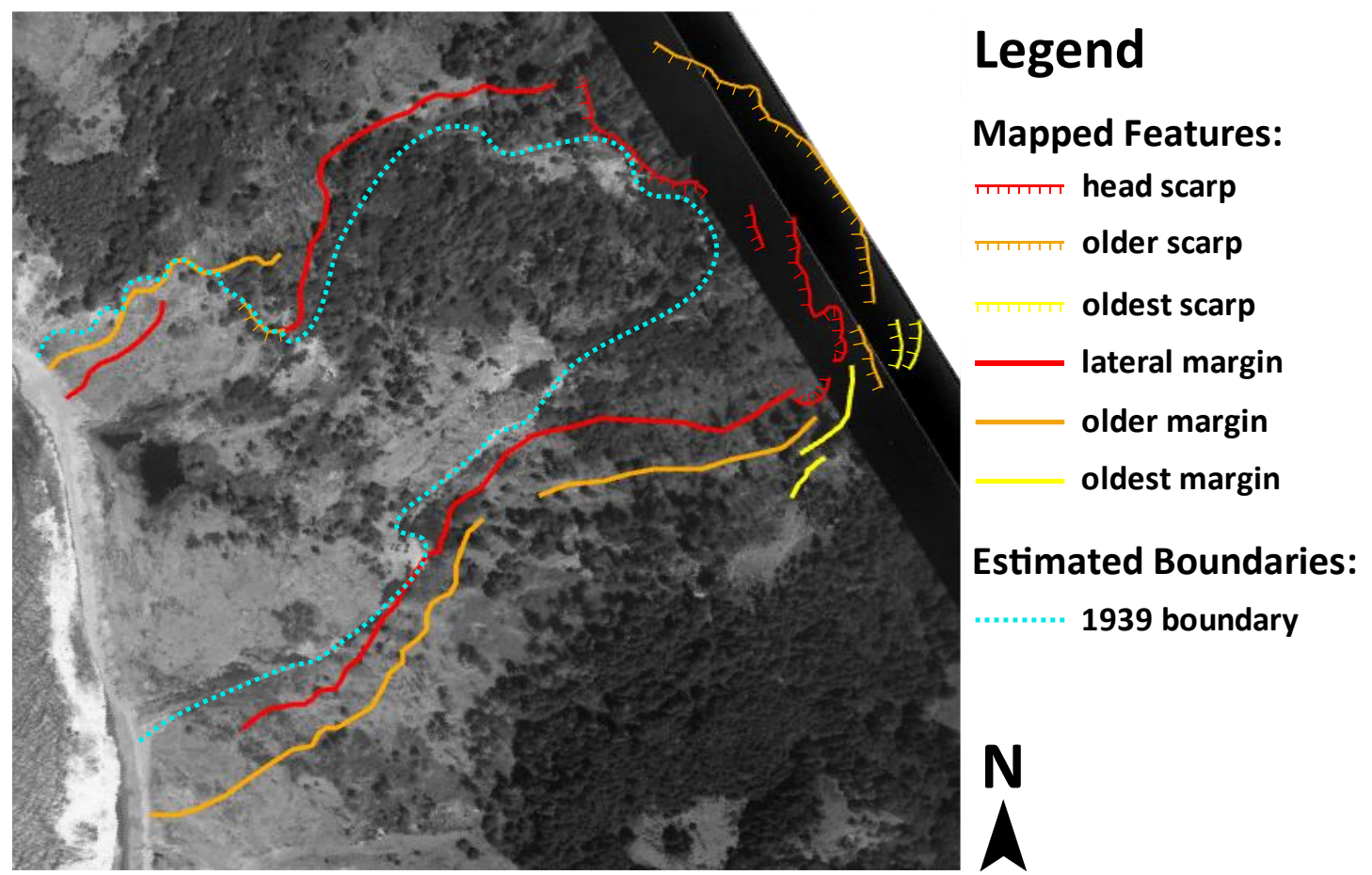

Figure 26: Surface features mapped during this study (shown in Figure 11, using same extent) overlaying USACE 1939 aerial imagery. The dotted blue line shows the approximate boundary of the landslide at the time of this image.

southeast margin in that section (Xu et al., 2021; Alberti et al., 2020). Gullying activity, which is more active along the southeastern lateral margin, indicates the direction of groundwater flow appears to be more north to south than the overall northeast to southwest motion of the earthflow - which could explain the higher surface velocities observed along the southern lateral margin. Ponding of water on the landslide surface, especially in the upper section, could indicate other possible contributions to the overall groundwater supply, such as agriculture upslope. No sources of agricultural contributions were directly observed, but the slide surface and the surrounding area are used for cattle grazing, and there are farms and other residences upslope of the slide.

Interestingly, despite constant erosion due to wave action at the toe of the slide, and the apparent growth of the slide since 1939 (Figure 26), the landslide does not appear to 
be continually retrogressing upslope. Instead, we see older (more diffuse) features still preserved upslope of younger (more angular) ones, indicating that the area of failure has decreased over time. This seems to point to toe erosion being a relatively small factor contributing to downslope motion when compared to groundwater and other driving forces. That said, the most recent surge would have erased any preexisting surficial record of any smaller previous surges. From the feature tracking data, it does to appear that the active area of the slide surface changed in size between 1980 and 2019, implying that those more diffuse features likely predate 1980. If the active part of the Hooskanaden Landslide is it fact decreasing in surface area relative to its geomorphic footprint, it is possible that it is slowly depleting its source material (Mackey and Roering, 2011). However, this does not appear to have a significant effect on the severity of surges, given that the 2019 surge resulted in much larger vertical and horizontal displacements than previously recorded surges in 1995, 2006 and 2016.

\subsection{Kinematic Behavior and Seasonal to Annual Climate Cycles}

Comparison between the TLS and satellite feature tracking datasets shows that manual feature tracking appears to overestimate displacements by an amount less than or roughly equal to the image resolution. This is obviously problematic for determining true displacements over slowly moving features, such as slow-moving earthflows. However, while displacements may be over-estimated, this method does appear to reflect true changes in relative velocities, or patterns in surface velocity (based on relationships between velocity and precipitation, and previous surge records). For that reason, I believe this approach is capable of identifying the effects of climate-driven precipitation changes 
on velocity behavior. However, there were no observed patterns in the apparent kinematics of the slide within the feature tracking data. Maximum velocities occurred across the slide mass seemingly randomly from one period to the next.

From Figure 15, it does appear that periods of higher than average (positive relative) precipitation broadly coincide with increased velocity. Some of the highest observed rates of motion and greatest daily precipitation values (quantified as the highest $2 \%$ of daily precipitation (Figure 17) occurred together between January and March of 2012, November of 2015 to February of 2016, November to December of 2016, and February of 2019. This record is partially substantiated by previously recorded surge events in both late 2016, and early 2019 (Xu et al., 2021; Alberti et al., 2020). The years 2009 and 2013 had none of the highest values for precipitation or velocity, and also had the lowest number of days with the highest $2 \%$ of relative precipitation (6 days each, compared to a maximum of 25$)$.

To further examine the relationship between surface motion and precipitation, I compiled all average velocity values corresponding to days with highest $2 \%$ relative precipitation and created a series of plots using precipitation metrics as the independent variable (Figure 27). Linear fits do not explain much of the variance $\left(\mathrm{R}^{2}\right.$ values are all less than 0.07 ) in average velocity for any of the precipitation metrics. Of the four plots, the precipitation metric that explains the highest proportion of the variance in velocity is daily precipitation, followed by relative precipitation. This initially appears to suggest that high daily precipitation is a greater indicator of landslide movement than lower intensity precipitation accumulation over time. 

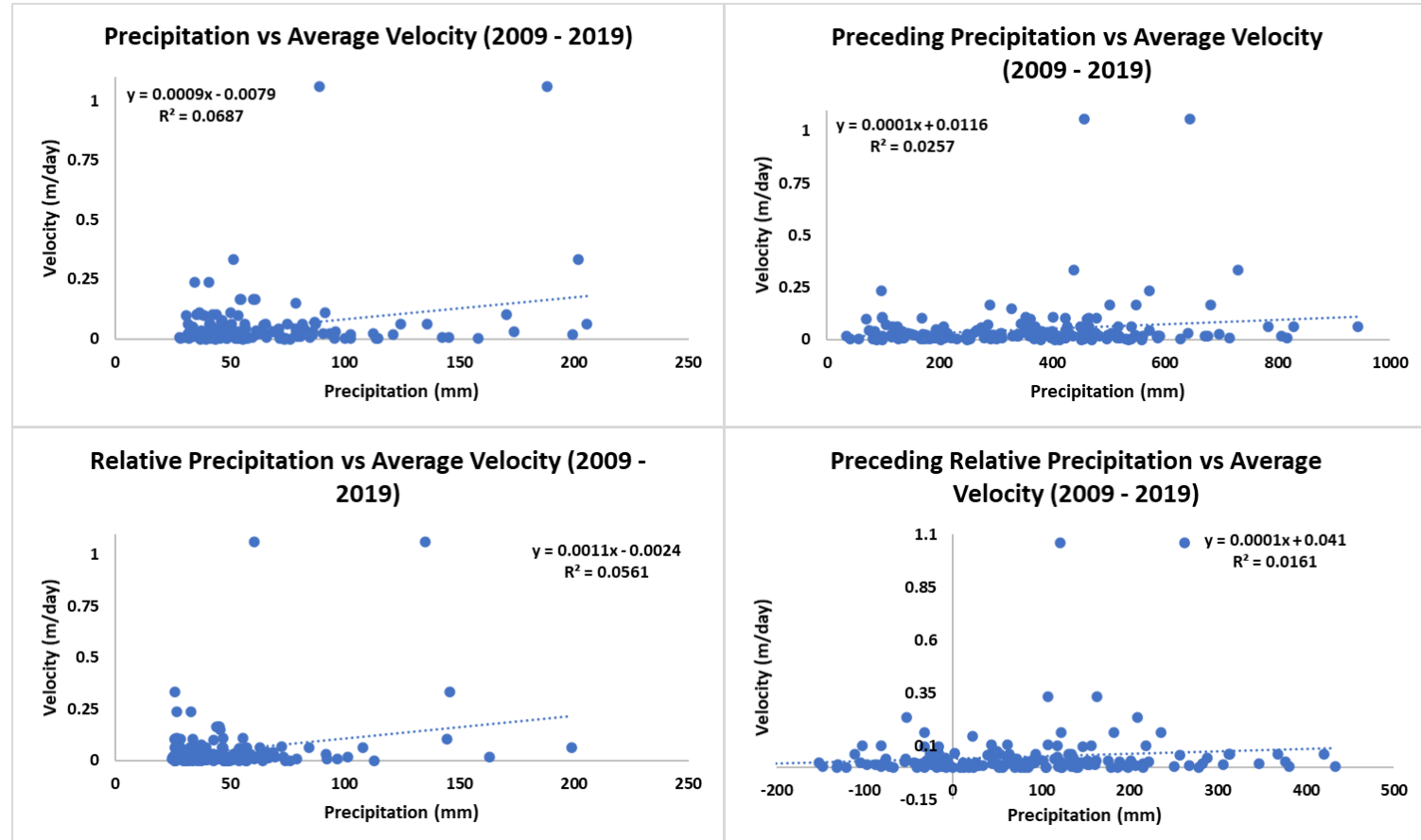

Figure 27: Graphs of average displacement vs. precipitation statistics for each day with highest $2 \%$ of precipitation, including daily precipitation (top left), relative precipitation (top right), a two week sum of daily precipitation (bottom left), and a two week sum of relative precipitation (bottom right).

However, further statistical analysis reveals that none of these relationships prove to have a statistically significant regression slope. For each relationship, the standard error (SE) was calculated using the equation:

$$
S E=\sqrt{\frac{\sum\left(y_{i}-\hat{y}_{i}\right)^{2}}{n-2}} \div \sqrt{\sum\left(x_{i}-\ddot{x}\right)^{2}}
$$

where $y_{i}$ is the recorded dependent variable for observation $i, \hat{y}_{i}$ is the estimated dependent variable (based on the linear equation for each relationship in Figure 27) for observation $i, x_{i}$ is the independent variable for observation $i, \ddot{\mathrm{x}}$ is the mean of the independent variable, and $\mathrm{n}$ is the number of observations. The margin of error (ME) is calculated by multiplying the SE value for each relationship by the t statistic - which can be found using any $t$ distribution table with the degrees of freedom $(n-2)$ and the desired probability. For this analysis, I chose a 95\% confidence interval (CI), where 


$$
C I=\text { slope coefficient } \pm M E \text {. }
$$

Table 3 shows the results of these calculations. Since all CI include 0 as a possible value, the null hypothesis cannot be rejected, and none of these relationships can be called significant for this confidence interval.

\begin{tabular}{|c|c|c|c|c|c|}
\hline & $\begin{array}{c}\text { Slope } \\
\text { Coefficient }\end{array}$ & SE & $\mathrm{ME}$ & \multicolumn{2}{|c|}{ 95\% Confidence Interval } \\
\hline Precipitation & 0.0009 & 0.0066 & 0.0131 & {$[-0.004064468$,} & 0.022064468 \\
\hline Relative & & & & & \\
\hline Precipitation & 0.0011 & 0.0088 & 0.0174 & {$[-0.016298954$,} & $0.018498954]$ \\
\hline $\begin{array}{l}\text { Preceding } \\
\text { Precipitation }\end{array}$ & 0.0001 & 0.0012 & 0.0025 & {$[-0.001463451$,} & $0.003463451]$ \\
\hline $\begin{array}{l}\text { Preceding } \\
\text { Relative } \\
\text { Precipitation }\end{array}$ & 0.0001 & 0.0017 & 0.0034 & {$[-0.002404764$,} & $0.004404764]$ \\
\hline
\end{tabular}

Table 3: Results of statistical analyses of relationship between average velocity and precipitation metrics. The SE column contains the standard error, and ME represents the margin of error.

\subsection{Kinematic Behavior and Decadal Climate Cycles}

The previously mentioned study by Xu et al. (2020) also used remote sensing methods to measure surface velocity along the Hooskanaden Landslide over longer timescales. Table 4 compares those findings to the surface velocities derived during this study. Clearly, results presented herein are much larger than those found by Xu et al. ( 3000-4000\% difference). This is likely due to the greater accuracy of their pixel offset tracking method, which resulted in much lower MDD values (0.28-0.8 m vs. 3-5 m), as well as the lower temporal resolution (one precise measurement, as opposed to several less precise measurements). Interestingly, Xu et al. (2020) mention a consistent increase in their velocity data from 2007 to 2019 . The average surface velocity roughly doubles from the period Feb 2007 - Jan 2011 to Jan 2011 - July 2016, then doubles again between July 2016 and Oct 2019. The data found within this study follows the same pattern, 
roughly doubling during each successive interval. This supports the previous assertion that while the feature tracking method described in this study may not be suitable for measuring precise displacements, it may still be useful for observing relative velocities, or patterns in velocity behavior.

\begin{tabular}{|l|r|r|r|}
\hline Period & Xu et al. (m/day) & Kingen (m/day) & Percent Difference \\
\hline Feb 2007 - Jan 2011 & 0.000356 & 0.012133 & 3306.514 \\
Jan 2011 - July 2016 & 0.000575 & 0.025048 & 4253.513 \\
July 2016 - Oct 2019 & 0.001452 & 0.048929 & 3269.655 \\
\hline
\end{tabular}

Table 4: Average surface velocities from Xu et al. (2020) compared to surface velocities from the same periods determined within this study (Kingen).

Given the poor temporal resolution of aerial images within the decadal timescale, it was much more difficult to accurately track individual features on the landslide's surface. For this reason, less displacement and velocity data is available to compare to climate data from the same timescale. However, even with fewer data points and larger temporal gaps, there does still appear to be a broad correspondence between point displacement or point velocity values and decadal climate trends. In 1996, we see both the highest daily and relative precipitation values, as well as the greatest number of days with the highest $2 \%$ of precipitation (30 days). For the period from 1992 to 1997, we also see the highest point velocity values. This coincides with major storm events occurring during 1996 and 1997 that caused catastrophic landsliding across the Oregon Coast Range, resulting in eight fatalities (Beaulieu and Olmstead, 1999).

Looking again at longer-term climate cycles, the period from 1992 to 1997 (with the highest point velocity values) is preceded by and coincident with both PDO and ENSO warm phases (Figure 23). The period from 1985 to 1992 (where we see the lowest point velocity values) is also coincident with PDO and ENSO warm phases at the end of 
the period, but the middle of the period is dominated by cold phase PDO and ENSO. As suggested by Figure 4, we do see increasing precipitation during warm phases of PDO and ENSO, and decreasing precipitation during cold phases of PDO and ENSO. If we accept that the Hooskanaden Landslide is driven primarily by changes in precipitation (as inferred in the previous section), then it also appears that the Hooskanaden Landslide is impacted by long-term climate cycling on the multiannual and decadal scale.

It is worth noting that the point velocity values observed during the decadal timescale are smaller than the average velocity values recorded in the seasonal to annual timescale. I believe this is related to biases in the features that are trackable on the satellite and aerial photos over different periods of time, which relate to the BIM-style movement of the slide mass. Over shorter timescales, it is much easier to track less persistent features observed within the weaker matrix (such as small bushes). But in some cases, this matrix deforms too quickly for those features to be observed 5 to 7 years later. Within the decadal timescale, the only features that are able to persist from one image to another are large features on the more stable blocks within the landslide - which move much more slowly, or not at all. These blocks are stable enough to allow for the growth of trees, whereas the matrix only seems able to support grasses and small brush. For this reason, I believe the average velocity values calculated for the seasonal to annual timescale may be more representative of the overall average rate of surface movement for the landslide, while the decadal point velocities may be more representative of the deformation rate of the more stable blocks within the slide mass, as the deformation of the matrix is too rapid to be observable at this temporal resolution. However, as rates of 
motion derived via manual feature tracking likely overestimate the actual velocity, this is better thought of as a comparison between relative rates.

\subsection{Age Interpretation of the Hooskanaden Landslide}

Two wiggle matching models were used to analyze the radiocarbon determinations from the second set of samples, D_Seq and the V_Seq wiggle match models. The D_Seq model did not yield any usable results, in part because one sample (HEF-0609-6-38) was excluded from the model, but also because the model would not accept the boundary condition of 1939 AD. Given that we have an aerial image of the Hooskanaden Landslide from 1939 AD that clearly shows it was active at that time, the age of our oldest sample must predate this. There are two factors that could have contributed to the failure of this model: sample contamination (which could explain the exclusion of that sample), or miscounted growth rings (which would explain the boundary condition issue). If sample HEF-0609-6-38 was contaminated prior to submission to NOSAMS with material from another growth ring, this could have happened during sanding (extraneous material caught in the pores of the wood), or sample collection. If the growth ring count is incorrect, it is possible that tree slab HEF-0609-6 may have skipped rings - where the living tree did not produce new growth for one or more years due to environmental stressors.

The two V_Seq wiggle match models that assumed different boundary conditions produced two different most probable ages - one which was quite modern ( 1922 AD), and one slightly younger than the most recent Cascadia earthquake ( 1770 AD). The first of these used a boundary condition of 1939 AD, and the second with a boundary 
condition of $1843 \mathrm{AD}$ (based on the results of the stratigraphic model). Both scenarios estimate the age of initiation of the Hooskanaden Landslide after the most recent Cascadia earthquake. However, the implications of these findings and their associated assumptions are worthy of further exploration.

If the stratigraphic model is disregarded, the first V_Seq model (boundary condition of 1939 AD) predicts a most probable calendar age of $\sim 1922$ AD (specifically, between 1905 and 1939 AD), indicating that the Hooskanaden Landslide initially failed approximately one century ago. While this is possible, an age that young does seem unlikely given the 1939 aerial photo (Figure 26). The presence of a landslide is clear in this image, and there are well defined margins, but the presence of large sag ponds and vegetation on the landslide surface suggest that this slide had been relatively inactive for some time prior to the photo. Additionally, the slide deposit shown is substantially smaller than the modern slide deposit, which has a basal surface at $\sim 30 \mathrm{~m}$ depth. The slide deposit in 1939 was likely much shallower, and would thus likely not have a failure plane at the modern beach, where slab HEF-0609-6 was recovered.

However, if the stratigraphic model is to be believed, then the second V_Seq model (boundary condition of 1843 AD), and a most probable calendar date of 1770 AD, appears to be the best representation of the age of initiation for this landslide. This is also the second most probable age indicated by the first V_Seq model. Therefore, given the 1939 aerial imagery, and the overlap between the two models, I interpret $\sim 1770$ AD to be the landslide's minimum age, indicating that it has likely been active for at least $\sim 250$ years. 
The likely age of $\sim 1770$ AD suggests that even if the most recent Cascadia earthquake didn't cause immediate failure, it is possible that coseismic dynamic stress could have permanently weakened the basal surface (Carey et al., 2019), and created additional flow paths for water to infiltrate the slide mass via fracturing the surface material, leaving it more susceptible to future failure. Over several cycles of wetting and drying, precipitation could travel to the weakened basal surface via newly fractured pathways, inducing failure (Marc et al., 2015). However, this study alone does not provide sufficient evidence to thoroughly support this argument.

It is also necessary to address what this possible age actually represents. Assuming that my oldest sample was entrained upon initiation (suggesting that no older representative samples exist), and that sample died upon entrainment, the age of this sample represents the true age of the earthflow. The presence of an older representative sample is possible, although HEF-0609-6 was taken from the lowest visible stratigraphic unit identified above the lowest failure plane. If this landslide failed below present sealevel, an even lower stratigraphic failure plane would not be visible, implying that sample HEF-0609-6 could be younger than the landslide itself, and that older samples may be buried at greater depths beneath the modern beach. This would be an interesting avenue for further exploration, as these older samples could date closer to the $1700 \mathrm{AD}$ or older Cascadia Earthquakes. 


\section{Conclusion}

This study addressed two questions about the Hooskanaden Landslide: one regarding the climatic controls on the surface velocity behavior of the landslide, and another regarding the landslide's age.

The first of these questions was addressed using manual feature tracking to complete a surface velocity time series, which was then compared to precipitation records over the same time period. While there is an apparent correlation between higher surface velocities and higher than average precipitation, this is not a one-to-one relationship. This implies that other controlling factors (frictional and resisting forces) may add to the stabilization of the slide mass, which are not always overcome by increased pore pressure alone.

It does appear that some surges occur following a switch from abnormally dry to abnormally wet years, or cold phase to warm phase climate cycles - but this is not the case with all surges on record. However, I suspect that as climate change continues, and the impact of climate cycles on precipitation patterns intensifies, we will see this pattern immerge much more clearly. Other studies have shown a strong relationship between desiccation cracking followed by intense rainfall, and slope failure (e.g., Handwerger et al., 2019). This effect will likely be amplified with future climate change predictions, where warming climates could increase desiccation, and increased storm severity could lead to larger and more frequent surge events. For these reasons, it may be beneficial to increase monitoring of slope movement on the Hooskanaden Landslide beginning in the new water year (Oct. $1^{\text {st }}$ ) following an unusually dry year. Remote sensing with monthly 
temporal resolution and 3-5 m spatial resolution may not be sufficient to pick up smaller surface displacement in the days prior to a surge, but higher precision sensors placed on the surface of the slide - particularly above and below the highway - may pick up on early signs of acceleration, which could alert ODOT geologists that a surge was about to occur.

To address the second question, carbon samples were collected from the toe of the landslide for radiocarbon analysis, the results of which were calibrated using dendrochronology to best constrain the age of the landslide. The models provided a most probable age of $\sim 1770 \mathrm{AD}$, which postdates the most recent Cascadia Subduction Zone earthquake by $\sim 70$ years. Although this date is not coincident with the 1700 AD Cascadia earthquake, it is still possible that the initial failure of the Hooskanaden was related to fracturing of the surface material, creating additional flow paths, and weakening of the basal surface as a result of coseismic stresses.

Whether or not the Hooskanaden Landslide was coseismically activated, it appears to have been active since the mid-late 1700s. While we have no way of obtaining surface velocity data from that period, what we can observe does not seem to indicate a decrease in surface velocity over time (at least since 1980). To the contrary, data produced for this study, as well as by other researchers (Xu et al., 2020) points to a measured increase in surface velocity over the past decade or so (Table 4). Similarly, the severity of surge events does not appear to be decreasing over time. The 2019 surge was significantly more catastrophic than surges recorded in 1995, 2006, and 2016. These trends, plus additional climate impacts, such as increased precipitation, and increased 
coastal erosion due to sea-level rise (debuttressing of the landslide toe), all seem to indicate surge behavior of the Hooskanaden Landslide will continue - and may even increase in severity - into the future. 


\section{References Cited}

Alberti, S., Senogles, A., Kingen, K., Booth, A., Castro, P., DeKoekkoek, J., GloverCutter, K., Mohney, C., Olsen, M., and Leshchinsky, B., 2020, The Hooskanaden Landslide: historic and recent surge behavior of an active earthflow on the Oregon Coast: Landslides, v. 17, doi:10.1007/s10346-020-01466-8.

Ayoub, F., Leprince, S., and Avouac, J., 2017, User's Guide to COSI-CORR: Coregistration of Optically Sensed Images and Correlation, p. 1-49.

Balco, G., Finnegan, N., Gendaszek, A., Stone, J.O.H., and Thompson, A., 2013, Erosional response to northward-propagating crustal thickening in the coastal ranges of the U.S. pacific northwest: American Journal of Science, v. 313, p. 790-806, doi:10.2475/11.2013.01.

Beaulieu, J.D., and Olmstead, D.L., 1999, Special Paper 31 Mitigating Geologic Hazards in Oregon: A Technical Reference Manual: Oregon Department of Geology and Mineral Industries Special Papers, p. 1-64.

Bennett, G.L., Miller, S.R., Roering, J.J., and Schmidt, D.A., 2016a, Landslides, threshold slopes, and the survival of relict terrain in the wake of the Mendocino Triple Junction: Geology, v. 44, p. 363-366, doi:10.1130/G37530.1.

Bennett, G.L., Roering, J.J., Mackey, B.H., Handwerger, A.L., Schmidt, D.A., and Guillod, B.P., 2016b, Historic drought puts the brakes on earthflows in Northern California: Geophysical Research Letters, v. 43, doi:10.1002/2016GL068378.

Besl, P.J., and McKay, N.D., 1992, A Method for Registration of 3-D Shapes: Sensor fusion IV: control paradigms and data structures, v. 14, p. 586-606, doi:10.1016/j.tws.2017.09.029.

Blake, M.C., Engebretson, D.C., Jayco, A.S., and Jones, D.L., 1985, Tectonostratigraphic terranes in southwest Oregon: Tectonostratigraphic terranes of the circum-Pacific region, v. 39, p. 147-157.

Bontemps, N., Lacroix, P., and Doin, M.P., 2018, Inversion of deformation fields timeseries from optical images, and application to the long term kinematics of slowmoving landslides in Peru: Remote Sensing of Environment, v. 210, p. 144-158, doi:10.1016/j.rse.2018.02.023.

Bounds, J.D., 1982, The geology of the Floras Creek area, Curry County, Oregon: Dissertations and Theses, Paper 3253, doi:10.15760/etd.3247.

Bourgeois, J., and Dott Jr., R.H., 1985, Stratigraphy and sedimentology of Upper Cretaceous rocks in coastal southwest Oregon: Evidence for wrench-fault tectonics 
in a postulated accretionary terrane: Geological Society of America Bulletin, v. 96, p. 1007-1019.

Bovis, M.J., and Jones, P., 1992, Holocene history of earthflow mass movements in south-central British Columbia: the influence of hydroclimatic changes: Canadian Journal of Earth Sciences, v. 29, p. 1746-1755.

Bronk Ramsey, C., 2017, Methods for Summarizing Radiocarbon Datasets: Radiocarbon, v. 59, p. 1809-1833.

Bronk Ramsey, C., 2009, Bayesian analysis of radiocarbon dates. Radiocarbon, v. 51(1), p. 337-360.

Bronk Ramsey, C., van der Plicht, J., \& Weninger, B., 2001, 'Wiggle matching' radiocarbon dates. Radiocarbon, v. 43(2A), p. 381-389.

Burgette, R.J., Weldon, R.J., and Schmidt, D.A., 2009, Interseismic uplift rates for western Oregon and along-strike variation in locking on the Cascadia subduction zone: Journal of Geophysical Research: Solid Earth, v. 114, doi:10.1029/2008JB005679.

Carey, J.M., Massey, C.I., Lyndsell, B., and Petley, D.N., 2019, Displacement mechanisms of slow-moving landslides in response to changes in pore water pressure and dynamic stress: Earth Surface Dynamics Discussions, doi:https://doi.org/10.5194/esurf-2018-73.

Castro, P., Mohney, C., DeKoekkoek, J., \& Cunningham, C. (2019). Hooskanaden landslide reconnaissance in response to 2019 episodic movement; Oregon Coast Hwy (US 101) (Hwy. 9, M.P. 343.5), Curry County, Oregon.

Cruden, D.M., and Varnes, D.J., 1996, Chapter 3 Landslide Types and Processes: Landslides: Investigation and Mitigation, Transportation Research Board Special Report 247, Washington D.C., p. 36-75.

DeBell, D.S., 1990, Black cottonwood, in Burns, R.M. and Honkala, B.H. eds., Agriculture Handbook 654, Washington D.C., USDA Forest Service, p. 570-576.

Dott Jr., R.H., 1971, Geology of the southwestern Oregon coast west of the 124th meridian, p. 6-53.

Fierro, A.O., 2014, Relationships between California rainfall variability and large-scale climate drivers: International Journal of Climateology, v. 34, p. 3626-3640, doi:10.1002/joc.4112.

Fredlund, D.G., and Krahn, J., 1977, Comparison of slope stability methods of analysis: Canadian Geotechnical Journal, v. 14, p. 429-439. 
Goodrich, G.B., 2007, Influence of the Pacific Decadal Oscillation on Winter Precipitation and Drought during Years of Neutral ENSO in the Western United States: Weather and Forecasting, v. 22, p. 116-124, doi:10.1175/WAF983.1.

Handwerger, A.L., Huang, M.H., Fielding, E.J., Booth, A.M., and Bürgmann, R., 2019, A shift from drought to extreme rainfall drives a stable landslide to catastrophic failure: Scientific Reports, v. 9, p. 1-12, doi:10.1038/s41598-018-38300-0.

Highland, L.M., and Bobrowsky, P., 2008, USGS The Landslide Handbook — A Guide to Understanding Landslides: Landslides, p. 129, doi:Circular 1325.

Iverson, R.M., and Major, J.J., 1987, Rainfall, ground-water flow, and seasonal movement at Minor Creek landslide, northwest California: Physical interpretation of empirical relations: Geological Society of America, v. 99, p. 579-594.

Keefer, D.K., and Johnson, A.M., 1983, Earth Flows: Morphology, Mobilization, and Movement, p. 53-56.

Kelsey, H.M., and Bockheim, J.G., 1994, Coastal landscape evolution as a function of eustasy and surface uplift rate, Cascadia margin, southern Oregon: Geological Society of America Bulletin, v. 106, p. 840-854, doi:10.1130/00167606(1994)106<0840:CLEAAF>2.3.CO;2.

Kelsey, H.M., 1978, Earthflows in Franciscan melange, Van Duzen River basin, California: Geology, v. 6, p. 361-364.

Koch, J.G., 1966, Late Mesozoic stratigraphy and tectonic history, Port Orford-Gold Beach area, southwestern Oregon Coast: Bulletin of the American Association of Petroleum Geologists, v. 50, p. 25-71.

Leprince, S., Barbot, S., Ayoub, F., and Avouac, J.P., 2007, Automatic and precise orthorectification, coregistration, and subpixel correlation of satellite images, application to ground deformation measurements: IEEE Transactions on Geoscience and Remote Sensing, v. 45, p. 1529-1558, doi:10.1109/TGRS.2006.888937.

Mackey, B.H., Roering, J.J., and McKean, J.A., 2009, Long-term kinematics and sediment flux of an active earthflow, Eel River, California: Geology, v. 37, p. 803806, doi:10.1130/G30136A.1.

Mackey, B. H., \& Roering, J. J., 2011, Sediment yield, spatial characteristics, and the long-term evolution of active earthflows determined from airborne LiDAR and historical aerial photographs, Eel River, California. Bulletin, 123(7-8), p. 15601576.

Malet, J.P., van Asch, T.W.J., van Beek, R., and Maquaire, O., 2005, Forecasting the behaviour of complex landslides with a spatially distributed hydrological model: Natural Hazards and Earth System Science, v. 5, p. 71-85, doi:10.5194/nhess-5-71- 
2005.

Mohney, C., Castro, P., DeKoekkoek, J., and Cunningham, C., 2019, Hooskanaden Landslide Reconnaissance In Response To 2019 Episodic Movement; Oregon Coast Hwy (US 101) (Hwy. 9, M.P. 343.5), Curry County, Oregon.

Muhs, D.R., Rockwell, T.K., and Kennedy, G.L., 1992, Late quaternary uplift rates of marine terraces on the Pacific coast of North America, southern Oregon to Baja California sur: Quaternary International, v. 15-16, p. 121-133, doi:10.1016/10406182(92)90041-Y.

Nelson, A.R. et al., 1995, Radiocarbon evidence for extensive plate-boundary rupture about 300 years ago at the cascadia subduction zone: Nature, v. 378, p. 371-374, doi:10.1038/378371a0.

Panek, T., 2015, Recent progress in landslide dating: A global overview Recent progress in landslide dating: A global overview: Progress in Physical Geography, v. 39, p. 168-198, doi:10.1177/0309133314550671.

Parker, E. (1979). Progress report-Hooskanaden Creek slide drilling, Oregon Coast Highway/Curry County.

Personius, S.F., Dart, R.L., Bradley, L.-A., and Haller, K.M., 2003, Maps and data for Quaternary faults and folds in Oregon: US Geological Survey Open-File Report, v. 2003-03-09, p. 212-222.

Peterson, C. D., \& Cruikshank, K. M., 2014, Quaternary tectonic deformation, Holocene paleoseismicity, and modern strain in the unusually-wide coupled zone of the Central Cascadia Margin, Washington and Oregon, USA, and British Columbia, Canada. Journal of Geography and Geology, 6(3), 1.

Peterson, C.D., Komar, P.D., and Scheidegger, K.F., 1985, Distribution, Geometry, and Origin of Heavy Mineral Placer Deposits on Oregon Beaches: SEPM Journal of Sedimentary Research, v. Vol. 56, p. 67-77, doi:10.1306/212F8887-2B24-11D78648000102C1865D.

Petley, D.N., Bulmer, M.H., and Murphy, W., 2002, Patters of movement in rotational and translational landslides: Geology (Boulder), v. 30, p. 719-722.

Ramp, L., Schlicker, H.G., and Gray, J.J., 1977, Geology, mineral resources and rock material of Curry County, Oregon.

Reid, M.E., Brien, D.L., LaHusen, R.G., Roering, J.J., de la Fuente, J., and Ellen, S.D., 2003, Debris-flow initiation from large, slow-moving landslides: Proceedings of the International Conference on Debris-Flow Hazards Mitigation, v. 3, p. 155-166.

Reimer, P.J. et al., 2013, IntCal13 and Marine13 Radiocarbon Age Calibration Curves 0- 
50,000 Years cal BP: Radiocarbon, v. 55.

Ritchie, A., 2018, Time-lapse view of California Highway 1 reconstruction after 2017 landslide: USGS Pacific Coastal and Marine Science Center.

Ropelewski, C.F., and Halpert, M.S., 1986, North American precipitation and temperature patterns associated with el Niño: Monthly Weather Review, v. 114, p. 2352-2362.

Sallenger, A.H., Krabill, W., Brock, J., Swift, R., Manizade, S., and Stockdon, H., 2002, Sea-cliff erosion as a function of beach changes and extreme wave runup during the 1997-1998 El Niño: Marine Geology, v. 187, p. 279-297, doi:10.1016/S00253227(02)00316-X.

Scheingross, J.S., Minchew, B.M., Mackey, B.H., Simons, M., Lamb, M.P., and Hensley, S., 2013, Fault-zone controls on the spatial distribution of slow-moving landslides: Bulletin of the Geological Society of America, v. 125, p. 473-489, doi:10.1130/B30719.1.

Schultz, W.H., Galloway, S.L., and Higgins, J.D., 2012, Evidence of earthquake triggering in large landslides: Geomorphology, v. 141-142, p. 88-98, doi:10.1016/j.geomorph.2011.12.026.

Seed, H.B., and Idriss, I.M., 1982, Ground Motions and Soil Liquefaction During Earthquakes: Berkeley, California, Earthquake Engineering Research Institute, 13$15 \mathrm{p}$.

Seed, H.B., and Wilson, S.D., 1967, The Turnagain Heights Landslide, Anchorage, Alaska: Journal of the Soil Mechanics and Foundations Division, v. 93, p. 325-353.

Speer, J. H., 2012, Fundamenals of tree ring research: Tucson, AZ, University of Arizona Press, $360 \mathrm{p}$.

Stark, T.D., Ph, D., Asce, F., Newman, E.J., Ph, D., and Peña, G. De, 2011, Fill Placement on Slopes Underlain by Franciscan Mélange: , p. 263-273, doi:10.1061/(ASCE)GT.1943-5606.0000394.

Strozzi, T., Delaloye, R., Kääb, A., Ambrosi, C., Perruchoud, E., and Wegmüller, U., 2010, Combined observations of rock mass movements using satellite SAR interferometry, differential GPS, airborne digital photogrammetry, and airborne photography interpretation: Journal of Geophysical Research: Earth Surface, v. 115, p. 1-11, doi:10.1029/2009JF001311.

U.S. Global Change Research Program, 2018, Fourth National Climate Assessment: v. II, p. 88-91, doi:10.1016/j.pbb.2008.09.016.

Wartman, J., Dunham, L., Tiwari, B., and Pradel, D., 2013, Landslides in Eastern Honshu Induced by the 2011 Off the Pacific Coast of Landslides in Eastern Honshu Induced by the 2011 Tohoku Earthquake: Bulletin of the Seismological Society of America, 
v. 103, p. 1503-1521, doi:10.1785/0120120128.

Williamson, D.A., Neal, K.G., and Larson, D.A., 1991, The field-developed crosssection: a systematic method of portraying dimensional subsurface information and modeling for geotechnical interpretation and analysis: Proceedings 34th Annual Meeting Association of Engineering Geologists, v. Proceeding, p. 719-738.

Xu, Y., Lu, Z., Schultz, W.H., and Kim, J., 2020, Twelve - Year Dynamics and Rainfall Thresholds for Alternating Creep and Rapid Movement of the Hooskanaden Landslide From Integrating InSAR, Pixel Offset Tracking, and Borehole and Hydrological Measurements Journal of Geophysical Research : Earth Surfac: Journal of Geophysical Research: Earth Surface, v. 125, p. 1-17, doi:10.1029/2020JF005640. 


\section{Appendices}

\subsection{Appendix A - List of Supplemental Files}

\begin{tabular}{|c|c|c|c|}
\hline File Name & Description & Type & Size \\
\hline PrecipitationData.csv & $\begin{array}{l}\text { All precipitation data used in } \\
\text { precipitation timeseries. }\end{array}$ & Comma Separated Values File & $856 \mathrm{~KB}$ \\
\hline FeatureTracking.csv & $\begin{array}{l}\text { Surface displacement, velocity, } \\
\text { and MDD values derived via } \\
\text { manual feature tracking. }\end{array}$ & Comma Separated Values File & $1.12 \mathrm{MB}$ \\
\hline
\end{tabular}

Table 5: Details and descriptions for all Supplemental Files. 
8.2 Appendix B $-{ }^{14}$ C Model Data

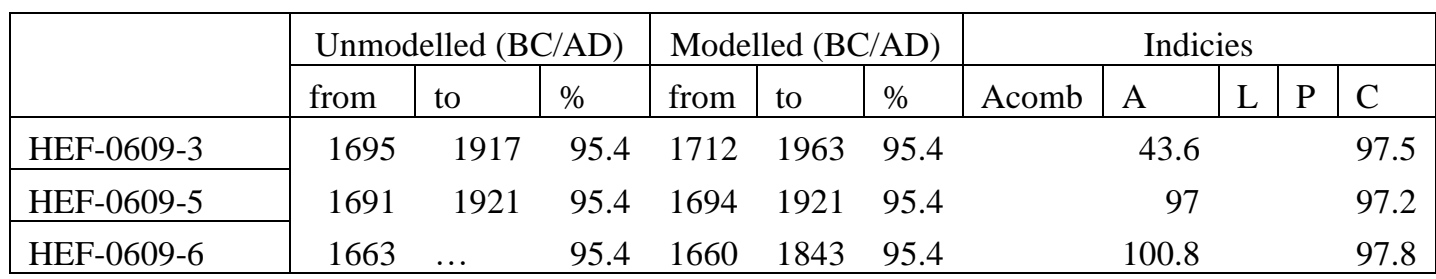

Table 6: Output table from OxCal stratigraphic model (Bronk Ramsey, 2009), including modeled and unmodeled age ranges and probabilities for the outermost growth rings of all three tree slabs.

\begin{tabular}{|c|c|c|c|c|c|c|c|c|c|c|c|}
\hline & \multicolumn{3}{|c|}{ Unmodelled (BC/AD) } & \multicolumn{3}{|c|}{ Modelled (BC/AD) } & \multicolumn{5}{|c|}{ Indices } \\
\hline & from & to & $\%$ & from & to & $\%$ & Acomb & $\mathrm{A}$ & $\mathrm{L}$ & $\mathrm{P}$ & $\mathrm{C}$ \\
\hline Boundary 1939 & 1938 & 1939 & 95.4 & 1938 & 1939 & 95.4 & & 10 & & & 100 \\
\hline HEF-0609-6-81 & 1664 & $\ldots$ & 95.4 & 1750 & 1939 & 95.4 & & 79. & & & 0.1 \\
\hline HEF-0609-6-51 & 1673 & 1942 & 95.4 & 1724 & 1917 & 95.4 & & 64. & & & 0.2 \\
\hline HEF-0609-6-24 & 1685 & 1927 & 95.4 & 1707 & 1891 & 95.4 & & 102. & & & 0.4 \\
\hline HEF-0609-6-0 & 1693 & 1918 & 95.4 & 1685 & 1868 & 95.4 & & 94. & & & 0.4 \\
\hline
\end{tabular}

Table 7: Output table from OxCal V_Seq model (Bronk Ramsey, 2009) using and upper age boundary of $1939 \mathrm{AD}$, including modeled and unmodeled age ranges and probabilities for all samples collected from growth rings on tree slab HEF-0609-6.

\begin{tabular}{|c|c|c|c|c|c|c|c|c|c|c|c|}
\hline & \multicolumn{3}{|c|}{ Unmodelled (BC/AD) } & \multicolumn{3}{|c|}{ Modelled (BC/AD) } & \multicolumn{5}{|c|}{ Indices } \\
\hline & from & to & $\%$ & from & to & $\%$ & Acomb & $\mathrm{A}$ & $\mathrm{L}$ & $\mathrm{P}$ & $\mathrm{C}$ \\
\hline Boundary 1843 & 1842 & 1843 & 95.4 & 1842 & 1843 & 95.4 & & 10 & & & 100 \\
\hline HEF-0609-6-81 & 1664 & $\ldots$ & 95.4 & 1751 & 1841 & 95.4 & & 94. & & & 50.6 \\
\hline HEF-0609-6-51 & 1673 & 1942 & 95.4 & 1724 & 1809 & 95.4 & & 63. & & & 65.7 \\
\hline HEF-0609-6-24 & 1685 & 1927 & 95.4 & 1705 & 1778 & 95.4 & & 82 & & & 84.8 \\
\hline HEF-0609-6-0 & 1693 & 1918 & 95.4 & 1683 & 1758 & 95.4 & & 100. & & & 87.5 \\
\hline
\end{tabular}

Table 8: Output table from OxCal V_Seq model (Bronk Ramsey, 2009) using and upper age boundary of $1843 \mathrm{AD}$, including modeled and unmodeled age ranges and probabilities for all samples collected from growth rings on tree slab HEF-0609-6. 